\title{
WestVirginiaUniversity
}

THE RESEARCH REPOSITORY @ WVU

Graduate Theses, Dissertations, and Problem Reports

2003

\section{Circulation control for download wake reduction on a scaled V-22 model}

Chad Alan Riba

West Virginia University

Follow this and additional works at: https://researchrepository.wvu.edu/etd

\section{Recommended Citation}

Riba, Chad Alan, "Circulation control for download wake reduction on a scaled V-22 model" (2003). Graduate Theses, Dissertations, and Problem Reports. 1308.

https://researchrepository.wvu.edu/etd/1308

This Thesis is protected by copyright and/or related rights. It has been brought to you by the The Research Repository @ WVU with permission from the rights-holder(s). You are free to use this Thesis in any way that is permitted by the copyright and related rights legislation that applies to your use. For other uses you must obtain permission from the rights-holder(s) directly, unless additional rights are indicated by a Creative Commons license in the record and/ or on the work itself. This Thesis has been accepted for inclusion in WVU Graduate Theses, Dissertations, and Problem Reports collection by an authorized administrator of The Research Repository @ WVU. For more information, please contact researchrepository@mail.wvu.edu. 


\title{
Circulation Control for Download Wake Reduction on a Scaled V-22 Model
}

\author{
Chad Alan Riba
}

Thesis submitted to the College of Engineering and Mineral Resources at West Virginia University in partial fulfillment of the requirements for the degree of

\author{
Master of Science \\ In \\ Mechanical Engineering \\ James E. Smith, Ph.D., Chair
Wade W. Huebsch, Ph.D., Co-Chair
Gregory J. Thompson, Ph.D.
Department of Mechanical and Aerospace Engineering
}

Morgantown, West Virginia

2003

Keywords: V-22 Osprey, tilt-rotorcraft, circulation control, wake reduction, blowing slot, scaled model 


\section{ABSTRACT \\ Circulation Control for Download Wake Reduction on a Scaled V-22 Model}

\section{Chad Alan Riba}

West Virginia University has developed a circulation controlled model of the V22 wing to reduce the size of the download in the wake region brought upon by the airflow from the proprotors. The techniques being used in this experiment are the implementation of blowing slots across the leading edge and trailing edge, activation of one or both of the blowing devices, and adjustment of slot velocity. The results of the study show a decrease in the download force through the incorporation of the Coanda Effect around the leading and trailing edges. The induction of this phenomenon will move the separation region of the airflow to the underside of the wing, thus decreasing the area of wake region separation. This technology, when applied to the leading and trailing edges, will open up a new door in the ability to effectively increase the download of this aircraft or future aircraft design. 


\section{Acknowledgements}

I would first like to thank Wade Huebsch for his patience throughout this time for trying to teach an electrical engineer the concepts behind aerospace engineering. I would also like to thank Jim Smith for his creativity and ingenuity as the driving force behind this project. I would like to thank Greg Thompson for his time and valuable insight for this project. I would like to thank my family for keeping their faith in me throughout all this. I especially would like to thank my father for all the time he spent aiding the construction of the WVU model. I would also like to thank Richard and Linda Moore, who are my "second set" of parents, for all their kindness, patience, and encouragement as I struggled through to get to this point. Special thanks also goes out to David Jayasinghe, Jason Gill, and Gerald Angle for the time and effort each has put into helping me with this project. Special thanks also goes to Dustin McIntyre for his encouragement and knowledge of technical writing and formatting. Special thanks also to Lee Methany and Cliff Judy for their thoughts and help during the implementation of this design.

This thesis is dedicated to my closest friends: Joshua Grim, Matt Maciejczyk, Todd McMahan, Chuck Keeney, and Stephanie Robison. Without these people, I wouldn't be even near where I am right now with this research and they have helped me through a lot of rough times to get here. They never stopped believing in me when I started to doubt myself and that has made the world of difference in the person that I am today. 


\section{Table of Contents}

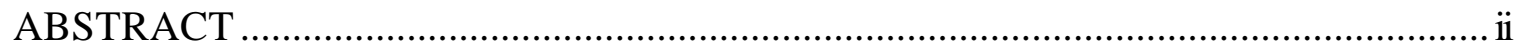

Acknowledgements.................................................................................................. ii

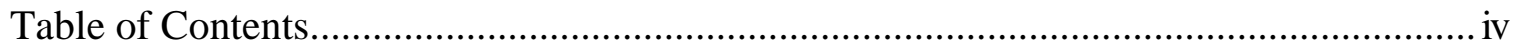

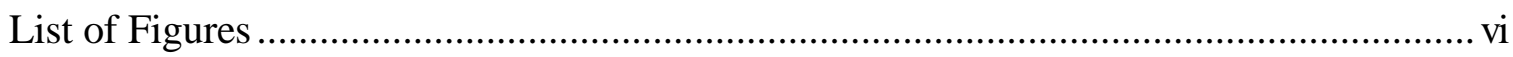

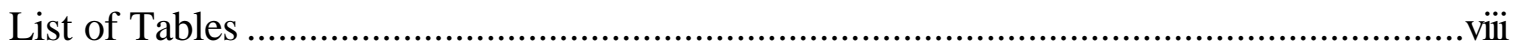

Nomenclature, Symbols, and Subscripts ..................................................................... ix

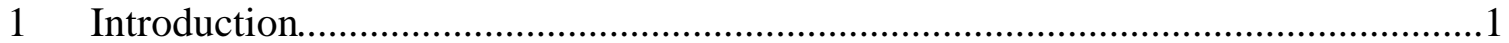

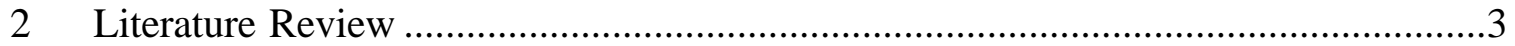

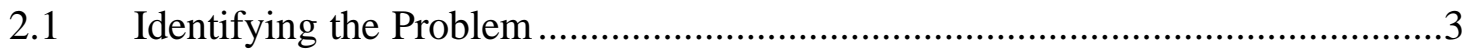

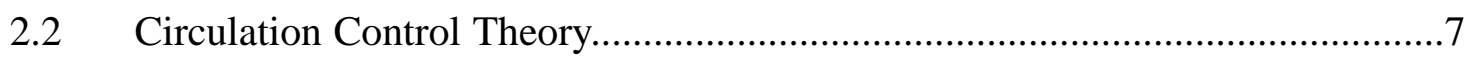

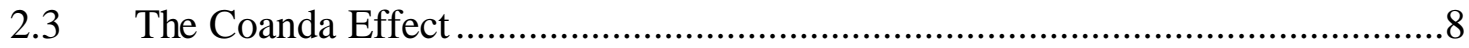

2.4 Use of the Coanda Effect to Enhance Aircraft Lift .............................................9

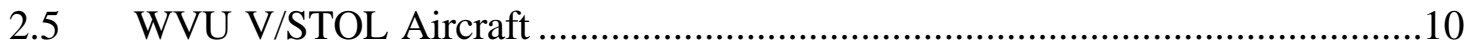

2.6 NASA Tiltrotor Circulation Control...............................................................12

2.7 NASA V-22 Rotor and Wing Hover Testing …….......................................14

3 WVU Model Circulation Control Integration on the V-22 Osprey...........................17

3.1 Integration of Circulation Control in Airfoils .................................................17

3.2 The WVU Circulation Controlled V-22 Osprey Model ....................................17

3.3 Wind Tunnel Mounting Setup ……………………………………………....21

4 Experimental Facilities and Equipement …………..........................................24

4.1 The West Virginia University Low Speed Wind Tunnel .................................24

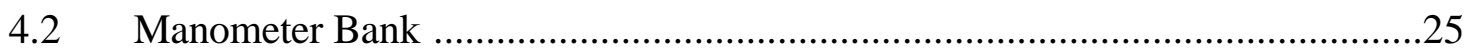

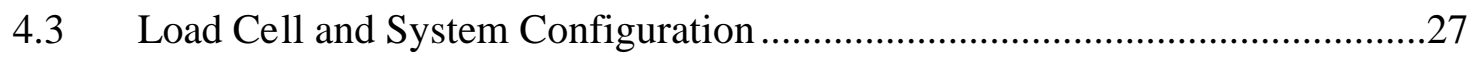

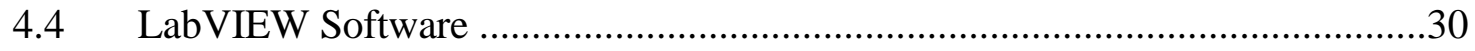

4.5 Power Consumption Calculations ……………….......................................30

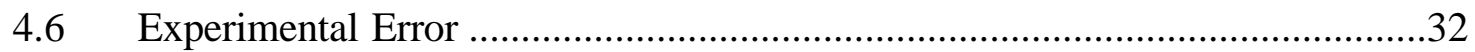

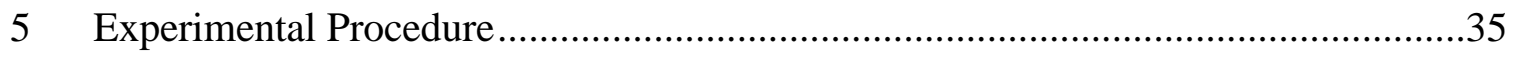

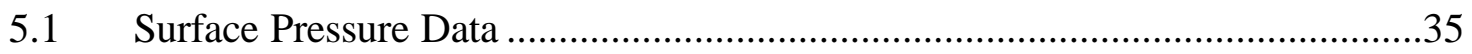

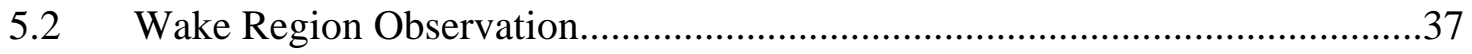

5.3 Load Cell Data ........................................................................................

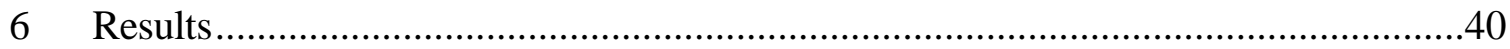




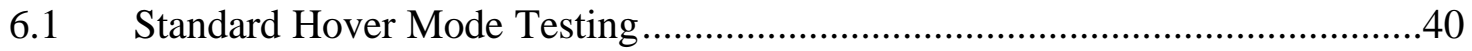

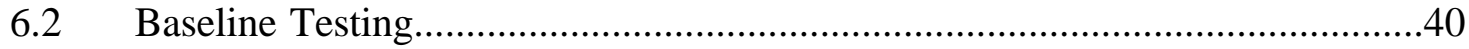

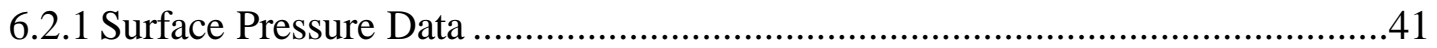

6.2.2 Wake Region Observation.....................................................................45

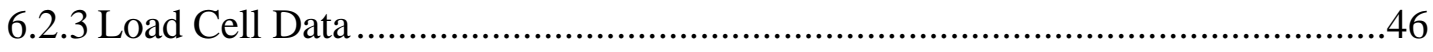

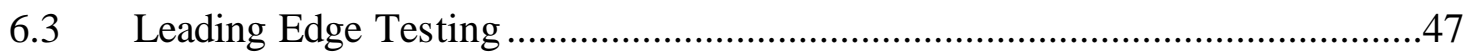

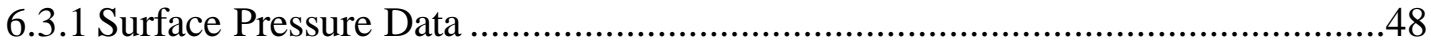

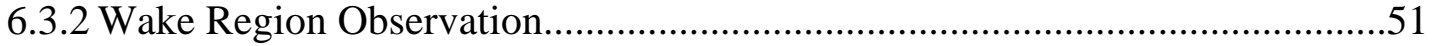

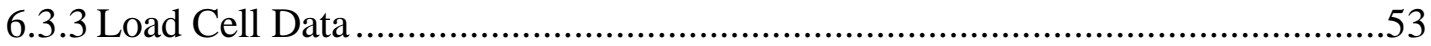

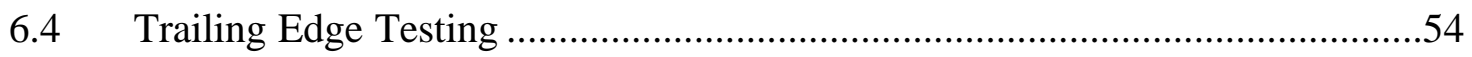

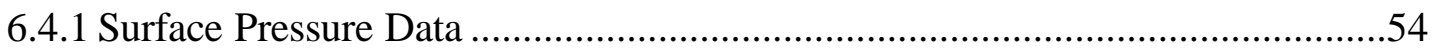

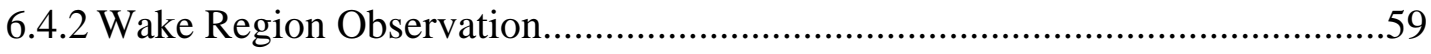

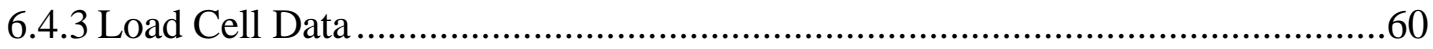

6.5 Leading and Trailing Edge Simultaneous Testing......................................61

6.5.1 Surface Pressure Data ...........................................................................61

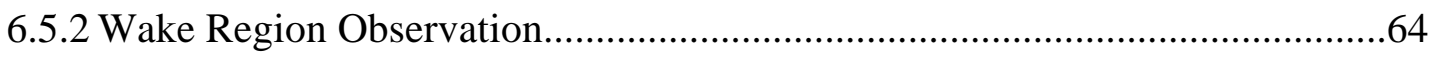

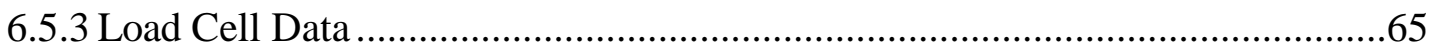

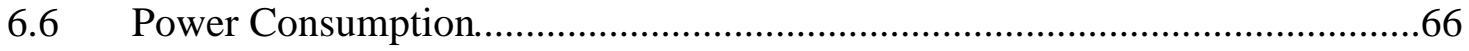

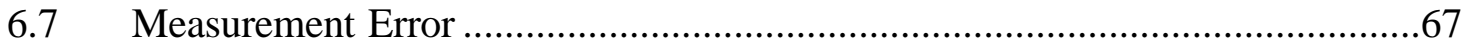

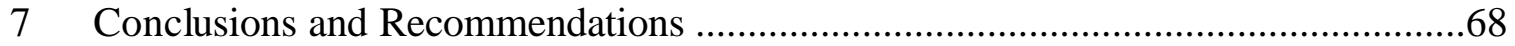

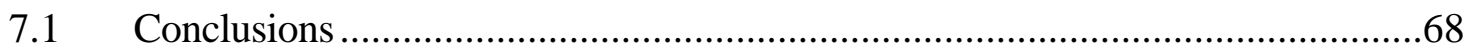

7.2 Recommendations .................................................................................. 70

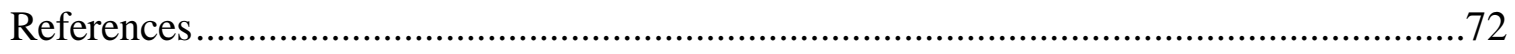

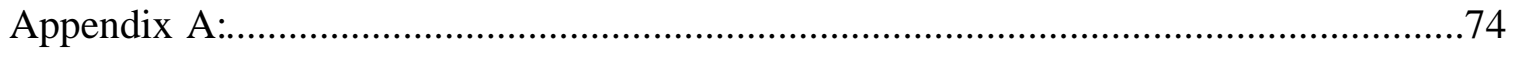

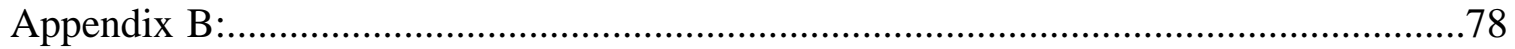

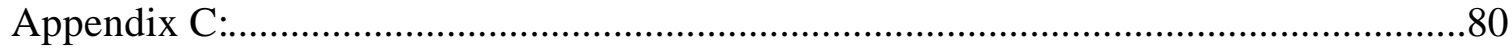

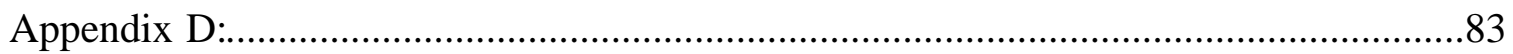




\section{List of Figures}

Figure 2.1: Bell/Boeing Osprey in flight and hover mode. ..............................................

Figure 2.2: V-22 Osprey wing flap converting from 0 degrees to 67 degrees. ....................4

Figure 2.3: Separation region with and without active blowing slots. ................................

Figure 2.4: Example of the Coanda Effect using water and a glass. ..................................

Figure 2.5: The Coanda Effect induced along the trailing edge of a blunt-edged airfoil. .10

Figure 2.6: WVU V/STOL airfoil with rotating circulation control flap. ..........................11

Figure 2.7: WVU V/STOL trailing edge circulation control device. .................................11

Figure 2.8: Airfoil section of the NASA circulation control wing. .....................................13

Figure 2.9: NASA outdoor tilt rotor testing configuration. ...............................................13

Figure 2.10: NASA 0.658-scale rotor and wing setup.....................................................15

Figure 3.1: Skeleton of airfoil body showing the implementation of the leading edge blowing slot (top of picture) and trailing edge blowing slot. ...................................20

Figure 3.2: Side view of airfoil showing the positions of the leading edge slot (left side of

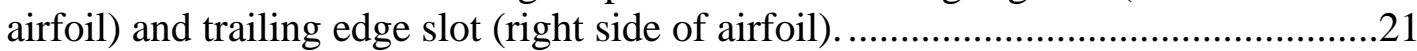

Figure 3.3: WVU V-22 scaled model with bracing system in low speed testing facility..22

Figure 4.1: Looking into the WVU wind tunnel low speed test section............................24

Figure 4.2: Manometer bank located adjacent to WVU low speed subsonic wind tunnel facility. .26

Figure 4.3: Free body diagram of entire airfoil system.

Figure 5.1: Cp vs. $\mathrm{x} / \mathrm{c}$ plot for NASA scaled V-22 Osprey model with 78 degree flap angle. .36

Figure 5.2: Airflow around the V-22 airfoil without circulation control. ...........................38

Figure 5.3: Airflow around the V-22 airfoil with active circulation control. .38

Figure 6.1: Baseline 2 surface pressure values in ordinance with position on the airfoil. 41

Figure 6.3: Baseline lower surface pressure values.

Figure 6.4: Baseline upper flap surface values.............................................................4

Figure 6.5: Baseline lower flap surface values...............................................................45

Figure 6.6: Baseline wake region plot. ......................................................................46

Figure 6.7: Baseline overall drag values......................................................................47

Figure 6.8: Upper surface $\mathrm{Cp}$ values for leading edge active circulation control .............49

Figure 6.10: Wake region of scaled model during leading edge active circulation control 
Figure 6.16: Drag values for trailing edge active circulation control

Figure 6.17: Upper surface $\mathrm{Cp}$ values for leading and trailing edge simultaneous active circulation control.

Figure 6.18: Lower surface $\mathrm{Cp}$ values for leading and trailing edge simultaneous active circulation control.

Figure 6.19: Flap upper surface $\mathrm{Cp}$ values for leading and trailing edge simultaneous active circulation control

Figure 6.20: Wake region of scaled model during leading and trailing edge simultaneous

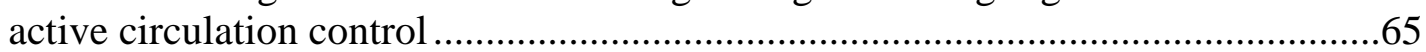

Figure B.1: Structure of LabVIEW code for scaled model testing...................................79

Figure D.1: Ansys representation of the WVU scaled model mounting system. .............84

Figure D.2: Calibration curve for trailing edge load cell....................................................85

Figure D.3: Calibration curve for leading edge load cell ...............................................86

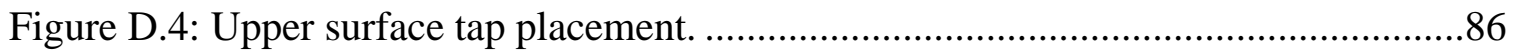

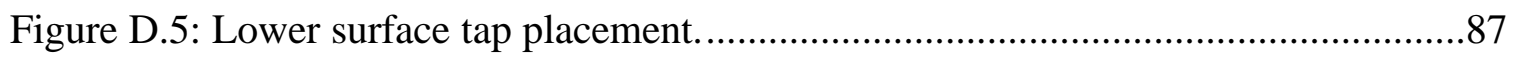




\section{List of Tables}

Table 4.1: Measurement Instrumentation Error Values ...............................................34

Table 6.1: Upper surface Cp values for leading edge active circulation control..............49

Table 6.2: Lower surface $\mathrm{Cp}$ values for leading edge active circulation control .............51

Table 6.3: Upper surface Cp values for trailing edge active circulation control..............55

Table 6.4: Lower surface $\mathrm{Cp}$ values for trailing edge active circulation control .............57

Table A1: Cp values for 67 degree testing ............................................................ 75

Table A.2: Load cell values for 67 degree testing ..................................................... 76

Table A.3: Drag error estimation for 67 degree testing ............................................. 76

Table A.4: Pressure error estimation for 67 degree testing ........................................77

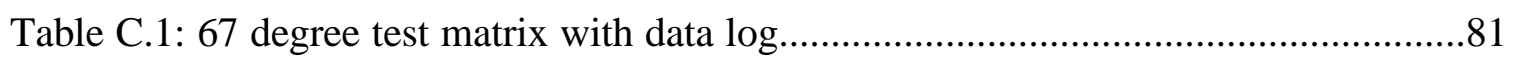

Table C.2: 67 degree test matrix with load cell offset values ......................................81

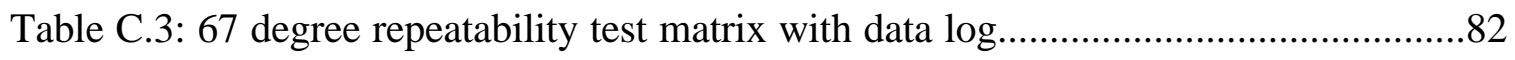

Table C.4: 67 degree repeatability test matrix with load cell offset values.....................82

Table D.1: Overall airfoil drag calculation setup example ..........................................85 


\section{Nomenclature, Symbols, and Subscripts}

\section{Nomenclature}
A
Model frontal area $\left(\mathrm{ft}^{2}, \mathrm{in}^{2}\right)$
c, C
Chord length (ft, in)
$\mathrm{C}_{\mathrm{D}} \quad$ Coefficient of Drag (-)
$\mathrm{C}_{\mathrm{P}} \quad$ Coefficient of Pressure (-)
D Drag (lbs)
F $\quad$ Force (lbs)
L Length (ft, in)
P Pressure (psf, psi)
$\mathrm{R} \quad$ Ideal gas constant (ft-lb/slug- $\left.{ }^{\circ} \mathrm{R}\right)$
S Wing Span (ft)
T Temperature $\left({ }^{\circ} \mathrm{R}\right)$
V Velocity (mph, ft/sec)
V/STOL Vertical/Short Take-Off and Land
x Distance across the airfoil chordwise (ft, in)
W Power (hp)

\section{Symbols}

$\partial \mathrm{C}_{\mathrm{D}} \quad$ Change in drag coefficient (-)

$\partial \mathrm{C}_{\mathrm{P}} \quad$ Change in pressure coefficient (-)

? $\quad$ Specific Weight $\left(\mathrm{lb} / \mathrm{ft}^{3}\right)$

? Density $\left(\right.$ slugs $\left./ \mathrm{ft}^{3}\right)$ 


\section{Subscripts}

$\begin{array}{ll}\text { atm } & \text { Atmospheric conditions } \\ \mathrm{D} & \text { Drag } \\ \mathrm{H}_{2} \mathrm{O} & \text { Water } \\ \mathrm{Hg} & \text { Mercury } \\ \text { in } & \text { Inputted Airflow (hose) } \\ \text { Model } & \text { Scaled V-22 Airfoil Model } \\ \text { out } & \text { Outputted Airflow (blowing slot) } \\ \mathrm{P} & \text { Pressure } \\ \text { Plane } & \text { Full Scaled V-22 Aircraft } \\ 8 & \text { Free stream conditions }\end{array}$




\section{Introduction}

The West Virginia University (WVU) Scaled V-22 Osprey Circulation Control Model has been designed to address some of the problems caused in the wake area of the tilt rotorcraft. With a substantial size wake region, the rotor-craft is unable to make use of full lifting capabilities. By placing active blowing devices, in the form of slots, across the leading edge and adjacent to the trailing edge flap, a reduction of the wake area can be obtained by the introduction of a phenomenon called the Coanda effect.

The testing of the airfoil was conducted in the low-speed testing section of the WVU Low Speed Subsonic Wind Tunnel Facility. The model was equipped with pressure taps, along with a wake rake and load cells, to show the effective changes circulation control has on the airfoil. The change in pressure at the surface taps and wake rake were monitored using a manometer bank, while the load cells and tunnel temperature are being monitored using a PC-based data acquisition system and LabVIEW software.

This work examined three separate blowing configurations. The first two configurations examined the change in the download due to the added air pressure from each isolated slot. The third configuration examined the effects of having both slots activated simultaneously. Each test is briefly described below:

- Leading Edge Testing - The leading edge blowing slot when activated by itself was used to examine the effects of the change in the size of the wake area and the overall lift of the model. 
- Trailing Edge Testing - The trailing edge blowing slot when activated by itself was used to examine the effects of the change in the size of the wake area and the overall lift of the model.

- Leading Edge and Trailing Edge Testing - Both slots will be activated simultaneously to determine the effects of the change in the size of the wake region and the overall lift of the model.

The purpose of this work is to develop preliminary data for implementing circulation control on the Bell V-22 Osprey. This work does not state that this testing proves that this technology can be taken from this modular testing and applied directly to the full-scaled aircraft. The purpose of this work is to prove a theory on how the reduction of download in the wake region of the V-22 could be approached. More rigorous testing would have to be performed by Bell Helicopter Textron in order to apply this technology properly to the V-22 rotorcraft. 


\section{$2 \quad$ Literature Review}

\subsection{Identifying the Problem}

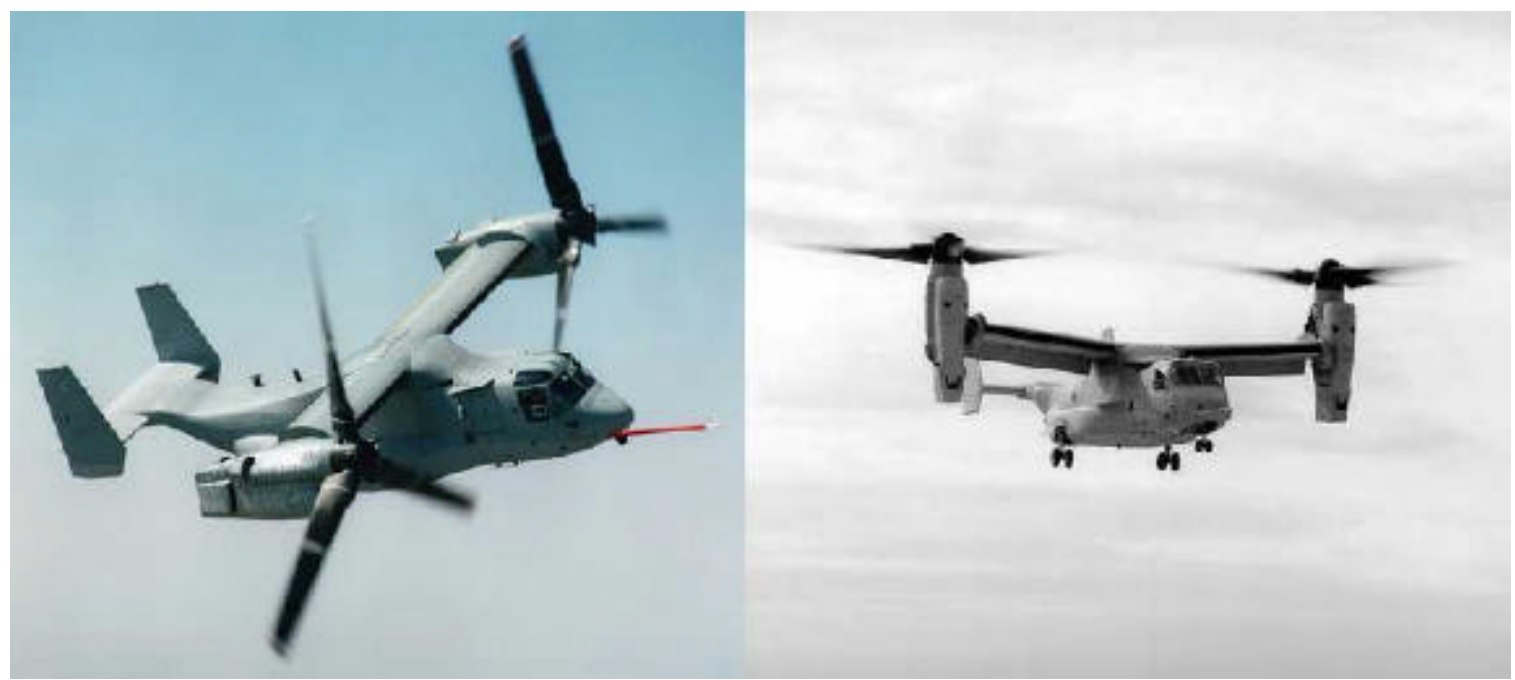

Figure 2.1: Bell/Boeing Osprey in flight and hover mode. ${ }^{1}$

The capabilities of the Bell/Boeing V-22 Osprey (Figure 2.1) to take on the duties of both the helicopter and the airplane have opened a new horizon in possibilities for the aircraft industry. For the military, the ability to have the lift and landing capabilities of a helicopter combined with the speed and maneuverability of an airplane unlock new ways for the transportation of troops and cargo. By having dual capabilities, the Osprey has the unique ability to travel at a faster rate than a helicopter and land in tighter areas than an airplane.

The V-22 Osprey Program has come under heavy criticism regarding the stability and reliability of the aircraft. ${ }^{2}$ During a series of test flights, the Osprey has failed four times and has lead to a crash, killing a total of 30 Marines. Several possible problems have been identified. The most common include 1) failure to meet specific aircraft standards (this has lead to the cancellation of numerous tests), 2) vulnerability to the 
vortex ring state (a rapid descent rate combined with the inability to maintain adequate forward speed can cause one of the proprotors to stall while the other remains at full speed), and 3) the handling of the download force from the proprotor blades.

Although the first two problems play a major role in the difficulties the V-22 Osprey is experiencing, the downwash, or vertical drag force, limits many of the in-flight capabilities of the tilt-rotorcraft. When the aircraft transfers into hover mode, the proprotors are raised to an 85-degree position and the wing flap angle is positioned at 67 degrees, as shown in Figure 2.2. While the proprotors are spinning, loading from the rotor disks causes heavy downwash on the wing, which makes it extremely difficult for the Osprey to maintain its payload capabilities. These payload capabilities are approximately 25 to $30 \%$ of the gross aircraft weight. Fort Felker ${ }^{3,4}$ and a team of engineers at NASA have shown that even small improvements in the download effects of the Osprey can have a major impact on the lifting capabilities of the aircraft.
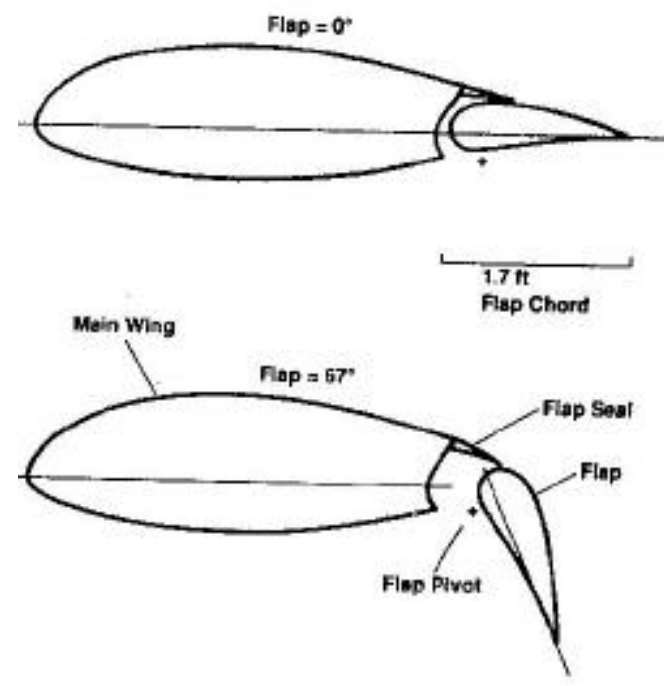

Figure 2.2: V-22 Osprey wing flap converting from 0 degrees to 67 degrees. ${ }^{4}$ 
The decrease in the lift is just a small part of the difficulties that the downwash places on the V-22 Osprey. The turbulent downwash also has a negative effect on several of the V-22's required operational capabilities, which are explained later in this section. Pilots are finding the rotorcraft difficult to land in remote areas, such as the desert, due to "brown out" effects. ${ }^{2}$ This is a direct result of the downwash causing the sand to be stirred up and blown around, obscuring the landing view of the pilot and adding excess difficulty in landing the aircraft, not to mention the increased potential for engine problems caused by the sand and debris. In order to overcome this problem, new landing and piloting techniques will have to be developed and incorporated.

Deployment and recovery of troops has been affected by the high downwash of the Osprey. The rotorcraft has design requirements that specify certain locations that troops must be able to deploy from. ${ }^{2}$ Although a few of these requirements were met, some of the specified areas of deployment were unable to be used because of the heavy downwash and ground effects. In order to reduce the ground effects caused by the proprotor downwash, the aircraft would have to hover between 65 to 75 feet off of the ground, exposing the aircraft and troops to potential threats and giving away aircraft location. Due to this limitation, alternative deployment locations and techniques are being examined to help meet the rappelling requirements.

The decreased capability in payload transport is also a result of the adverse effects caused by downwash. The problem is not in the carrying of the cargo itself, but in the landing of the payload. While in hover mode, the rotorcraft prepares to deploy the load and the inability to avoid the downwash becomes a problem to the ground crew waiting 
for the cargo. Techniques have not yet been developed to help minimize the risk of injuries to the ground crew while working in the downwash. ${ }^{2}$

Due to theoretical and computational limitations in determining certain tendencies that the aircraft may experience while in the air, many of the problems could not be determined prior to flight-testing. For example, simulations of a full-scale downwash while in flight could not be done to investigate the inadequacies that the V-22 Osprey would encounter during rappelling and landing missions. This makes it more difficult to predict any failures or aerodynamic phenomena that could occur during flight. Many problems, such as the vortex ring ${ }^{2}$ and heavy downwash, couldn't be predicted during the design and preflight preparations. The impact of these problems was unknown until the aircraft took flight.

Testing and new theories have been developed to help make the V22 Osprey a safer aircraft. New methods to repel and deploy troops from the aircraft are being designed to meet specific government requirements. ${ }^{2}$ To decrease the downwash effects, NASA $^{5}$ has started to apply the theory of circulation control by entraining the airflow around the wing of a basic tilt-rotorcraft. With this added capability, the payload of the aircraft can be significantly increased and other downwash effects can be minimized. Focusing on this theory and the previous experimentation performed on tilt-rotorcraft, the WVU model investigates the download reduction capabilities of circulation control as applied the wing of the V-22 Osprey. 


\subsection{Circulation Control Theory}

Through the use of flow entrainment devices, such as blowing slots and flaps, circulation control devices can be used to allow the V-22 aircraft to control the airflow around the wing. West Virginia University ${ }^{6}$ became a center of study and development of this technology in the 1970's, creating a V/STOL plane that incorporated this technology for naval usage.

Circulation control is the ability to use streamed air to change the boundary layer around an airfoil. By implementing flow entrainment devices, the airflow patterns around the wing can be altered. For example, a small amount of air from the surface can push the airflow away from the boundary layer, effectively creating a new airfoil shape.
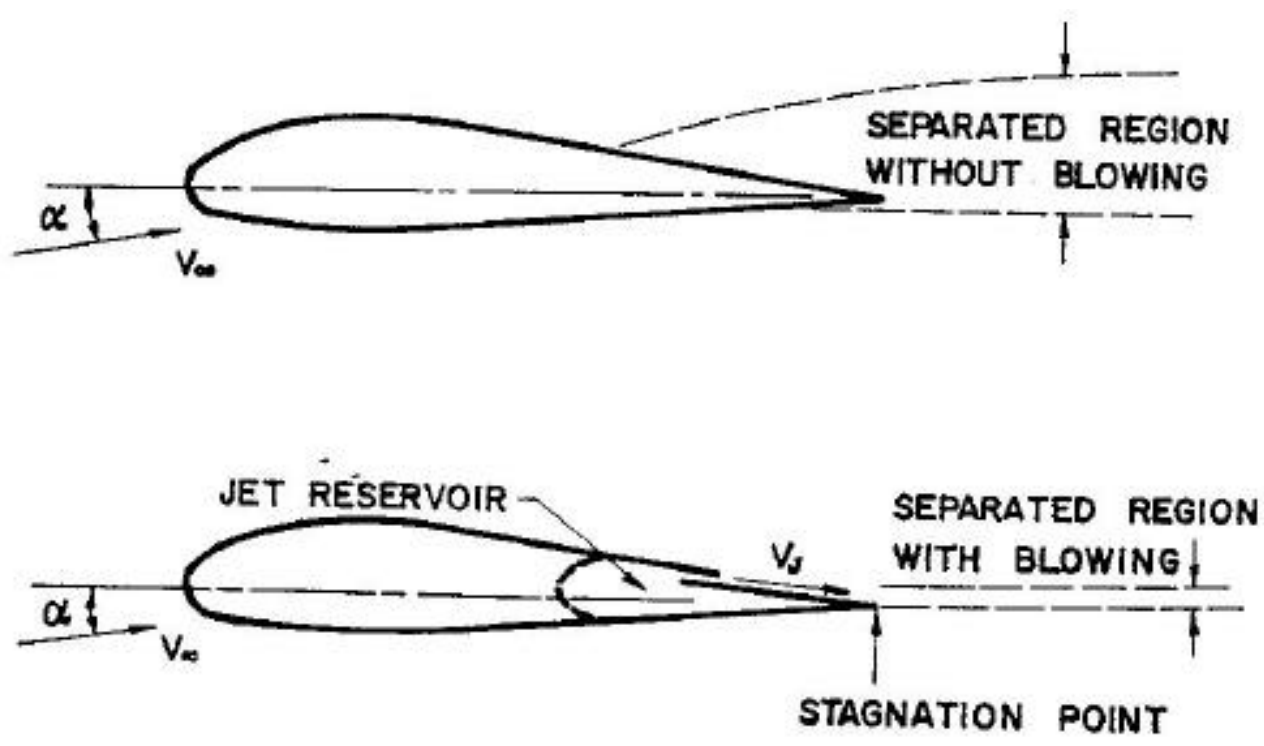

Figure 2.3: Separation region with and without active blowing slots. ${ }^{6}$

As higher velocity air is streamed out of these devices, particularly in the trailing edge region, the area of separation can be controlled and changed (Figure 2.3). The separation area will begin to decrease and the point of separation will move further 
downstream on the airfoil, causing the stream of air to take on a different shape and increase the effective length of the airfoil.

By adding a blowing slot on the leading edge or curved trailing edge, the injected air stream can help the flow field take advantage of a phenomenon called the Coanda Effect, which enables the flow to follow the leading or trailing edge curvature. These circulation control devices make it possible for lower speed aircraft to enhance their lifting capabilities and allow for the possibility of a shorter take off and landing, albeit with significant increases in total power required for the aircraft.

\subsection{The Coanda Effect}

In the 1930's, a Romanian aerodynamicist named Henri Coanda was testing his airplane, the Coanda-1910. In order to prevent exhaust fumes from touching the aircraft fuselage, he positioned curved plates on the plane to deflect the flames. Instead of deflection, the burned gases and flames seemed to follow the curvature of the plates and remained very close to the fuselage. This ability for the fluid to follow the path of a curved surface is the phenomenon referred to as the Coanda Effect. ${ }^{7}$

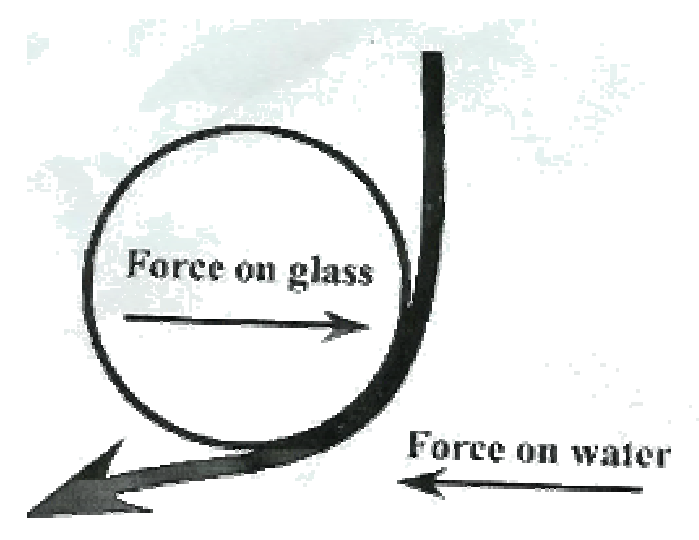

Figure 2.4: Example of the Coanda Effect using water and a glass. ${ }^{7}$ 
But why does this phenomenon occur? How does it work? Force and viscosity are the key elements. For a fluid to follow a curved path, there must be a force acting on it, as shown in Figure 2.4. Also, due to Newton's Third Law of equal and opposite forces, a counterforce must also be present in order for this to work. Viscosity, or the 'tackiness' of a fluid, allows the molecules of the fluid to stick to the surface. The relative velocity between the surface in which the fluid is moving and the nearest fluid molecules is zero. The farther away from the surface one moves, the faster the fluid will travel until the peak velocity is obtained at the edge of the boundary layer. Due to the changes in velocity away from the surface, the fluid is bent toward the surface by shear forces. The tighter the bend of the surface, the greater the forces will be acting on the fluid.

\subsection{Use of the Coanda Effect to Enhance Aircraft Lift}

Taking this phenomenon to the next level, the Coanda Effect can be applied to an aircraft to help create greater lift potential. For example, by adding a blowing slot to the trailing edge of a standard airfoil, the boundary layer separation point of the airfoil is moved farther downstream by the circulated airflow (see Figure 2.3). Thus, the effective length of the airfoil is changed, but this change will not have a prominent impact on the pressure distribution and the vertical lift of the aircraft.

If the same principle is added to the trailing edge of a blunt, or circular-edged airfoil, the Coanda Effect can be induced. ${ }^{8} \quad$ By placing the slot at the tangent of the circular edge, the airflow will follow the path of the curved surface. This produces a downward movement of the rear stagnation point to the underside of the airfoil body. ${ }^{6}$ 
With the higher velocity airflow injected into this region, the difference in pressure between the upper and lower surface is increased, therefore generating more lift on the airfoil.

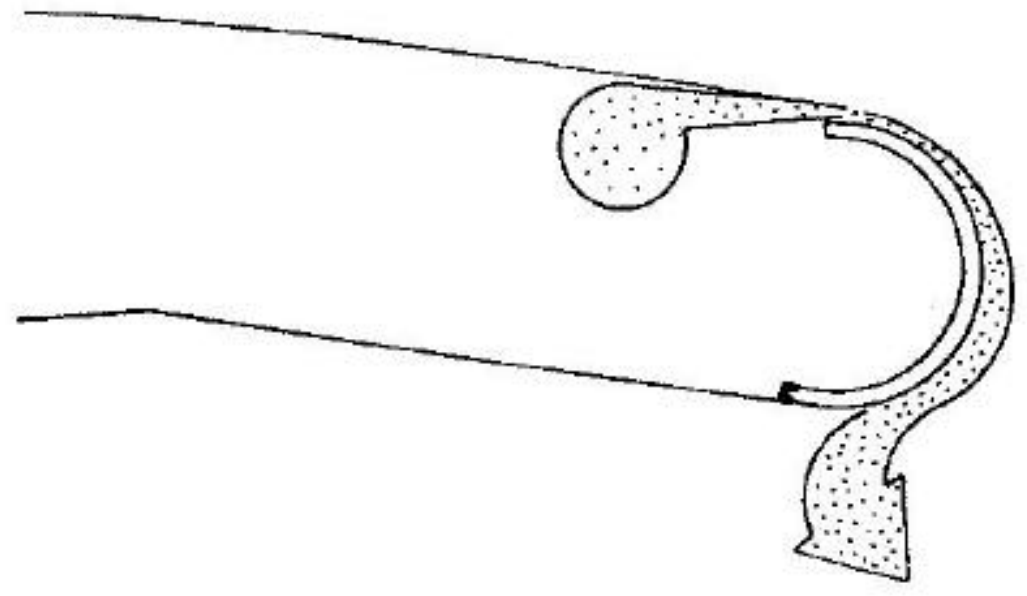

Figure 2.5: The Coanda Effect induced along the trailing edge of a blunt-edged airfoil. ${ }^{8}$

\subsection{WVU V/STOL Aircraft}

In previous experimentation on circulation control, WVU was involved in a multiyear study and development of a circulation controlled airplane in the early 1970's. Led by $\operatorname{Loth}^{6}$, the project was part of a contract with the Department of Defense and the Office of Naval Research to examine the possibilities of augmenting the lift of aircraft. Throughout the research, numerous ways of incorporating high-lift devices into airfoils were examined, simulated, and some were built as prototypes for testing. Some of the methods included blunt-ended airfoils, thrust augmentation, and flap modification. As a conclusion to this development, a flight vehicle called the West Virginia University Technology Demonstrator STOL Aircraft was built. 
In order to incorporate circulation control on this new aircraft, the use of the movable trailing edge was created to give the vehicle additional lift. During conventional flight stages, the normal sharp trailing edge would be present. When higher lift needed to be induced, a round trailing edge circulation control device was rotated out from underneath the wing to enhance the vertical lift.

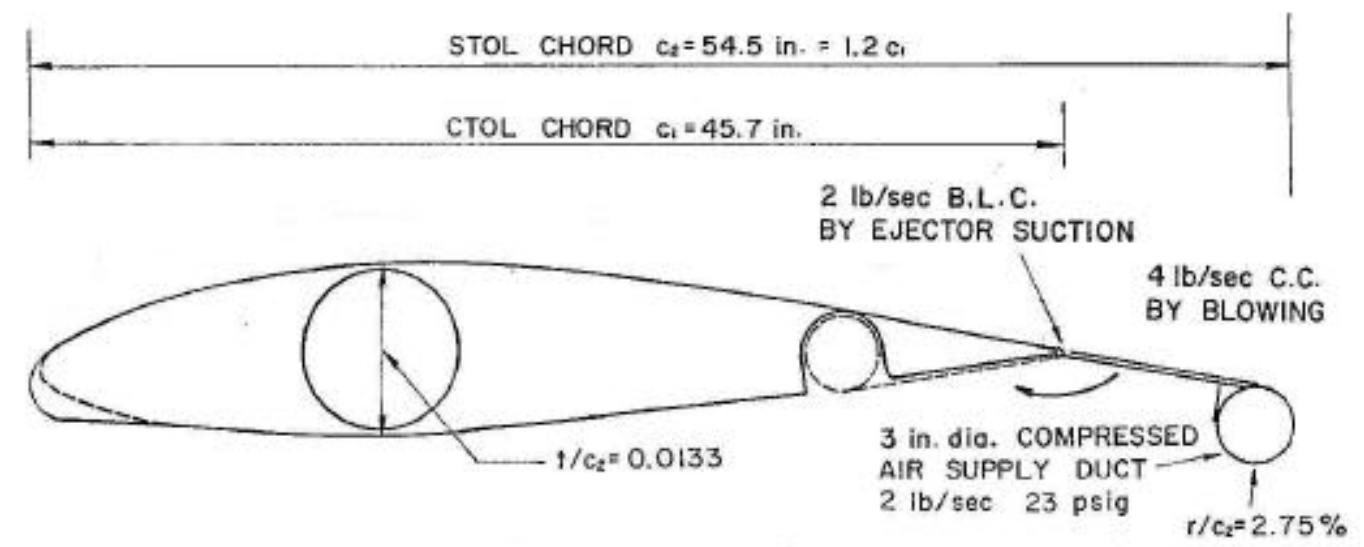

Figure 2.6: WVU V/STOL airfoil with rotating circulation control flap. ${ }^{6}$

To create vertical lift from the circular trailing edge device, the Coanda Effect was created. The trailing edge piece was equipped with a compressed air supply, as shown in Figure 2.6 and detailed more in depth in Figure 2.7, in which the air would pressurize and then pass through the blowing duct.

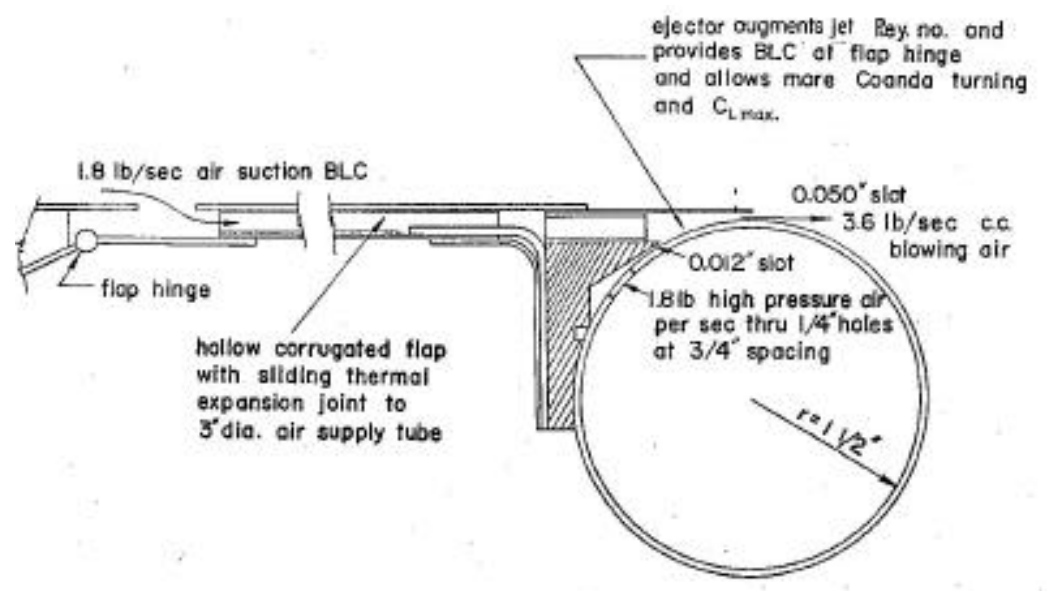

Figure 2.7: WVU V/STOL trailing edge circulation control device. ${ }^{6}$ 
As the compressed air is blown across the trailing edge device, the airflow follows the surface of the curvature. The airflow through the blowing slot is regulated by an ejector, which induces suction at the flap hinge and helps to reduce the velocity of the circulation control jet in order for the Coanda Effect to be maximized. This aircraft is believed to be the first of its kind to incorporate circulation control by blowing air to create higher lift.

\subsection{NASA Tiltrotor Circulation Control}

In 1985, NASA $^{5}$ conducted extensive testing on tilt rotorcraft, implementing circulation control theory to a basic tiltrotor setup in an attempt to decrease the effects of the downwash on this type of aircraft.

Testing was done at the NASA Ames Outdoor Aerodynamic Research Facility, located in California. This facility is equipped with a 30-m square concrete testing pad, a below-ground-level frame for attaching support struts to the model, and an underground control room that houses the data acquisition system. The rotor used was a 0.16 scale model of the Sikorsky S-76 rotor system. This rotor was positioned on the Ames Test Rig, which contains a six component, internal strain-gauge balance used to measure steady-state rotor forces and moments.

The wing used was a symmetrical shaped airfoil section (Figure 2.8). The airfoil incorporated high lift devices (adaptations in the aircraft used to increase the potential lift of the vehicle) in the form of blowing slots along the leading and trailing edges. Each slot was placed at approximately $2 \%$ of the chord length from the edge of the airfoil. Their position was critical, as the slots were placed along the tangent of the blunt edges 
of the aircraft. This allows for the flow of the air to induce the Coanda Effect necessary to circulate the airflow underneath of the wing.

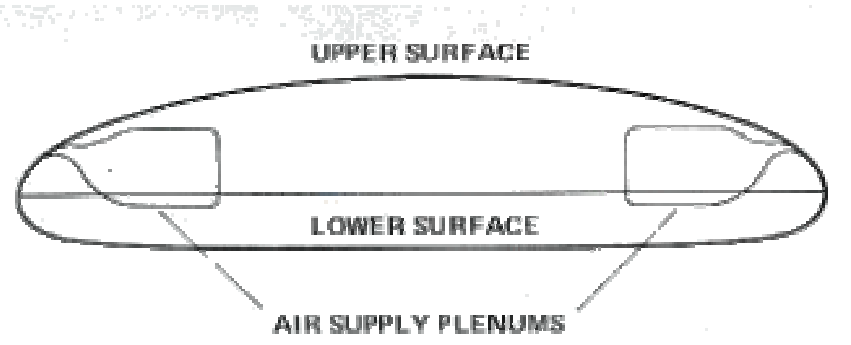

Figure 2.8: Airfoil section of the NASA circulation control wing. ${ }^{5}$

The test setup was structured with the airfoil and rotor model placed upside down (Figure 2.9). The rotor was operated with the rotor thrust upward, which caused the wake to travel upward. The airfoil was placed upside down on a model support system, with the downwash striking the top of the wing. This configuration was necessary to avoid any ground effects and allow for unobstructed flow between the rotor and the airfoil.

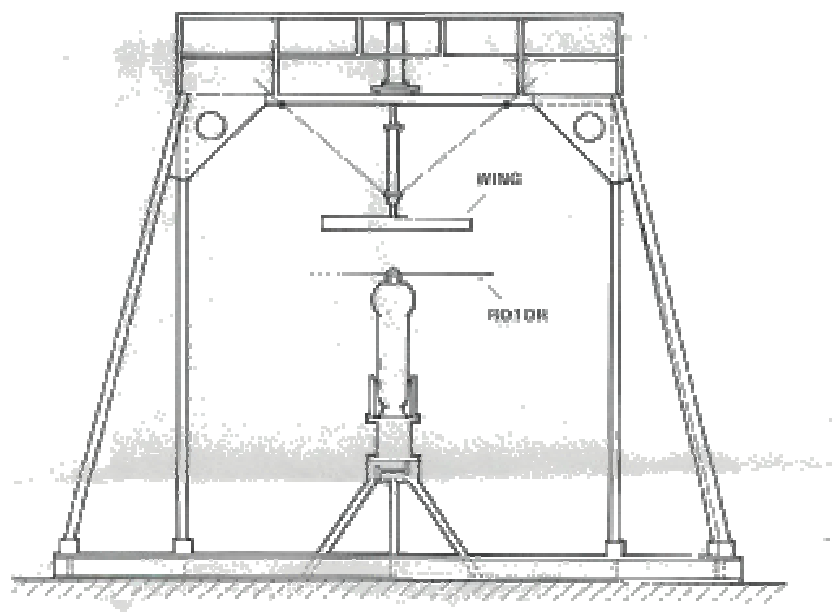

Figure 2.9: NASA outdoor tilt rotor testing configuration. ${ }^{5}$

The effects of circulation control were tested through changes in slot pressure and thrust coefficients while controlling the blowing slots: one, both, or none. Through changes in the slot pressure, the download was steadily reduced as the blowing pressure increased. 
By utilizing both blowing slots simultaneously, the download was reduced between $25 \%$ (higher thrust coefficients) and $54 \%$ (lower thrust coefficients). The range of download reduction is due to the change in the thrust coefficient of the rotor. With the velocity of the upper surface blowing being higher at lower thrust coefficients, the download is reduced further due to the maximization of the Coanda Effect around the blunt edge.

\subsection{NASA V-22 Rotor and Wing Hover Testing}

On the outset of rigorous testing on the hover performance of the tilt rotorcraft, such as mentioned above, $\mathrm{NASA}^{3,4}$ took part in a series of tests in the hover performance of the V-22 Osprey. This experimentation was performed to examine the properties of the hovering capabilities with respect to changes in the rotor thrust coefficient, flap angle, nacelle angle and the direction of the rotor rotation. The testing was conducted at the Ames 40’x80’ Wind Tunnel.

The rotor and wing sections used for this test were 0.658-scale models of those used on the V-22. The airfoil was mounted vertically and the nacelle and rotor were mounted horizontally above an image plane. This image plane was used to simulate the presence of the second rotor and wing of the V-22.

The rotor thrust coefficient was the first of the four main parameters tested on the model. The nacelle was set at an angle of 85 degrees and the wing flap angle was set at 67 degrees, the standard configuration for the hover mode of the V-22. From this experiment, the download reduction was minimal and was not of any significant importance to changing the effects of the wake downloading. 
The wing flap angle change showed beneficial results for the ability to control the amount of downwash. Again, with the wing flap angle and nacelle set at the standard configuration, the flap angle was steadily increased. As the angle was increased up to 78 degrees, the download effects were decreased. Once the angle went beyond this point, the download began to increase. The increase in the download after this point is thought to be due to the separation of the flow on the upper surface of the flap as it increases to higher angles.

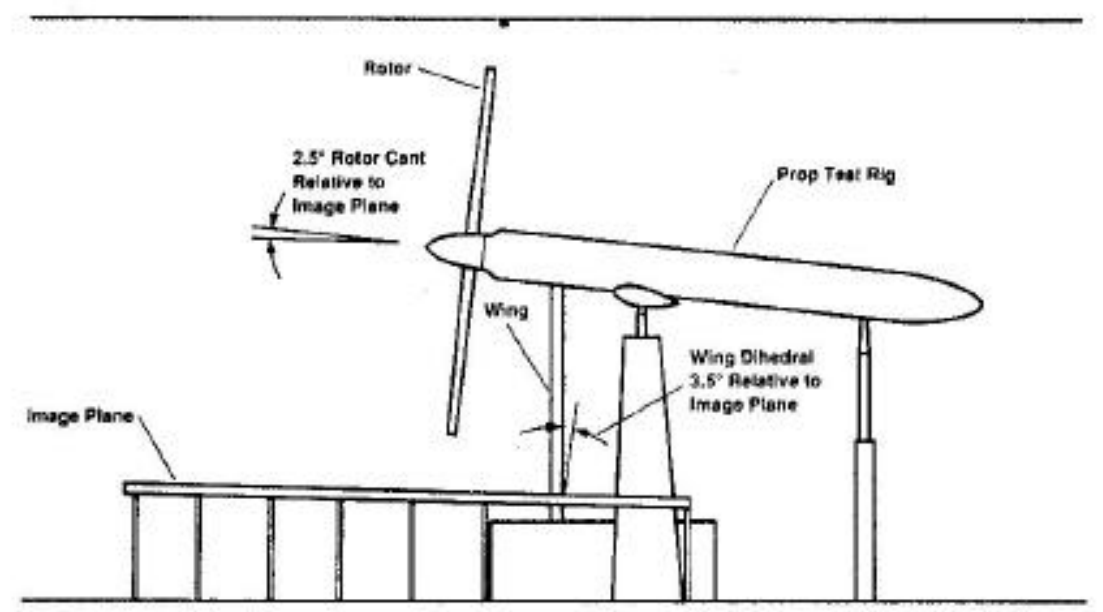

(a) Side view.

Figure 2.10: NASA 0.658-scale rotor and wing setup. ${ }^{4}$

The effects of the rotor rotational direction were examined for potential to decrease the download. During the test, the rotor was run in reverse rotational direction, which showed signs of a decrease in download as the flap angle was increased. The problem with this particular test was that one certain rotational direction could outperform another with the nacelle and wing flap angles set at specific points. 
The final test conducted was a change in the nacelle angle. This test was conducted with the wing flap angle set at 67 degrees and the nacelle angle varied. As the nacelle angle was moved from the standard 85 degrees to 75 degrees, the download was reduced by 0.8 percent of the rotor thrust. From this particular phase of testing, a "rule of thumb" was developed that concluded that for every 10 degrees of forward nacelle tilt, the download is approximately reduced 1 percent of the rotor thrust. 


\section{WVU Model Circulation Control Integration on the V-22 Osprey}

\subsection{Integration of Circulation Control in Airfoils}

In previous research conducted at NASA Ames Research Center, drastic improvements to the lift enhancement of tilt-rotorcraft have been observed through the implementation of circulation control. Through the use of leading edge and trailing edge blowing slots on a symmetrical airfoil, the airflow from the rotor downwash could be entrained by the induction of the Coanda Effect. With both slots active, the downwash was decreased up to $52 \%$, creating more lift potential for the rotorcraft.

In an attempt to build upon this previous research, WVU developed a circulation controlled model of the V-22 Osprey airfoil. Based on the previous track record of the aircraft and the inability to live up to the lifting capabilities that the designers had in mind, the V-22 proposes a challenge for the implementation of circulation control.

\subsection{The WVU Circulation Controlled V-22 Osprey Model}

In order to take complete advantage of the WVU testing facility, a scaled model of the V-22 Osprey wing was created. Due to size limitations of the testing sections, a full scaled wing model was incapable of being placed in the facility. The scaled model enabled the ability to incorporate the necessary circulation control devices while creating an accurate simulation of the particular testing environment needed to answer the questions posed by this research. From the model, optimal values for slot blowing pressures can be determined as well as any pressure changes along the surface of the airfoil. The scaled model enables the ability to observe any change in the wake region to 
determine whether or not active blowing would have any positive impact on this problem area.

During the development stages of this project, a scale size had to be selected that would allow for adequate testing. Factors such as test section size, tunnel blockage, implementation of force and pressure measurement devices, and ease of model setup were looked heavily upon during the design process. The original plan was to place the wing in the high-speed test section, which is approximately 3 feet high and 4 feet wide, of the WVU Closed Return Wind Tunnel Facility. With an airfoil chord of just over six inches designed for minimal tunnel blockage, the model size would not allow for adequate measurement instrumentation and circulation control device to be implemented.

The use of the low speed test section of the closed return facility was then explored. At 6 feet high and 4 feet wide, this area of the wind tunnel would allow for a model large enough to properly incorporate the needed measurement instrumentation and circulation control devices while providing enough airspeed to allow for adequate data readings to demonstrate proof of concept. With the ability to reach airspeeds up to 60 miles per hour, the WVU model was then designed around the dimensions and properties of this section.

Starting with the Bell A802120 V-22 airfoil, an AutoCAD representation was created of the wing using the actual two-dimensional wing coordinates. Once the template was finished, a suitable scale had to be determined for the model. The scale model needed had to be large enough to allow for correct theoretical implementation as well as to allow for $10 \%$ or less blockage in the test section. By running a basic blockage 
calculation with the width of the airfoil set at 18 inches, a chord length of 19 inches would allow for the greatest possible chord length that would meet the blockage specifications:

$$
\frac{\text { AreaWing }}{\text { AreaTunnel }} * 100 \%=\frac{1.5 f t * 1.583 f t}{6 f t * 4 f t} * 100 \%=9.89 \%
$$

Once the chord length was determined, the AutoCAD plot was scaled to match the chord length. This plot was then used as a basic template for the wing shape during construction.

The main modification to the airfoil was the addition of the leading and trailing edge blowing slots (Figure 3.1). The correct placement of each slot would allow for the ability to entrain the airflow properly and induce the Coanda Effect around the leading edge and the trailing edge flap to move the area of air separation underneath of the airfoil. The leading edge slot was placed along the tangent of the curvature of the leading edge upper surface (Figure 3.2). In previous work by Felker ${ }^{5}$ of NASA, the slots of the symmetrical wing were placed along the tangent to allow for induction of the Coanda Effect and maximum change in the point of separation. By placing the slot at a similar position on the V-22 Osprey model, this will allow for the point of airflow separation to be moved farther back along the chord length of the lower surface. 


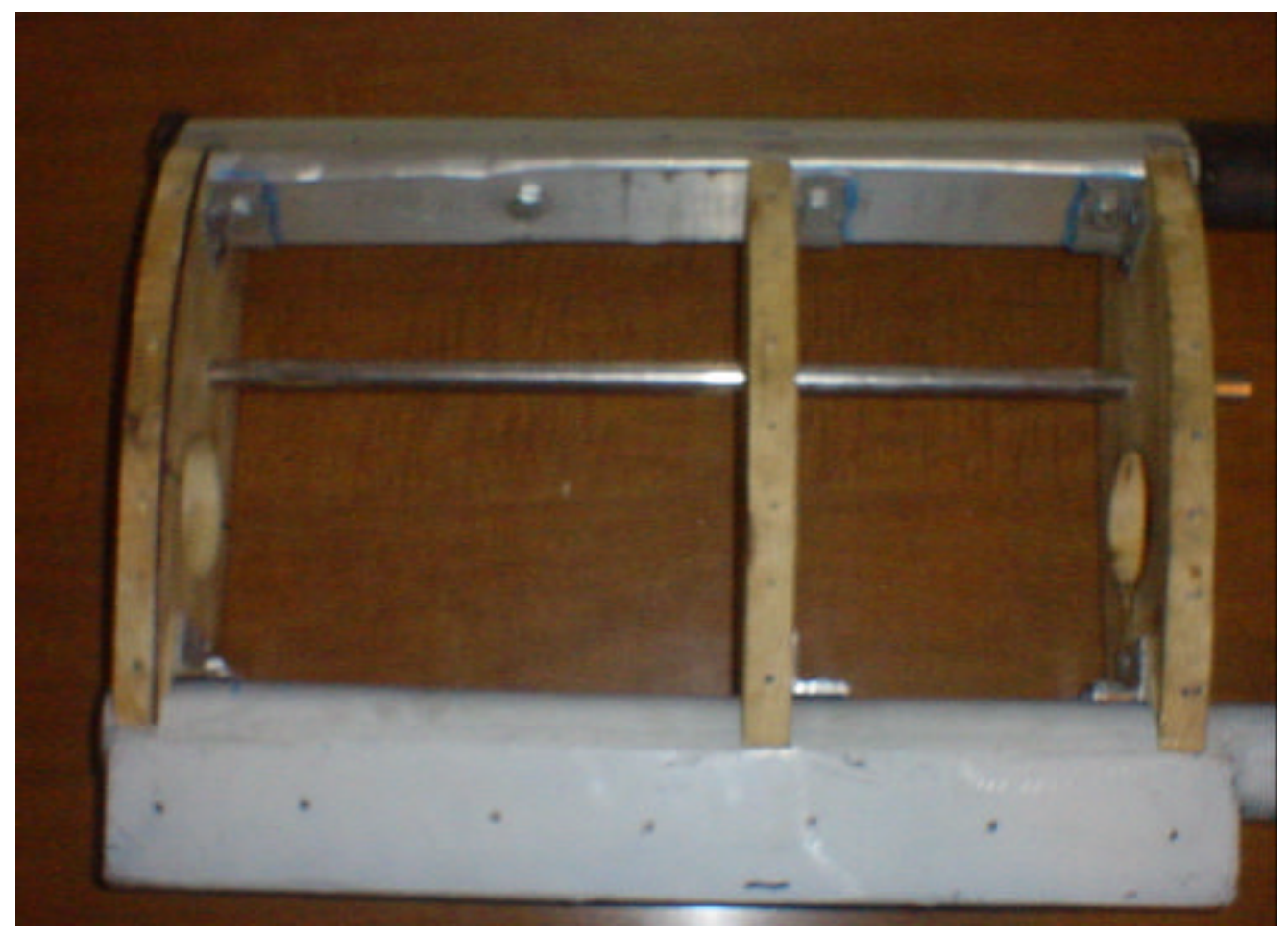

Figure 3.1: Skeleton of airfoil body showing the implementation of the leading edge blowing slot (top of picture) and trailing edge blowing slot.

The trailing edge blowing slot was a challenge to implement. During the hovering mode of the Osprey, the flap angle moves from neutral ( 0 degrees) to 67 degrees. Previous testing by Felker ${ }^{3,4}$ of NASA showed that the flap played an integral role in entraining the airflow to the underside of the wing until the flap reached 78 degrees. At this point, the air began to separate farther back on the flap and the blowing slot was no longer of use in helping to aid in the lift of the rotorcraft. The WVU model has added a blowing slot tangent to the upper surface curvature of the flap (Figure 3.2). By adding high pressure air to the downwash flow, the flap will further induce the Coanda Effect and allow for a greater degree of angle change without airflow separation. 


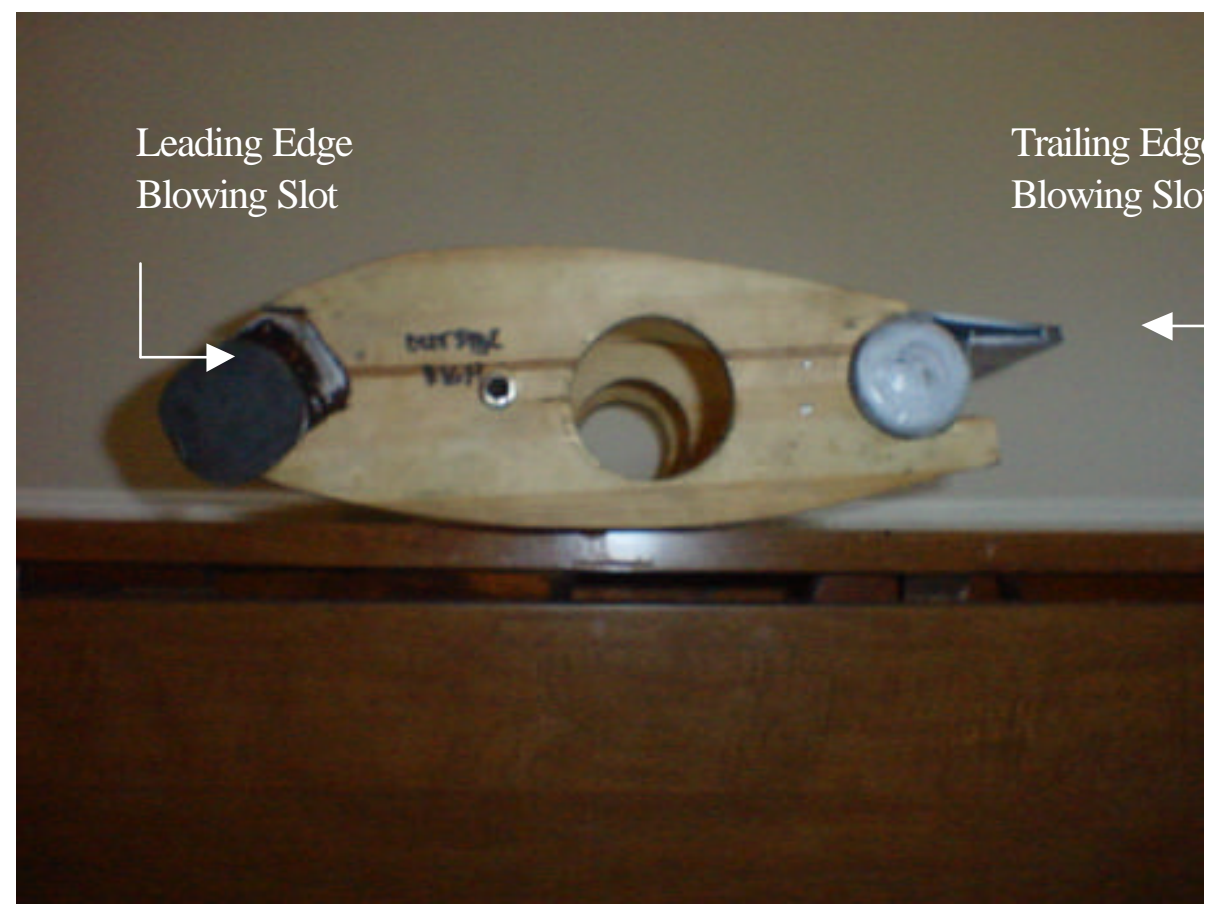

Figure 3.2: Side view of airfoil showing the positions of the leading edge slot (left side of airfoil) and trailing edge slot (right side of airfoil).

The upper and lower surfaces of the main airfoil body, as well as the surfaces of the flap, are made of 0.32 " thick aluminum. The upper and lower surfaces both contain 4 taps across the middle of the surface, as well as 2 taps on the right and left sides. The flap contains 2 taps across the middle as well as 1 tap on the right and left sides of the upper surface. The lower surface of the flap also contains the same tap configuration. Diagrams of the tap placements are located in Appendix D.

\subsection{Wind Tunnel Mounting Setup}

With ease of mounting the model in the tunnel a priority in design, the WVU scaled model was designed around a central pipe mounting system. With the thickness of the airfoil approximately 4 inches, a 7 feet length of 2.5 " diameter pipe was run through the end of the airfoil, leaving the upper and lower surfaces untouched. The lower portion 
of the mounting pipe is equipped with a coupling that is attached to a separate piece of piping that exits the floor of the wind tunnel. This separate pipe is connected to a pair of Omega Dyne S-type load cells (described in more detail in Section 4.3), which are placed alongside the floor of the tunnel laboratory.

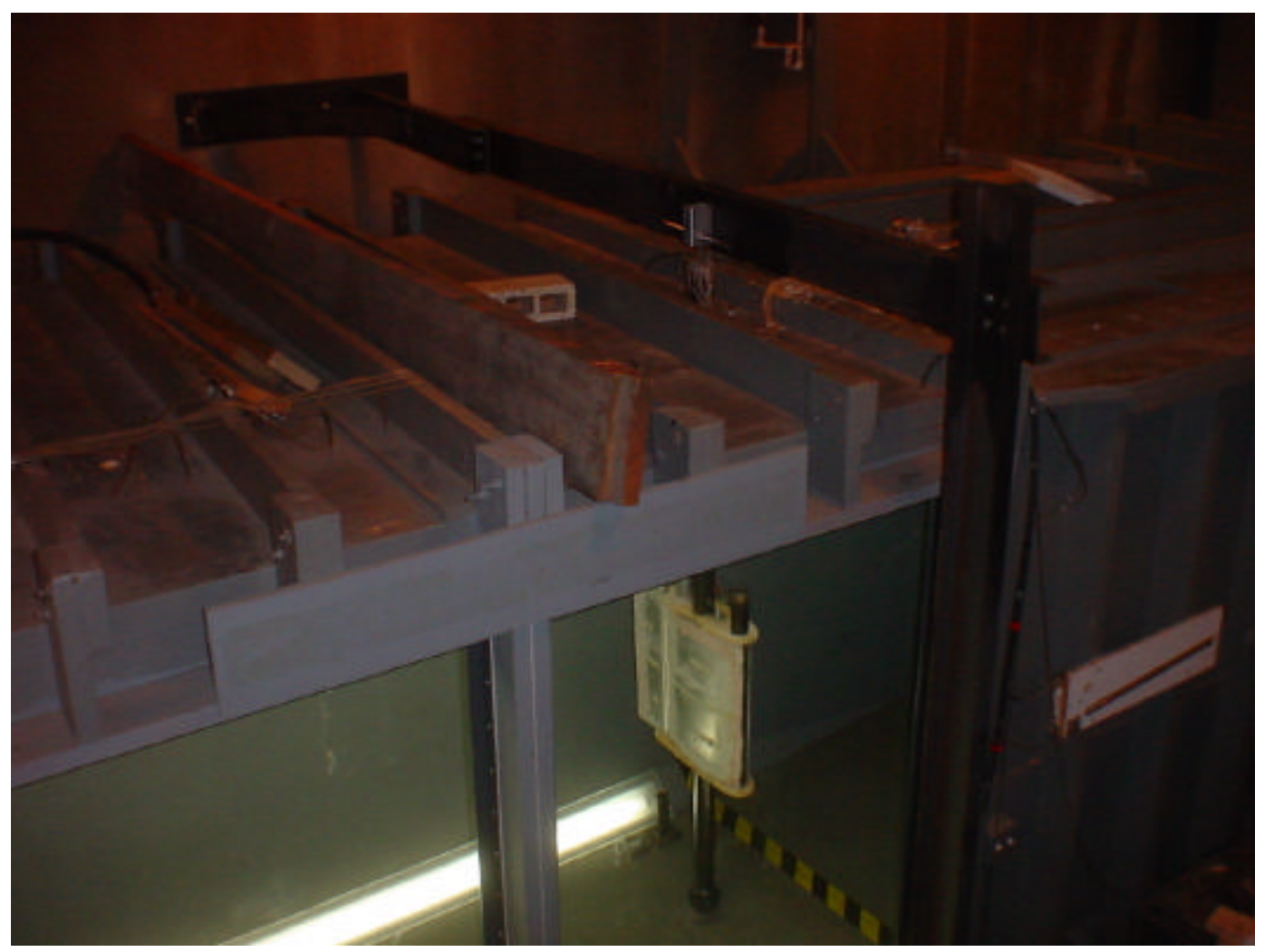

Figure 3.3: WVU V-22 scaled model with bracing system in low speed testing facility.

The upper pipe is fed through the roof of the wind tunnel facility (Figure 3.3). All tubing from surface pressure taps located along the airfoil is placed through this pipe and out through the roof of the facility. The tip of the upper pipe is equipped with a ball and socket joint. The ball and socket joint is connected using hardened steel shaft to a steel bracing system positioned along the outside of the low speed testing section of the wind tunnel facility. The bracing system is designed to harness the airfoil in a suitable testing 
position while providing enough freedom of movement in the system to allow for accurate data collection.

Due to the inclusion of the piping support system in the overall area consumed by the model in the testing facility, the overall blockage was recalculated to take this into account. With the pipe area calculated and added to the frontal area derived for the airfoil, a new blockage value of $12.5 \%$ was determined, slightly above the anticipated level of $10 \%$ or less. 


\section{Experimental Facilities and Equipement}

\subsection{The West Virginia University Low Speed Wind Tunnel}

The WVU subsonic wind tunnel is a closed return tunnel that includes both high speed and low speed test sections. The tunnel contains a 150 horsepower variable pitch fan, a series of turning vanes, and removable screens. To increase the strength of the airflow, the screens can be removed to allow for a greater passage of air. The WVU tunnel is also equipped with a three-point balance, pitch and yaw controls for the fan, a smoke generator and injector for easier flow visualization, and manometers for pressure measurement. A PC-based data acquisition system, also located at the tunnel, can be used for flow measurement instrumentation. ${ }^{9}$

The low speed test section will be used for the circulation controlled airfoil experimentation. The cross section of the tunnel is approximately 50 inches wide by 73 inches high. The speed of the section can be varied from 0 to $60 \mathrm{mph}$, without tunnel blockage.

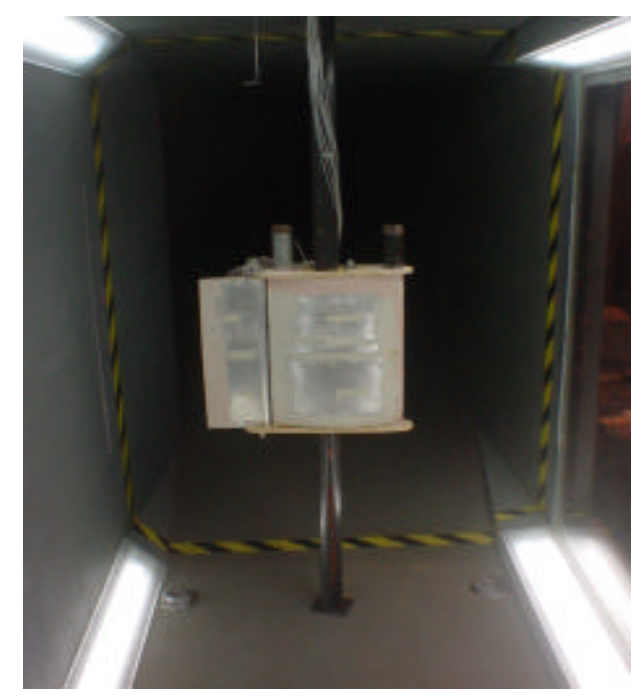

Figure 4.1: Looking into the WVU wind tunnel low speed test section 
The procedure for tunnel operation is as follows:

- Close the main tunnel breaker

- Turn on propeller generator circuit

- Press the motor generator start up button

- Press the line contactor close button

- Slowly increase the speed of the motor

- Increase the pitch of the rotor blades to obtain desired tunnel velocity

\subsection{Manometer Bank}

In previous attempts to read pressure, all of the lines from the airfoil and wake rake were connected to a ScaniValve machine that contained a pressure transducer. After numerous testing was completed with this device, the data was inconclusive and showed no significant pattern trends or data reliability. Due to this issue, the manometer bank became the device for collecting the data needed to show any changes in these monitored areas.

The airfoil contains 24 pressure taps ( 23 working) and the wake rake, located 2 feet from the lower surface of the airfoil, contains 23 pressure taps. A static port in the wind tunnel is also monitored to determine a useful $p_{\infty}$ for $\mathrm{C}_{\mathrm{p}}$ calculations. All of these pressure lines are connected into the 50 Manometer Bank located adjacent to the WVU Closed Return Wind Tunnel. 


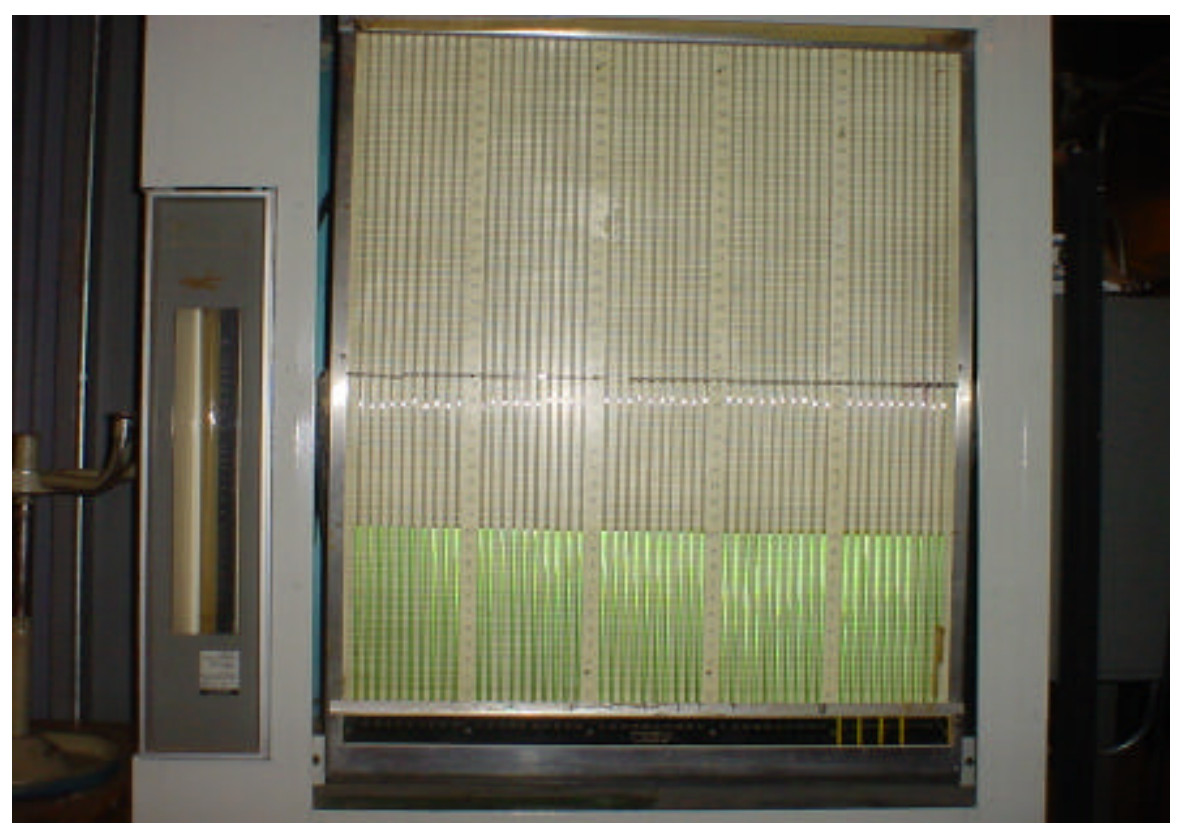

Figure 4.2: Manometer bank located adjacent to WVU low speed subsonic wind tunnel facility.

To obtain a pressure reading, the manometer shows a change in level of water from an initial value. In order to obtain a proper reading from this device, the following steps need to be followed:

1. The local atmospheric pressure is to be calculated. One may obtain the temperature and barometric readings from the thermometer and barometer located in the Aerospace Laboratory building.

2. Since the barometric pressure (or height) is in inches of Mercury, this needs to be converted to feet of Mercury.

3. Given the specific weight of Mercury $\left(\gamma=847 \mathrm{lb} / \mathrm{ft}^{3}\right)$, the atmospheric pressure in pounds per square inch can be determined by the following:

$$
P_{a t m}=\left(h e i g h t * \gamma_{H g}\right)\left(1 f t^{2} / 144 i n^{2}\right)
$$


4. Once the atmospheric pressure is calculated, the pressure change shown by the manometer height can be calculated. An initial value on the manometer needs to be obtained before any testing takes place. This serves as the reference height.

5. Once the wind tunnel was activated, the levels in each of the manometers on the bank will change in height due to a change in air pressure. The new values of each manometer were recorded. Once the values were recorded, the new height value can be obtained by subtracting the new height reading from the initial height values recorded before testing. The new height will be in inches of water and will need to be converted to feet of water.

6. Given the specific weight of water $\left.\gamma=62.2 \mathrm{lb} / \mathrm{ft}^{3}\right)$, the change in pressure can be calculated by the following:

$$
P_{\text {read }}=\left(\text { height } * \gamma_{\mathrm{H}_{2} \mathrm{O}}\right)\left(1 f t^{2} / 144 \mathrm{in}^{2}\right)
$$

7. Since the above value is only the amount of change in pressure due to the change in tunnel speed, the calculated pressure change is to be added onto the value calculated for the atmospheric pressure in order to obtain the actual air pressure at that point.

\subsection{Load Cell and System Configuration}

The WVU Circulation Control V-22 Model test configuration contains two Omega Dyne 25-lb S-type load cells, located just below the model on the underside of the wind tunnel test section. A twelve-volt power supply was used to provide the excitation 
voltage to each cell. The placement of the cells is crucial in understanding the change in the system load due to activation of the leading edge or trailing edge blowing slots or both. Load Cell One is referred to as the trailing edge load cell. Load Cell Two is referred to as the leading edge load cell. The cells are not directly mounted to the corresponding edges. They are simply referred to this due to the placement of them in line on the shaft outside of the wind tunnel (see Figure 4.3). Each cell is positioned directly underneath the corresponding edge of the airfoil, and each cell shows the effects of the activation of that particular slot.

Each cell has been calibrated to obtain an equation to convert the read voltage from LabVIEW to a corresponding value in pounds. Zero to twenty-five pounds were placed upon each cell individually and the following equations represent the calibration of each cell:

$$
\begin{aligned}
& \text { Force }_{1}(l b s)=679.67 * V_{1}-0.4172 \\
& \text { Force }_{2}(l b s)=684.55 * V_{2}-0.3661
\end{aligned}
$$

Using the above equations, the forces determined from the load cells are used as part of the static equation (Equation 6) to determine the drag force placed upon the airfoil itself.

The diagram on the following page (Figure 3) is a free-body representation of the wing and structural system located in the WVU Low Speed Subsonic Wind Tunnel. There is one main pipe that is run through the entire system, attached by a rod end from above the wind tunnel. The pipe bottom is connected to a rod, which the two load cells are attached. The lengths to the center of each drag component are represented by $\mathrm{L}_{1}, \mathrm{~L}_{2}$, 
$\mathrm{L}_{3}$, and $\mathrm{L}_{4}$. The forces on the bottom of the diagram, $\mathrm{F}_{1}$ and $\mathrm{F}_{2}$, represent those forces being read by the load cells during testing. $D_{1}$ symbolizes the drag on the upper pipe, where as $D_{2}$ represents the drag located on the lower region of piping. $D_{3}$ is the main component in which we are solving for, as it represents the drag dissipated on the airfoil itself.

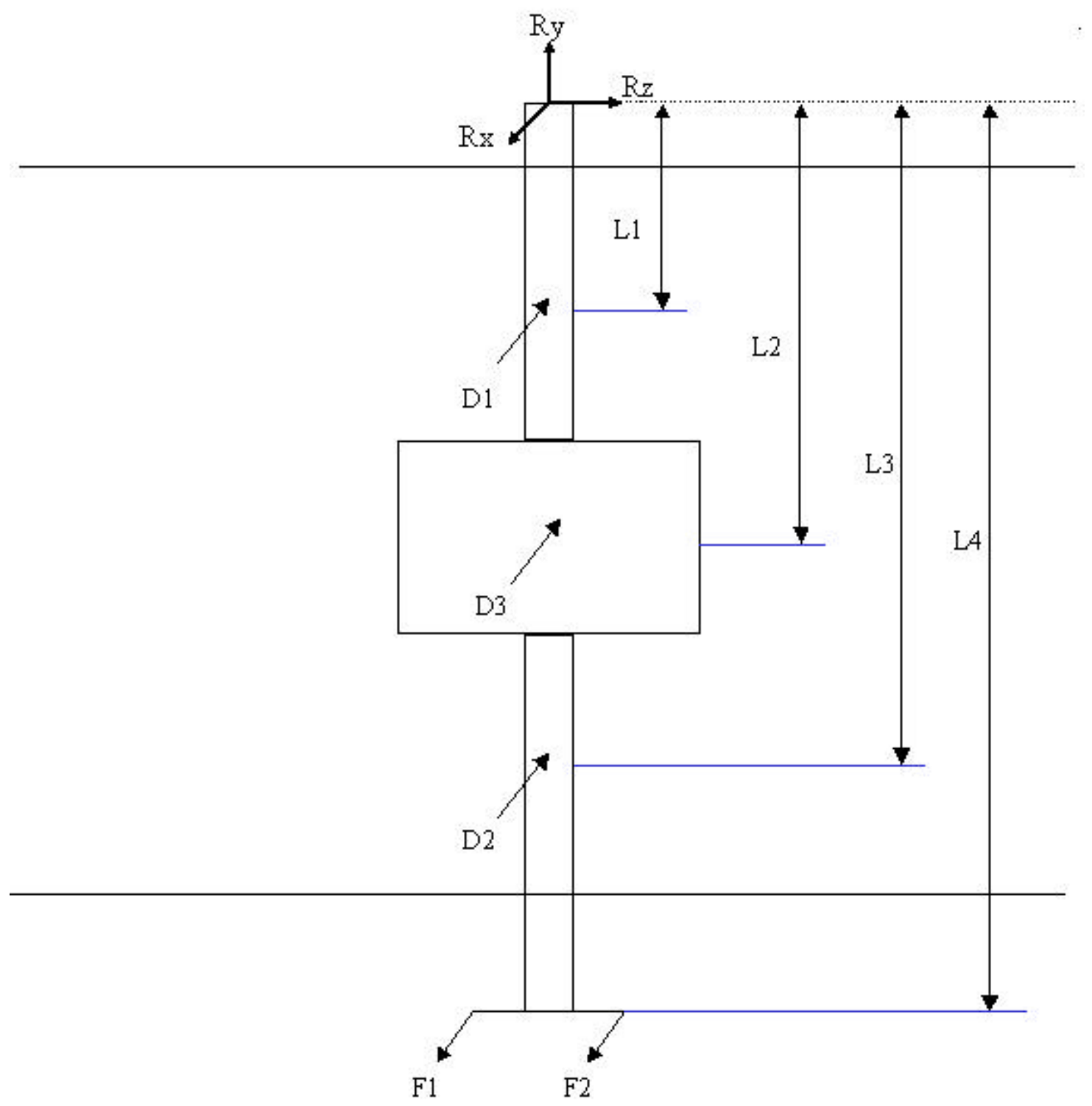

Figure 4.3: Free body diagram of entire airfoil system. 
Using the free body diagram setup, a static equation was obtained to solve for the drag on the airfoil, or $\mathrm{D}_{3}$. Having the values for $\mathrm{L}_{4}, \mathrm{~L}_{2}, \mathrm{~L}_{3}, \mathrm{~L}_{4}, \mathrm{~F}_{1}$ and $\mathrm{F}_{2}$ known, the values for $\mathrm{D}_{1}$ and $\mathrm{D}_{2}$ were estimated and solved as the drag around a smooth cylinder. After calculating the Reynolds Number for each pipe, a drag coefficient of 1.4 was determined for both pipes. Using the equation $\operatorname{Drag}=1 / 2 \rho V^{2} A$, the drag on each pipe was estimated and the solved values were used in determining the value of $D_{3}$. By taking the moments around R (Figure 4.3), the static equation used for this system:

$$
D_{3}=\frac{L_{4}\left(F_{1}+F_{2}\right)-L_{1} D_{1}-L_{3} D_{2}}{L_{2}}
$$

\subsection{LabVIEW Software}

LabVIEW is a software package designed by National Instruments to interface analog test equipment with digital processing equipment, such as a PC. This software allows the output of the load cells and a J-Thermocouple (located in the wind tunnel facility) to be read, monitored, and then written to a spreadsheet file for ease of use during data reduction. For this particular experiment, LabVIEW was structured to read the outputs from both load cells, writing both outputs to a single spreadsheet file. The output from the J-Thermocouple was written to a separate temperature file. The structure and code for this software is located in Figure B.1 of Appendix B.

\subsection{Power Consumption Calculations}

An approximation of the maximum amount of power needed to supply the airflow to the blowing slots at its optimal state is another factor to take into account when judging whether or not this technology is going to be beneficial to the rotorcraft. By use of the 
following equation, the amount of power (or work) it takes to supply the airflow to the slot was calculated:

$$
W_{\text {in }}=m\left[\left(\frac{p_{\text {out }}}{\rho_{\text {out }}}+\frac{V_{\text {out }}^{2}}{2}\right)-\left(\frac{p_{\text {in }}}{\rho_{\text {in }}}+\frac{V_{\text {in }}^{2}}{2}\right)\right]
$$

The outputted values are those corresponding to the blowing slot and the inputted values are those corresponding to the supply tank and hosing. Bernoulli's equation was used to solve for inputted velocity from the tank hosing. The mass flow $(m)$ needed for Equation 7 have been calculated as follows:

$$
m=\rho V A
$$

Keeping the mass flow constant for the input and the output, the velocity of the blowing slot was calculated by rewriting Equation 8 in terms of velocity.

The power supplied to the airflow was calculated for both the scaled model and for the full sized V-22 airfoil wingspan. In order to take into account the amount of difference in the airfoil scale, Equation 9 was used to determine the amount of power needed to supply the airflow to a full-scaled wing, with $\mathrm{C}$ representing the chord length and S representing the span of either the model or full-scale plane. The value for the span of the model $\left(S_{\text {Model }^{*}}\right)$ is represented by a calculation of the span of a full-scaled chord section with the span length proportional to the model. The quantity is multiplied by 2 in order to take into account the leading and trailing edge blowing slots.

$$
W_{\text {Plane }}=2 W_{\text {Model }}\left(\frac{C_{\text {Plane }}}{C_{\text {Model }}}\right)\left(\frac{S_{\text {Plane }}}{S_{\text {Model }}}\right)
$$




\subsection{Experimental Error}

Any measurements taken during experimentation have an error associated with that type of testing. The method for error estimation in this experimentation was calculated using the propagation of error technique. ${ }^{10}$ The amount of uncertainty in a given variable $W_{r}$ is determined using the Equation 10, which is structured around those variables, $x_{i}$, in which the outcome of the examined variable is dependent.

$$
W_{r}=\left[\left(\frac{\partial R}{\partial x_{1}} w_{1}\right)^{2}+\left(\frac{\partial R}{\partial x_{2}} w_{2}\right)^{2}+\ldots+\left(\frac{\partial R}{\partial x_{n}} w_{n}\right)^{2}\right]^{1 / 2}
$$

Applying the above equation to the drag coefficient, results in Equation 11. There was only one measured variable that had an impact on the coefficient of drag due to the location of the load cells outside of the wind tunnel facility.

$$
C_{D}=\left(\frac{\partial C_{D}}{\partial D} \partial D\right)^{2}
$$

Using the definition of the coefficient of drag (Equation 12) and the ideal gas law, the equation for the drag coefficient was rewritten to incorporate the terms of pressure and temperature, which were also measured during testing (Equation 13). $R$ used in this derivation is the ideal gas constant for air.

$$
\begin{gathered}
C_{D}=\frac{D}{0.5 \rho V^{2} A} \\
C_{D}=\frac{D}{0.5 \frac{P}{R T} V^{2} A}=\frac{2 R D T}{P V^{2} A}
\end{gathered}
$$

From the above equations, the partial derivative of $C_{D}$ with respect to drag was determined and shown below. The value of $\partial D$ is the instrumentation error from the 
drag reading determined by the load cells. All instrumentation errors are shown in Table 4.1, located at the end of this section.

$$
\frac{\partial C_{D}}{\partial D}=\frac{2 R T}{P V^{2} A}
$$

The pressure measurement error equation was constructed the same way as that of the drag measurement error. Unlike the equation derived for the drag measurement, the pressure measurement is effected by three measured variables: pressure, temperature of the wind tunnel, and velocity of the wind tunnel. Starting with the equation for the propagation of error, the new equation in terms of pressure is as follows:

$$
C_{P}=\left[\left(\frac{\partial C_{P}}{\partial P} \partial P\right)^{2}+\left(\frac{\partial C_{P}}{\partial T} \partial T\right)^{2}+\left(\frac{\partial C_{P}}{\partial V} \partial V\right)^{2}\right]^{1 / 2}
$$

Similar to the way the partial derivatives were obtained above, the derivation begins with the definition of the coefficient of pressure (Equation 16). In order to put the equation in terms of the measured independent variable, the ideal gas law was substituted into the equation.

$$
\begin{gathered}
C_{P}=\frac{\left(P-P_{\infty}\right)}{0.5 \rho V^{2}} \\
C_{P}=\frac{\left(P-P_{\infty}\right)}{0.5 \frac{P}{R T} V^{2}}=\frac{2\left(P-P_{\infty}\right) R T}{P V^{2}}
\end{gathered}
$$

From this relationship, the partial derivatives of $C_{P}$ were determined with respect to each of the measured variables and are shown below. Again, the values of instrumentation error are located in Table 4.1 at the end of this section. 


$$
\begin{gathered}
\frac{\partial C_{P}}{\partial P}=\frac{4 R T P_{\infty}}{P^{2} V^{2}} \\
\frac{\partial C_{P}}{\partial T}=\frac{2\left(P-P_{\infty}\right) R}{P V^{2}} \\
\frac{\partial C_{P}}{\partial V}=-\frac{4\left(P-P_{\infty}\right) R T}{P V^{3}}
\end{gathered}
$$

Table 4.1: Measurement Instrumentation Error Values

\begin{tabular}{|l|l|}
\hline Instrument & Error \\
\hline Omega Dyne 25 lb. Load Cell & $\pm 0.03 \%$ \\
\hline Manometer Bank and Tunnel Manometer & $\pm 0.05 "$ \\
\hline Omega Type-J Thermocouple & $\pm 0.20 \mathrm{degC}$ \\
\hline
\end{tabular}




\section{Experimental Procedure}

Previous research has shown the ability of circulation control to increase the lift capabilities of aircraft. This research is to expand on that experimentation and to show the effects of this technology when incorporated to a scaled model of the V-22 Osprey tilt-rotorcraft.

The WVU V-22 Circulation Control testing examined the effects of three active circulation control configurations: leading edge active circulation control, trailing edge active circulation control, leading and trailing edge simultaneous active circulation control. Each testing configuration was broken into three specific areas that will determine the effectiveness of the application of active circulation control: surface pressure data, wake region observation, and load cell data. This section will expand on the importance each of these specific areas demonstrates in showing the capabilities active circulation control.

\subsection{Surface Pressure Data}

With the V-22 Osprey in hover mode, the wings of this craft are positioned normal to the downwash flow from the proprotors. The purpose of the surface pressure data is to monitor the changes in impact of the airflow across the upper and lower surfaces.

As the circulation control is activated, the flow should begin to entrain around the leading and trailing edges of the airfoil. The surface pressures around the leading and trailing edges will change due to the additional flow added to these areas. From baseline 
testing, results similar to those shown in Figure 5.1 are expected. This plot shows the impact of the normalized airflow on a scaled model if the V-22 Osprey performed by NASA at Ames Research Center. As the airflow from the proprotors was increased, the pressure along the upper surface of the airfoil withstands the initial impact of the flow, leading to the high pressure readings along the surface. Due to the upper surface absorbing the initial impact of the flow, the lower surface becomes an area of lower pressure due to additional turbulence and the lack of streamlined flow into this zone.

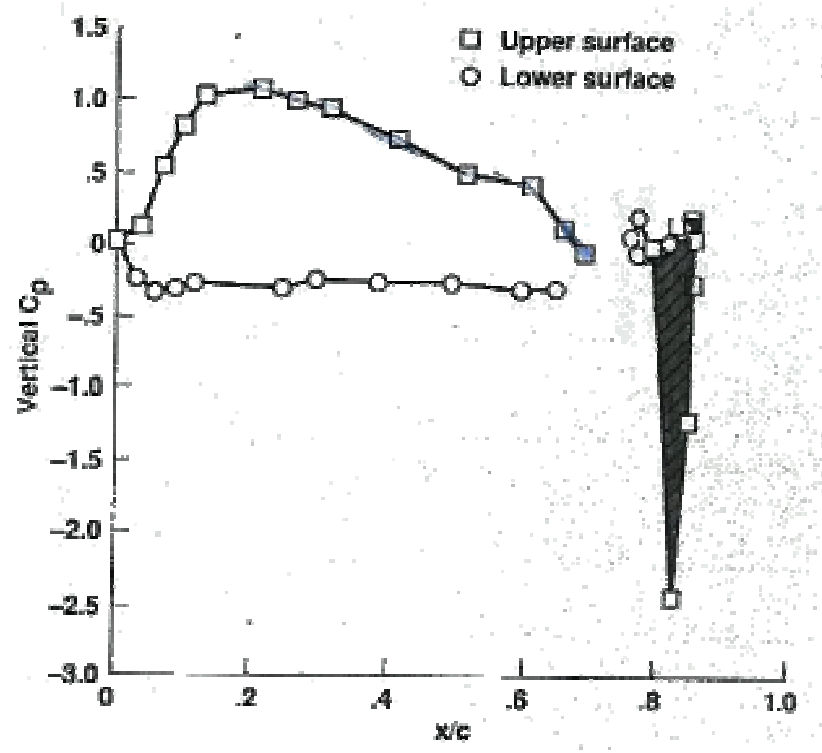

Figure 5.1: Cp vs. $\mathrm{x} / \mathrm{c}$ plot for NASA scaled V-22 Osprey model with 78 degree flap angle. ${ }^{3}$

Due to the lack of pressure taps along the leading edge and flap region, the WVU scaled model is unable to obtain a sufficient evaluation of the flow around these regions. With the circulation control activated along these regions, the lack of surface pressure taps inhibits the ability to detect the magnitude of the Coanda Effect as the slot pressure is increased. With the heightened magnitude of the Coanda Effect, the area of separation is moved to the underside of the airfoil. With this movement of the area of separation, the WVU scaled model is incapable of relaying the position of the new separation area. 
The surface pressure data from the WVU scaled model testing allowed the monitoring of the flow patterns of the upper and lower surfaces, as well as the flap, during active circulation control. As the slot pressure is increased, the data from this particular testing showed any slight behavioral modifications in the flow around these particular areas around the airfoil. If any strange or subtle trend is caused in the wake region, upper surface, or flap, this particular phase of testing will help detect those and will allow for the monitoring of these effects during future work and testing.

\subsection{Wake Region Observation}

Due to the lack of surface pressure taps to monitor the flow pattern changes that occur during active circulation control, a wake rake was installed approximately 2 feet down-stream of the lower surface of the airfoil. This piece of equipment enhanced the ability to detect a change in the size of the wake region and determined the magnitude of change the Coanda Effect exhibited during wake reduction.

As the airflow from the proprotors impacts the upper surface of the airfoil, the air separates from the leading and trailing edges. This separation creates the boundary for the wake region (Figure 5.2). The wake region on the V-22 Osprey is located along the lower surface of the airfoil. With the turbulence created in this area and no beneficial airflow, the lift capabilities of the aircraft are hindered. Due to early separation on the downwash air, excessive vertical drag is produced. 


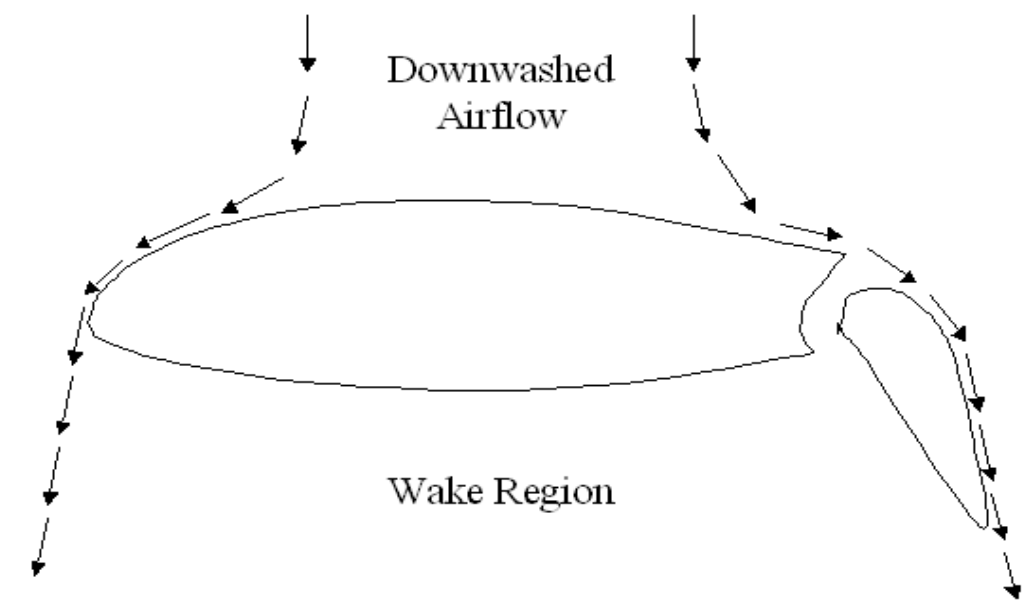

Figure 5.2: Airflow around the V-22 airfoil without circulation control.

By activating circulation control around the leading and trailing edges, the additional airflow will induce the Coanda Effect around these areas, drawing the airflow toward the underside of the airfoil. By inducing the beneficial airflow into the wake region, the size of this region will decrease, as shown in Figure 5.3.

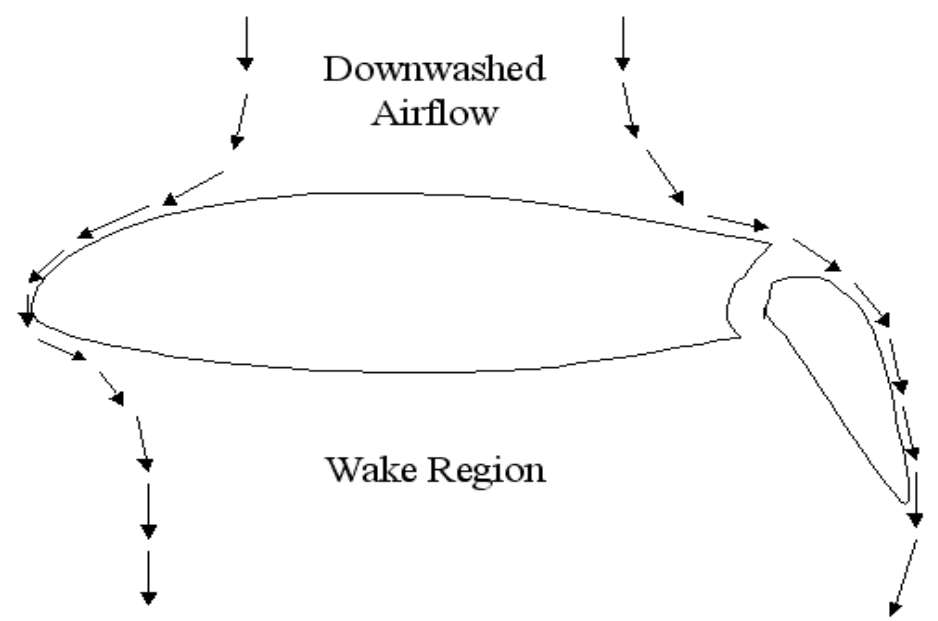

Figure 5.3: Airflow around the V-22 airfoil with active circulation control.

When the wind tunnel is activated, the manometer bank monitors the flow patterns across the wake region from the wake rake. With circulation control activated, higher velocity air is induced into the wake region. As the velocity of the air is increased, this increase will be shown on the manometer bank as an increase in pressure 
corresponding to the area in which circulation control is active. The higher the pressure shown by the manometer bank in these regions, the smaller the wake region becomes because of the beneficial airflow moving into this area. As with the surface pressure taps, the wake rake observation does not produce enough data to pinpoint the exact location of the new point of separation.

\subsection{Load Cell Data}

In addition to the ability of the wake rake to detect the changes of the wake region, the load cell data is used congruently to show any changes in the drag on the airfoil as the wake region is altered by active circulation control. As the flow patterns around the airfoil begin to change, the drag on the airfoil will either increase or decrease.

If the trends of the wake region show a decrease in the region size from the data gathered in the described testing above, the load cell data will show a decrease in the overall load dissipated on the airfoil. The same is true for an opposite reaction in the wake region. If the wake region is increasing in size, the overall load on the airfoil is increased.

The load cell readings will also display the prominent areas where circulation control is active. For example, as the leading edge circulation control is activated, the load cell placed at this point will display the changes in loss of vertical drag. Due to the placement of the opposite edge cell, the railing edge cell would show a slight increase in drag reading caused by the torque on the system. The same patterns of behavior should be displayed as the trailing edge active circulation control is enabled. 


\section{Results}

This section explains the results collected from the testing described in the previous section. All data collected was taken during standard hover mode testing and the results of all configurations of slot blowing are covered here also.

\subsection{Standard Hover Mode Testing}

The results of the WWU V-22 scaled model were conducted at the standard hover flap angle of 67 degrees. At this flap angle, the testing was broken down into three separate categories: leading edge active circulation control, trailing edge active circulation control, and simultaneous leading and trailing edge active circulation control. The first two categories, or series of tests, were performed with one blowing slot active, being either the leading or trailing edge slot. The third series of tests are performed with both blowing slots activated simultaneously.

\subsection{Baseline Testing}

In order to evaluate the ability of circulation control, baseline testing was conducted to determine the initial values used for testing comparison. The data obtained during baseline testing consists of the following: surface pressure data, wake region observation, and load cell data. Three sets of baseline tests were performed during the main round of testing. Another set of baseline tests was performed on a later date to examine repeatability. 


\subsubsection{Surface Pressure Data}

An example of the baseline surface pressures can be seen in Figure 6.1. In this diagram, the surface pressures are shown in the four sections of the airfoil in which they are monitored: upper surface, lower surface, upper flap surface, and lower flap surface. This figure shows the values in relation to where each tap falls in line on the surface of the airfoil. Due to the lack of pressure taps along these surfaces, changes shown by the induction of the Coanda effect were unable to be monitored and the location of the separation region is unknown.

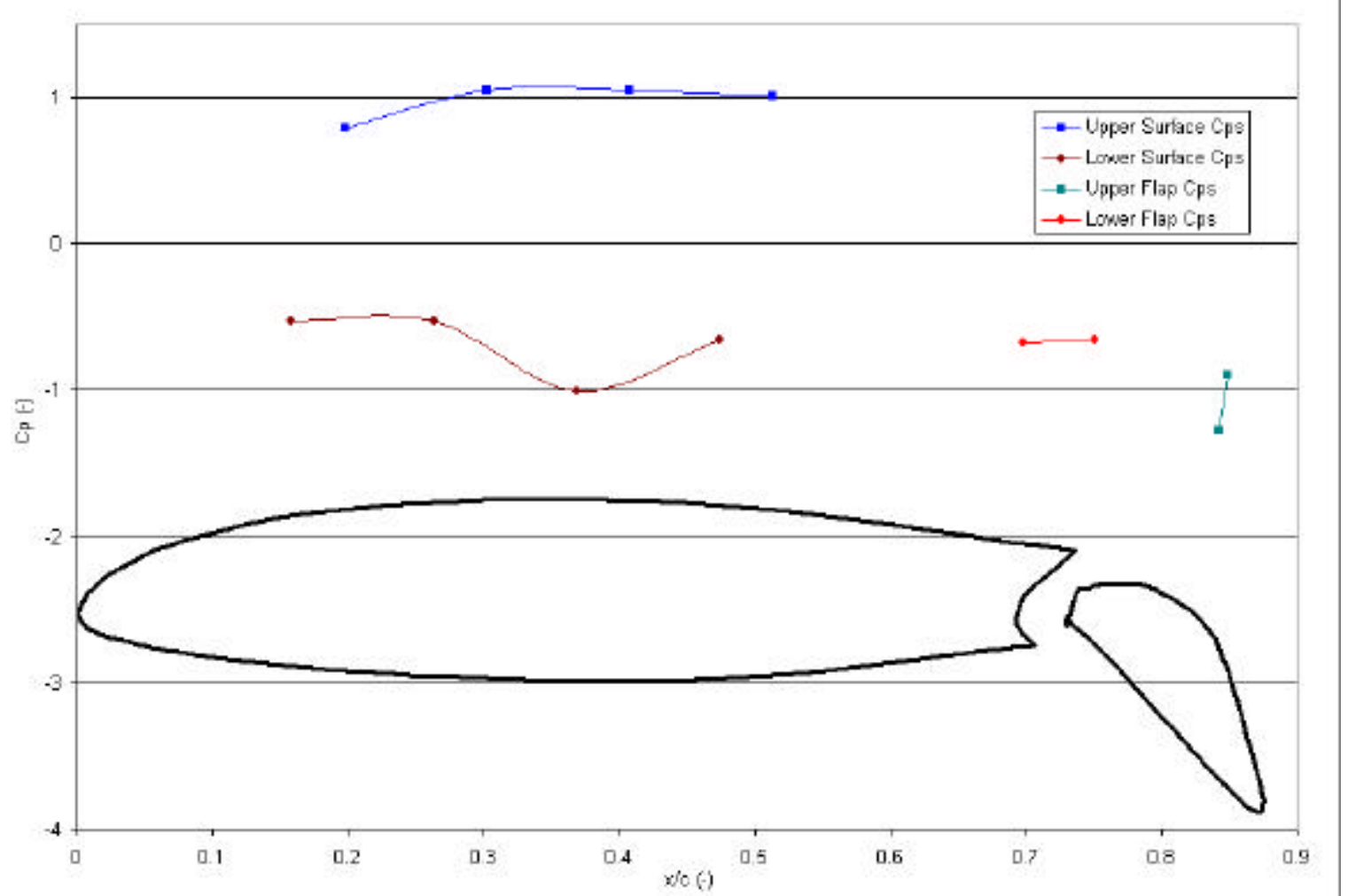

Figure 6.1: Baseline 2 surface pressure values in ordinance with position on the airfoil.

In Figure 6.2, the upper surface pressure values from each baseline are shown. The first two original baseline tests follow the exact same pattern. The third original baseline test shows a tailing off at the data point collected, leading to the offset in this 
area during the average baseline testing. The repeat baseline testing is shown with a higher magnitude than the original baseline test, but essentially following the same pattern as the original baselines. The increase in magnitude could be lead to the inability to properly recalibrate the velocity manometer to the exact initial value as used during the original set of testing. The manometer was moved to the high speed testing section for use and then moved back. An offset in the manometer reading may have occurred and therefore may have created a small indifference in the speed calculated for these tests. This slight difference in speed may have lead to the heightened magnitude of some of the repeated values.

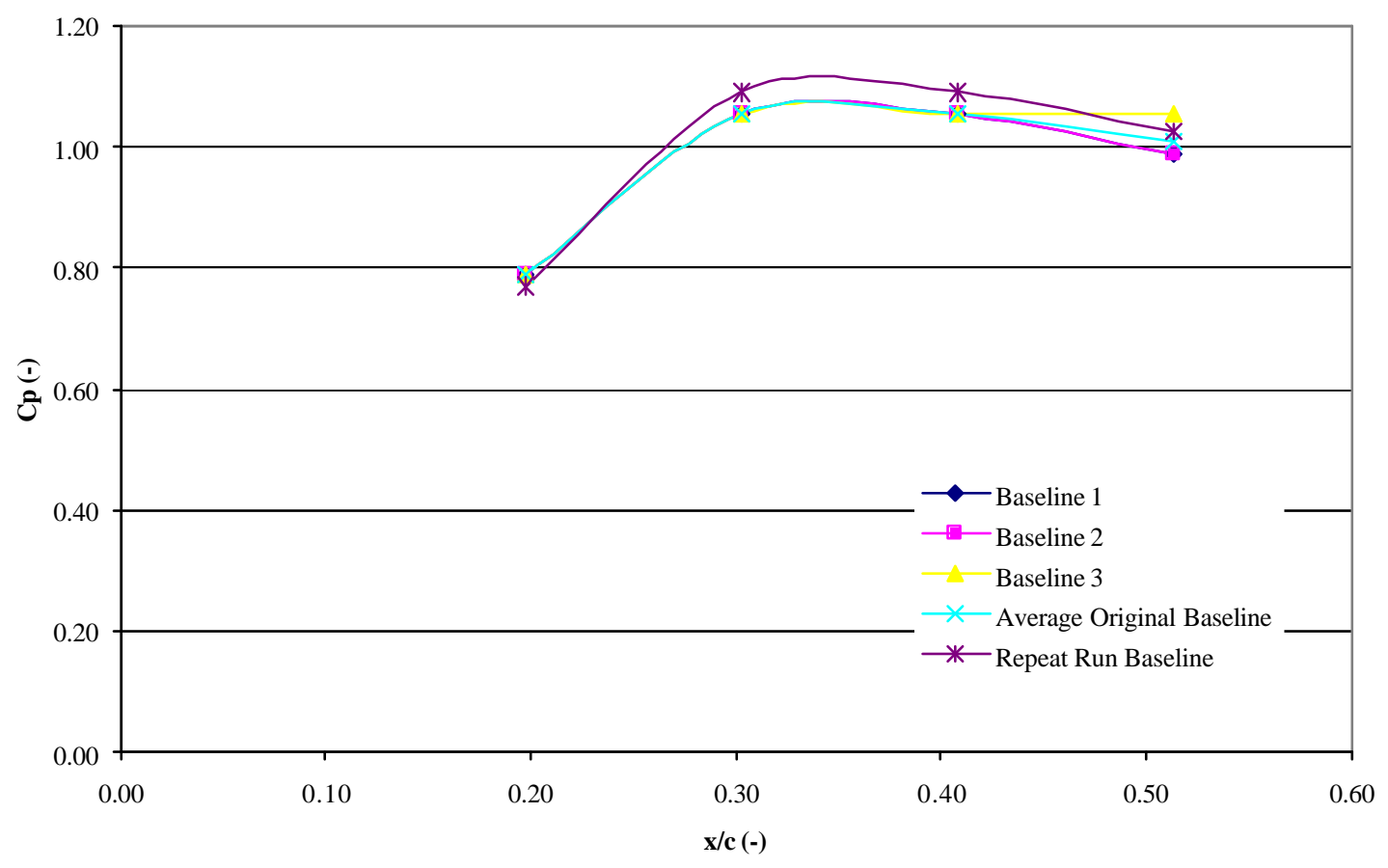

Figure 6.2: Baseline upper surface pressure values.

Figure 6.3 represents the values from the lower surface pressures extracted from the Baseline tests. All tests display the same pattern trend: slightly level for the first two taps measured, a drop off in pressure on the third tap, and a rise in pressure on the final 
tap. Points one (Tap 19), two (Tap 20), and four (Tap 22) remain consistent from test to test in value. Point three (Tap 21) shows a consistency in pattern, but there is a minor inconsistency in magnitude. This inconsistency may be lead to turbulence along the lower surface of the airfoil.

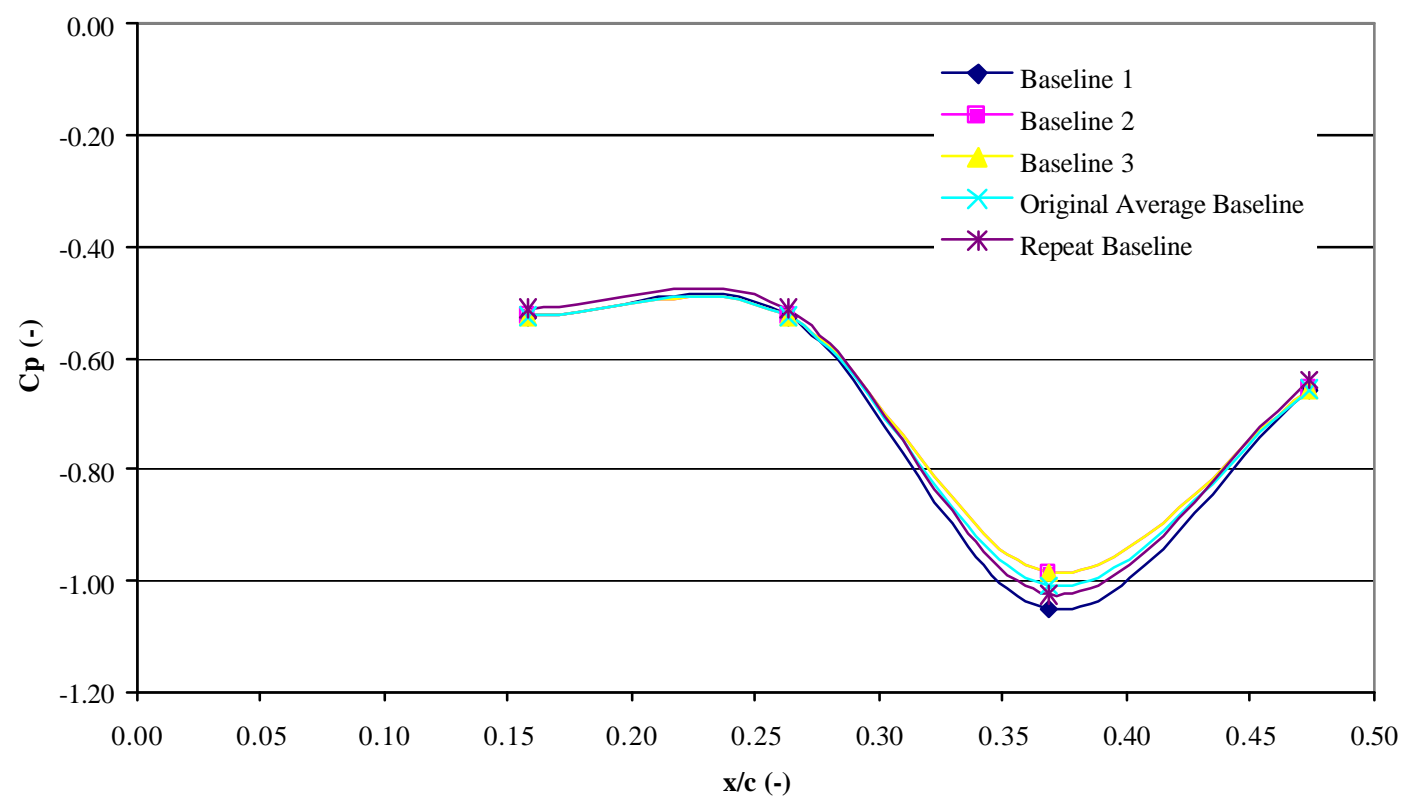

Figure 6.3: Baseline lower surface pressure values.

The flap surface pressure trends are displayed in Figure 6.4. The trend for these tests shows Tap 2 (point 1) at a lower $\mathrm{Cp}$ value then increasing up to a higher value at Tap 3 (point 2). The values for the Baseline 1 are lower than the rest of the original Baselines test. This test was started just as the tunnel was running, so the flow of the tunnel may not have reached steady state at this point. Baselines 2 and 3 show a closer similarity in value, but still not completely consistent. The reason for this is unknown at this point. The repeat baseline shows a similar trend as those tested before, but the slope of the repeat run is slightly lower than those previous tests (see Figure 6.4). The offset 
again could be related to the recalibration of the inclined manometer being used to read the velocity.

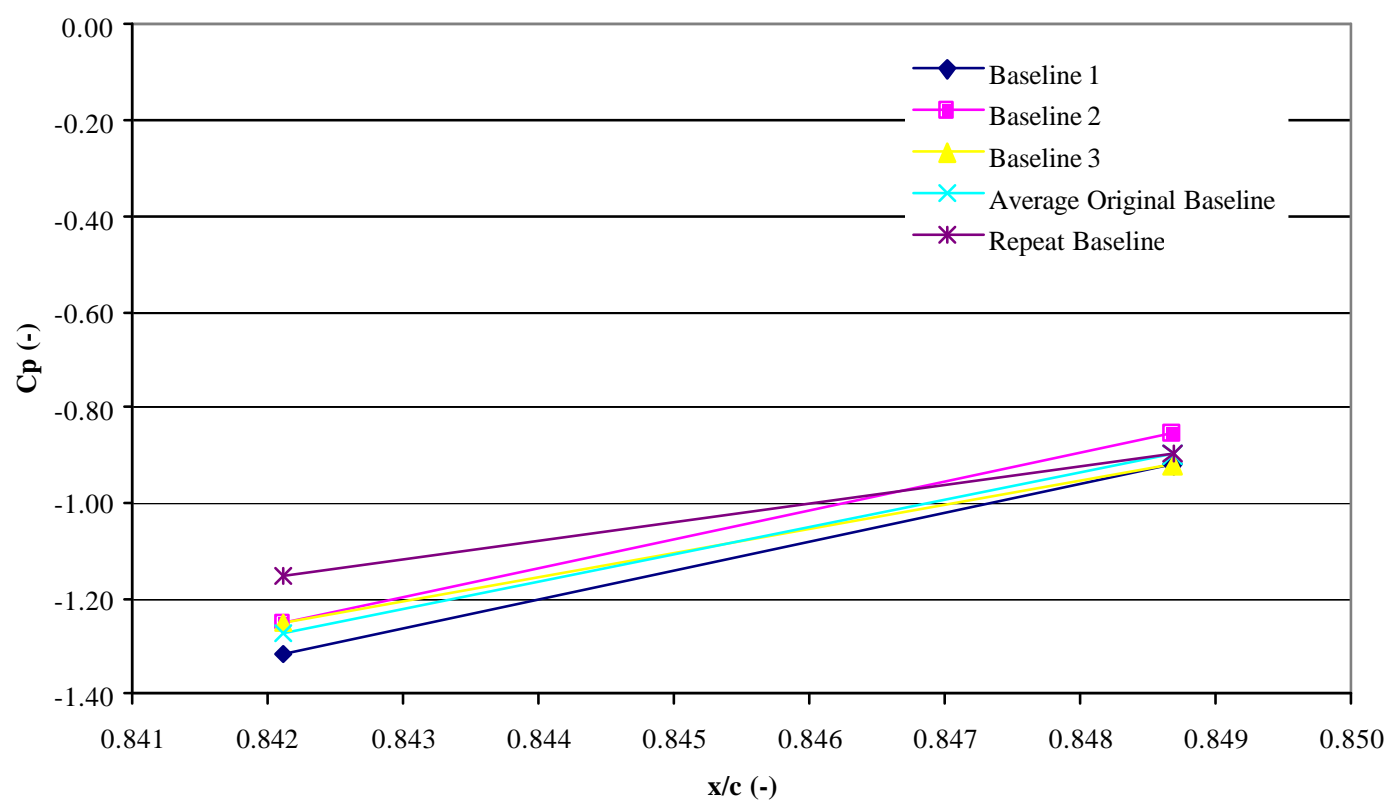

Figure 6.4: Baseline upper flap surface values.

The lower flap values show some consistency in the trends of the patterns between the final two original Baseline tests and the repeat Baseline testing. In Figure 6.5, these trends can be noticed. The Baseline 1 testing shows an inconsistency in the trend. This again may be lead to the irregularity in the flow of the wind tunnel at that point, and again leads to the offset displayed in the average of the original baseline values. The repeat testing, as stated above, shows the same trend as the final original Baseline runs, except with a greater magnitude in value. Again, this may be attributed to a possible change caused by movement of the velocity manometer between the original testing and the repeated runs. 


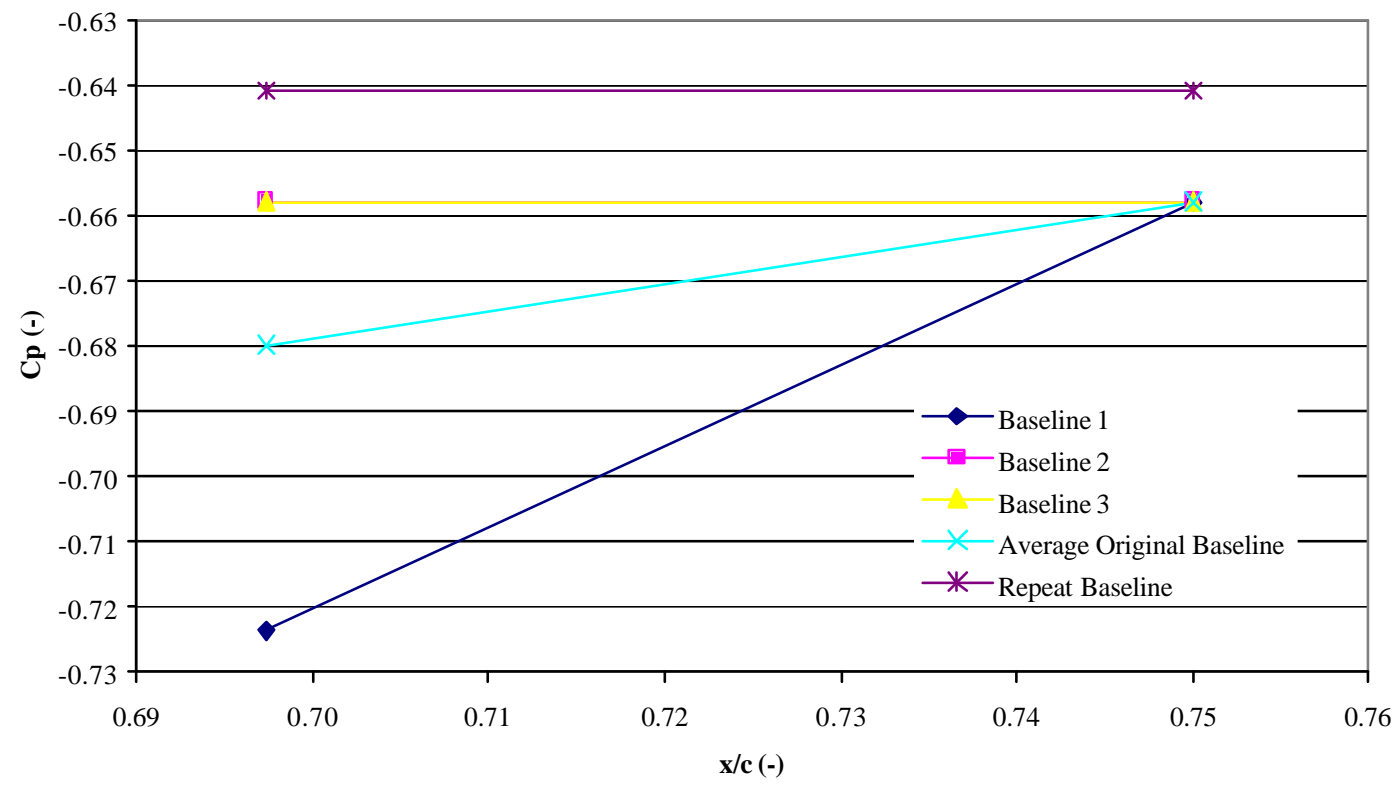

Figure 6.5: Baseline lower flap surface values.

\subsubsection{Wake Region Observation}

The wake region plot of the Baseline testing provides an initial idea of the trends of the airflow around this area. The plots for the wake region during each of these tests are shown in Figure 6.6. During the all runs of the Baseline testing, the trends of the wake region observation follow the same patterns. Each wake plot overlays the patterns of the others, providing confidence in repeatability of this testing. The dropping peaks shown in the plot are repeatedly displayed as a trend in each test and are possibly caused by turbulence or lack of productive airflow in these areas. 


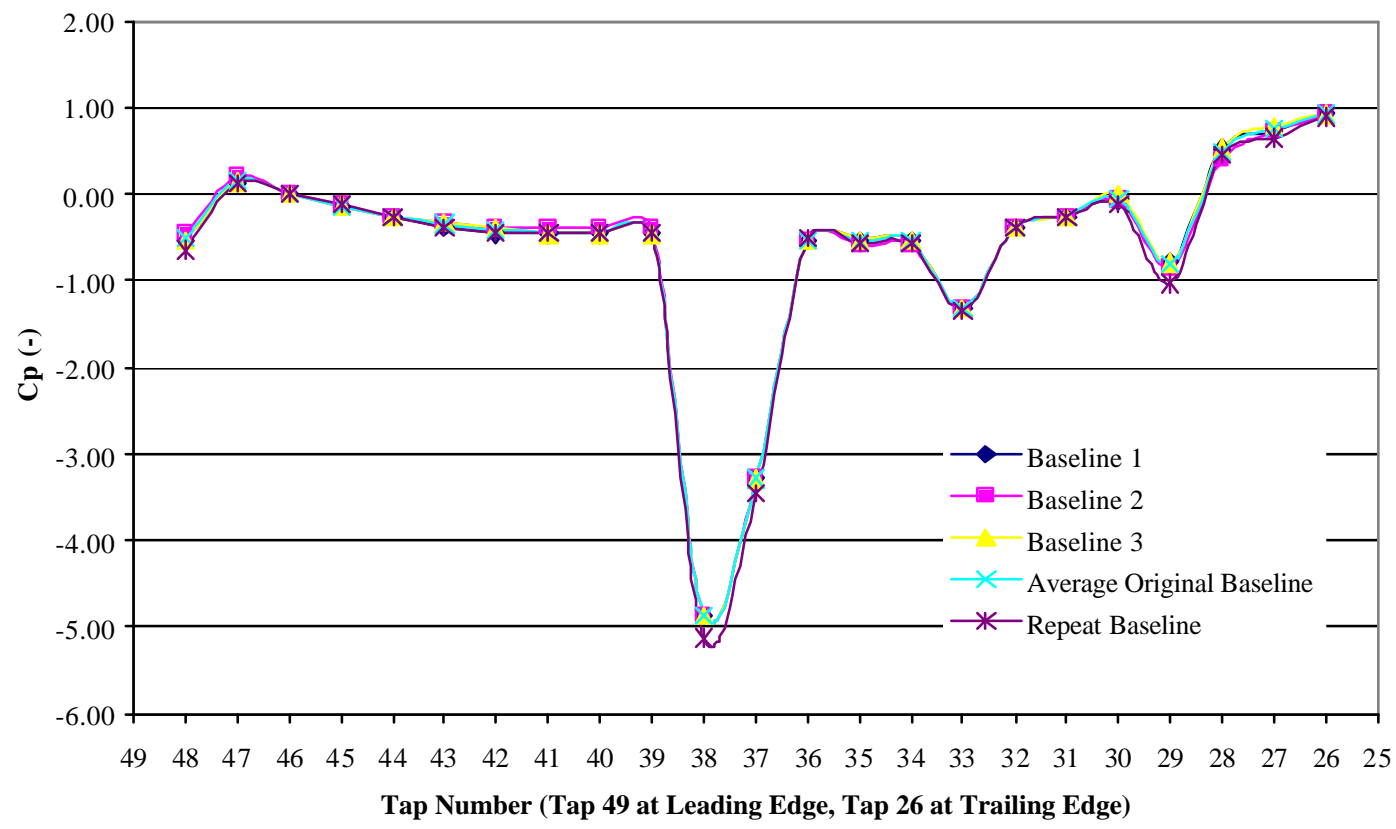

Figure 6.6: Baseline wake region plot.

\subsubsection{Load Cell Data}

Like the previous testing explained above, the load cell data taken during the baseline testing will provide the initial data for comparison to better understand the effectiveness of circulation control. Unlike the surface pressure data and wake observation, the load cell data allows the ability to directly view the actual drag gain or loss during the activation of circulation control.

Figure 6.7 shows the overall drag values from the Baseline tests performed. The first four values shown are the three Baseline tests performed with the original testing. The last is the value of the overall drag from the repeated Baseline test. The original Baseline testing demonstrates the ability to maintain a steady value of approximately 5.45 lbs throughout each test performed. 


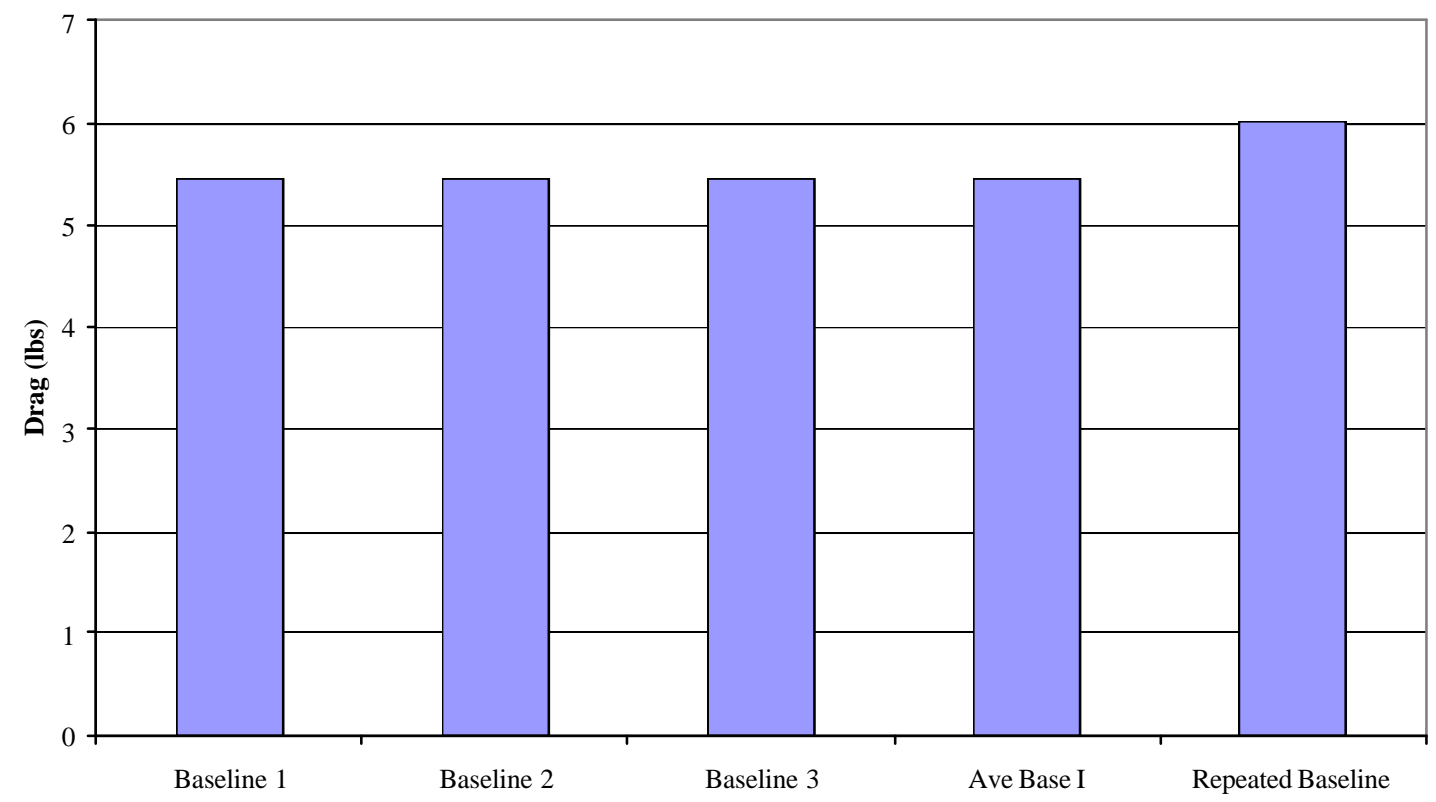

Figure 6.7: Baseline overall drag values.

The repeated Baseline test showed an increase in the overall drag value, increasing from the original Baseline value of $5.45 \mathrm{lbs}$ to $6.01 \mathrm{lbs}$. This increase in value may again be lead to the slight increase in the speed of the wind tunnel during this particular set of testing. This also may be lead to a flaw in the recalibration of the inclined manometer bank before the repeated testing. Even though there is a difference in the load cell values of the initial testing and the repeated testing, the differences in the actual amount of drag being reduced, in pounds, remains the same.

\subsection{Leading Edge Testing}

The leading edge testing was conducted by increasing the pressure supplied to leading edge blowing slots. The examined pressures ranged from 5 psi to $25 \mathrm{psi}$, changing in increments of 5 psi from the previous test. During each set of tests, the 
surface and wake pressures were monitored and recorded, as well as the load cell data and tunnel temperature.

\subsubsection{Surface Pressure Data}

The surface pressure data taken from the V-22 airfoil during Baseline testing was comparable to that taken during previous hover testing performed by NASA. The upper surface is shown to have greater values of $C_{p}$ compared to the lower surface due to the impact of the airflow against the upper surface. The lower surface shows negative values of $\mathrm{C}_{\mathrm{p}}$ due to the lower pressures in the wake region caused by flow separation.

During the examination of the pressures along the upper surface, a trend was noticed as the slot pressure is increased from 0 psi to 25 psi (Figure 6.8). As the pressure is increased to $5 \mathrm{psi}$ on the leading edge slot, the surface pressure shows a slight increase from that of the baseline testing. An increase from 5 psi to 10 psi shows the values returning to that of the baseline testing. Once the slot pressure is increased above $15 \mathrm{psi}$, a steady decrease in the surface pressure of the upper surface can be seen. 


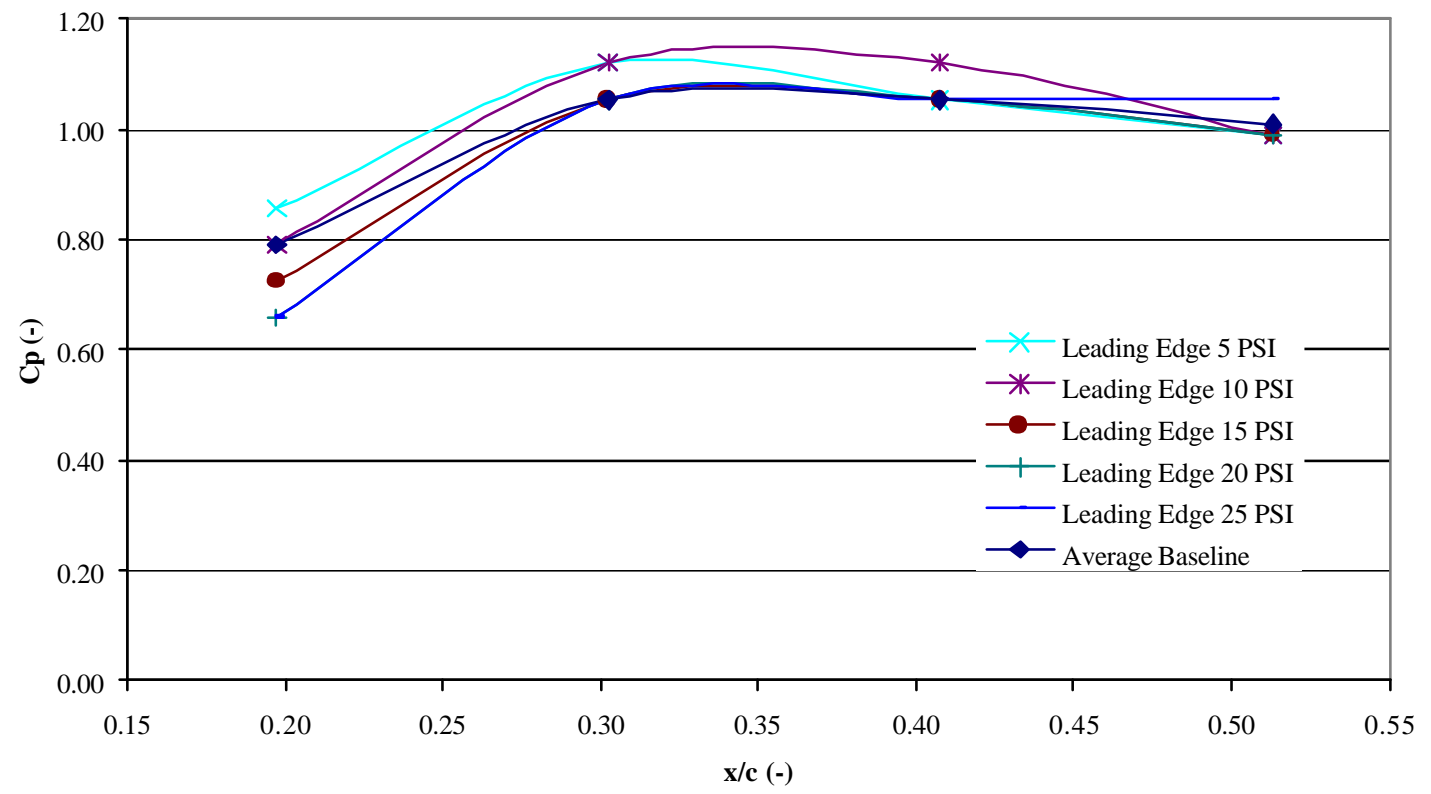

Figure 6.8: Upper surface Cp values for leading edge active circulation control

Table 6.1 provides numerical values for the above Figure 6.8. Due to the overlapping of graphical data, the trends of each test can be shown better using the numerical values.

Table 6.1: Upper surface $\mathrm{Cp}$ values for leading edge active circulation control

\begin{tabular}{|c|c|c|c|c|}
\cline { 2 - 5 } \multicolumn{1}{c|}{} & \multicolumn{4}{c|}{ Upper Surface Cp Values } \\
\hline Test & Tap 11 & Tap 12 & Tap 13 & Tap 14 \\
\hline Ave Baseline & 0.7895 & 1.0526 & 1.0526 & 1.0088 \\
\hline Lead 5 PSI & 0.8553 & 1.1184 & 1.0526 & 0.9868 \\
\hline Lead 10 PSI & 0.7895 & 1.1184 & 1.1184 & 0.9868 \\
\hline Lead 15 PSI & 0.7237 & 1.0526 & 1.0526 & 0.9868 \\
\hline Lead 20 PSI & 0.6579 & 1.0526 & 1.0526 & 0.9868 \\
\hline Lead 25 PSI & 0.0046 & 1.0526 & 1.0526 & 1.0526 \\
\hline
\end{tabular}

Unlike the pressures from the upper surface, the changes in the lower surface pressures are less significant (Figure 6.9 and Table 6.2). As the slot pressure is increased from 0 psi to $20 \mathrm{psi}$, the values of the lower surface pressures show very little or no change in value. At 25 psi, a slight decrease in pressure can be observed primarily in the 
tap closest to the leading edge. This decrease in the delay of separation is caused by the increase in the magnitude of the Coanda Effect.

At 15 psi, a change in the trend displayed by the other pressure values is evident. The final point (Tap 22) flares outward instead of showing an increase in pressure from the previous point. In order to see if this pattern was consistent, two repeatability runs were conducted of this test. As shown in Figure 6.9, the two repeatability runs for the 15 psi test observe the same trends as the testing performed at other tank pressures. The value of Tap 22 from the original testing may have been read improperly from the manometer, creating the flaw in the observed pattern displayed by this particular testing.

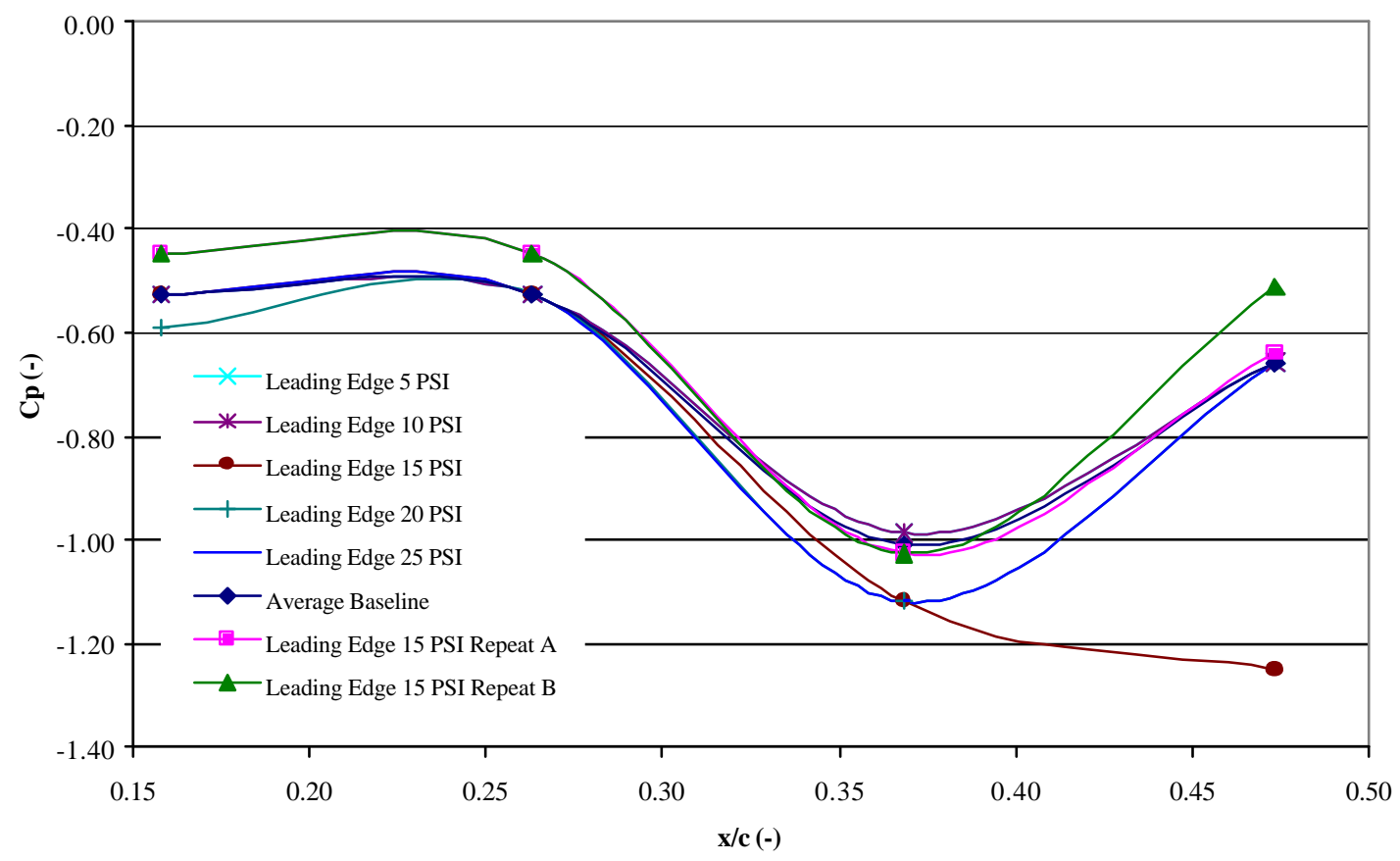

Figure 6.9: Lower surface $\mathrm{Cp}$ values for leading edge active circulation control 
Table 6.2: Lower surface $\mathrm{Cp}$ values for leading edge active circulation control

\begin{tabular}{|c|c|c|c|c|}
\cline { 2 - 5 } \multicolumn{1}{c|}{} & \multicolumn{4}{c|}{ Lower Surface Cp Values } \\
\hline Test & Tap 19 & Tap 20 & Tap 21 & Tap 22 \\
\hline Ave Baseline & -0.5263 & -0.5263 & -1.0088 & -0.6579 \\
\hline Lead 5 PSI & -0.5263 & -0.5263 & -0.9868 & -0.6579 \\
\hline Lead 10 PSI & -0.5263 & -0.5263 & -0.9868 & -0.6579 \\
\hline Lead 15 PSI & -0.5263 & -0.5263 & -1.1184 & -1.2500 \\
\hline Lead 20 PSI & -0.5921 & -0.5263 & -1.1184 & -0.6579 \\
\hline Lead 25 PSI & -0.5263 & -0.5263 & -1.1184 & -0.6579 \\
\hline Lead 15 PSI A & -0.4487 & -0.4487 & -1.0255 & -0.6409 \\
\hline Lead 15 PSI B & -0.4487 & -0.4487 & -1.0255 & -0.5127 \\
\hline
\end{tabular}

As the blowing slot is incorporated at the leading edge, the surface pressure across the trailing edge flap area shows no significant change. Since there is no change, the values of the pressure taps along the flap are not directly affected.

\subsubsection{Wake Region Observation}

During leading edge testing, a significant change in the wake region is observed during the activation of the leading edge circulation control (i.e. blowing slots). In Figure 6.10, a change in the size of the leading edge wake region can be noticed with the increase in slot pressure. By changing the blowing slot pressure, the airflow around the leading edge has further induced the Coanda effect. The higher velocity air is being pulled closer to the surface, moving the point of separation to the underside of the airfoil. At the present time, the exact location of separation is unknown due to an insufficient number of surface pressure taps on the airfoil. 


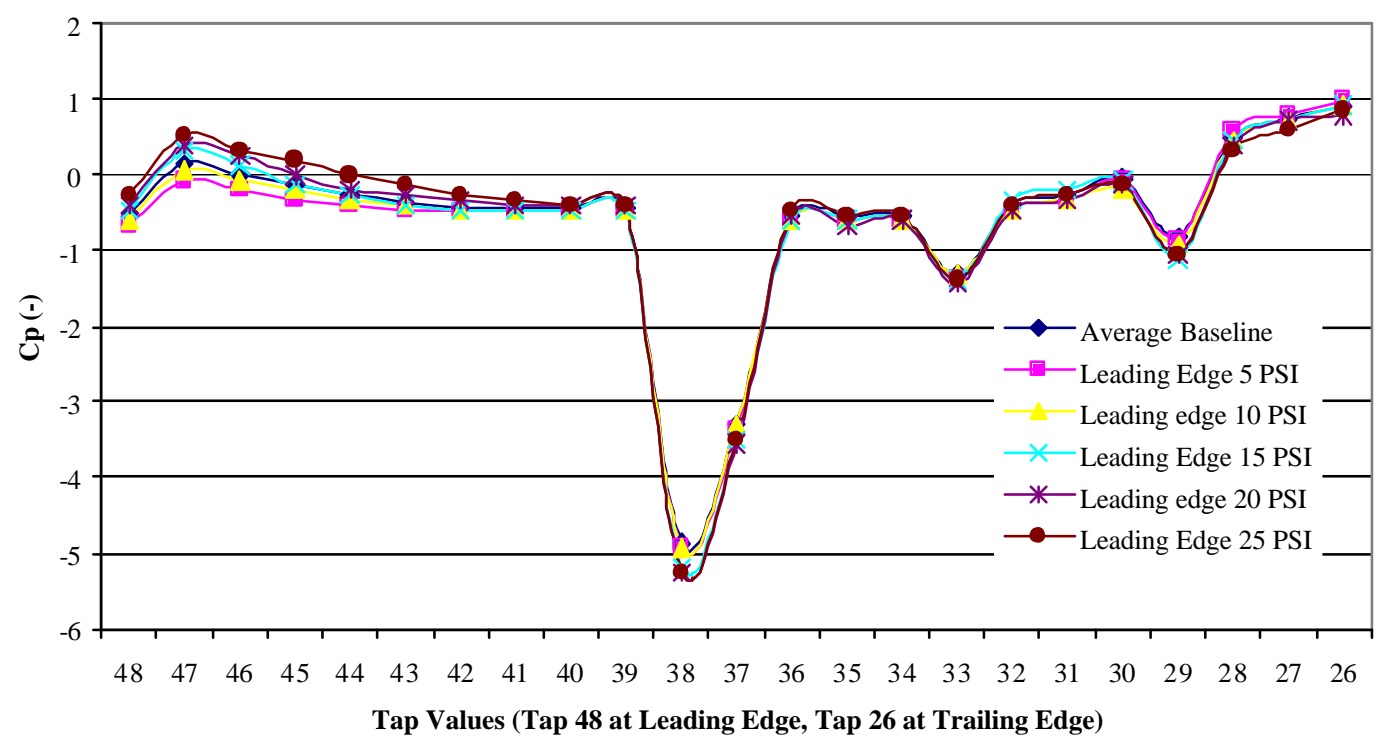

Figure 6.10: Wake region of scaled model during leading edge active circulation control

One main observation of this wake trend can be seen when the air pressure tank is first activated. As the air pressure is increased from 0 to $5 \mathrm{psi}$ in the slot, the size of the wake region actually increases. This may in turn be caused by the inability for 5 psi to have any direct effect on the change in the wake region. A greater pressure is needed to make a positive change in the size of the effective area. As the slot pressure increases from 5 to $10 \mathrm{psi}$, the wake region begins to decrease in size, but still does not recover the size of the original baseline values. Once the slot pressure is set at $15 \mathrm{psi}$, the size of the region then falls below that of the baseline. The 20 psi and 25 psi tests show a continuation of this trend as the size of the region continues to decrease as the higher velocity airflow is pulled into the wake region. 


\subsubsection{Load Cell Data}

The load cell data from this particular series of tests is in agreement with the information provided by the previous wake region observation. A similar trend to that in previous section can be shown in Figure 6.11, as the overall load of the system increased as the compressed air tank pressure was increased to 5 psi. As the pressure was steadily increased, the overall download force begins to decline.

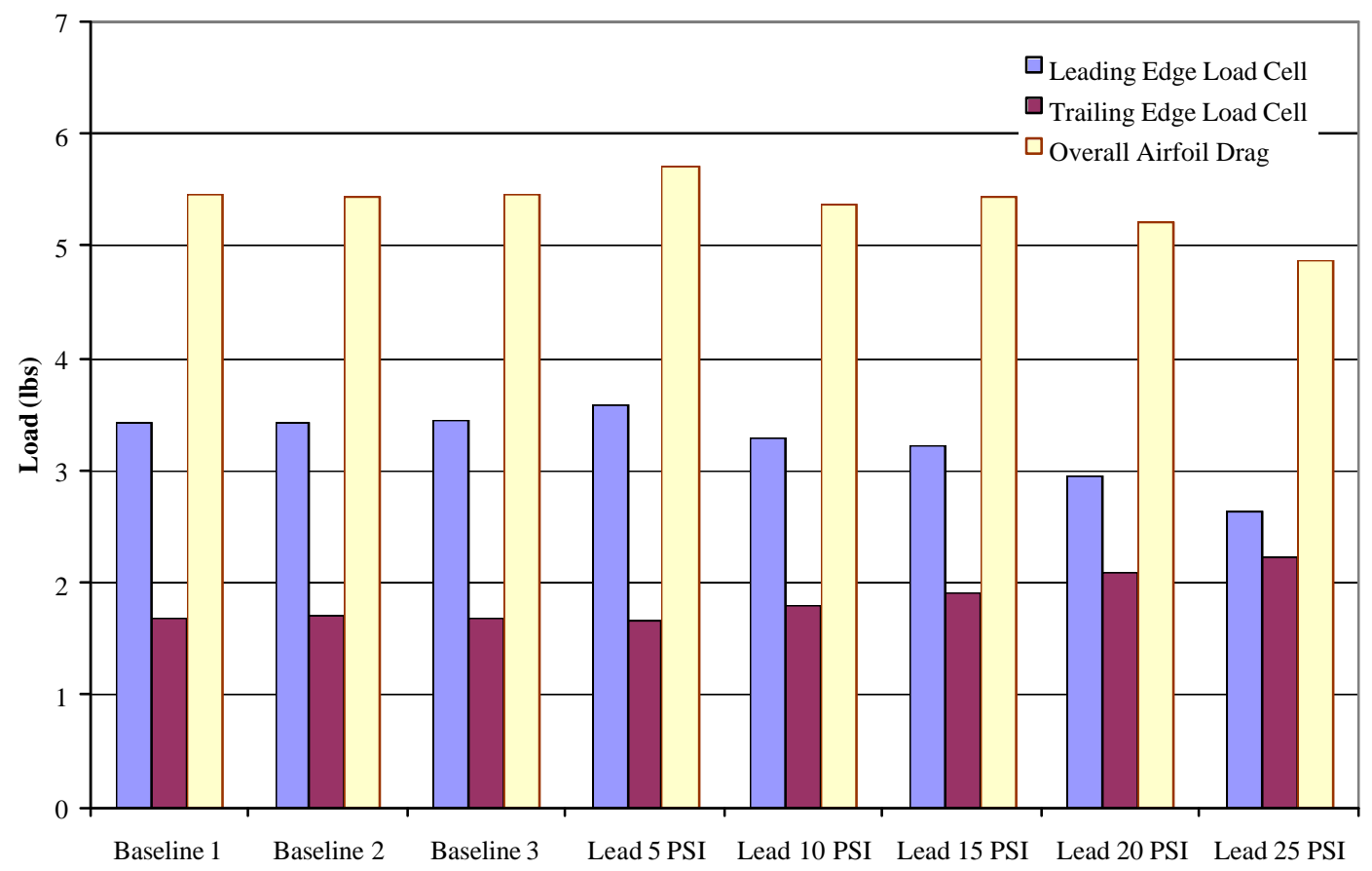

Figure 6.11: Drag values for leading edge active circulation control

Before leading edge circulation control is activated, the overall drag of the airfoil is approximately $5.447 \mathrm{lbs}$. As the slot pressure is increased above $15 \mathrm{psi}$, a decrease in the airfoil drag takes place. At a maximum testing slot pressure of $25 \mathrm{psi}$, the overall drag reaches a minimum of $4.874 \mathrm{lbs}$, giving a $10.5 \%$ decrease in the overall drag. 
One observation that can be noticed is the trend the trailing edge load cell presents as the leading edge blowing slot is activated. As the load begins to decrease on the leading edge load cell, the trailing edge load cell begins to proportionally increase due to torque produced on the system. Because the airfoil is mounted around a central pole in the wind tunnel test section, any positive change in one edge will contribute to a negative effect on the opposite edge. The difference in this change shows the amount of torque produced on the system.

Even though the trailing edge load cell produces an opposite load reaction to that of the leading edge, the overall drag on the airfoil shows a decline and follows the trend of the load cell corresponding the activated blowing slot.

\subsection{Trailing Edge Testing}

The trailing edge testing was conducted by increasing the pressure supplied to trailing edge blowing slots, while maintaining the leading edge slot at 0 psi. The examined pressures ranged from 5 psi to $25 \mathrm{psi}$, changing in increments of $5 \mathrm{psi}$ from the previous test. During each set of tests, the surface and wake pressures were monitored, as well as the load cell data and tunnel temperature.

\subsubsection{Surface Pressure Data}

Unlike the leading edge testing, a different trend developed along the upper and lower surfaces during the trailing edge active circulation control testing. For the upper surface, the pressure along parts of the surface began to slowly decline as the slot pressure increased from 0 psi to 15 psi. As shown in Figure 6.12 along with Table 6.3, 
once the slot pressure reached above $15 \mathrm{psi}$, the pressures values along the surface steadily conformed back to those similar to the original baseline testing.

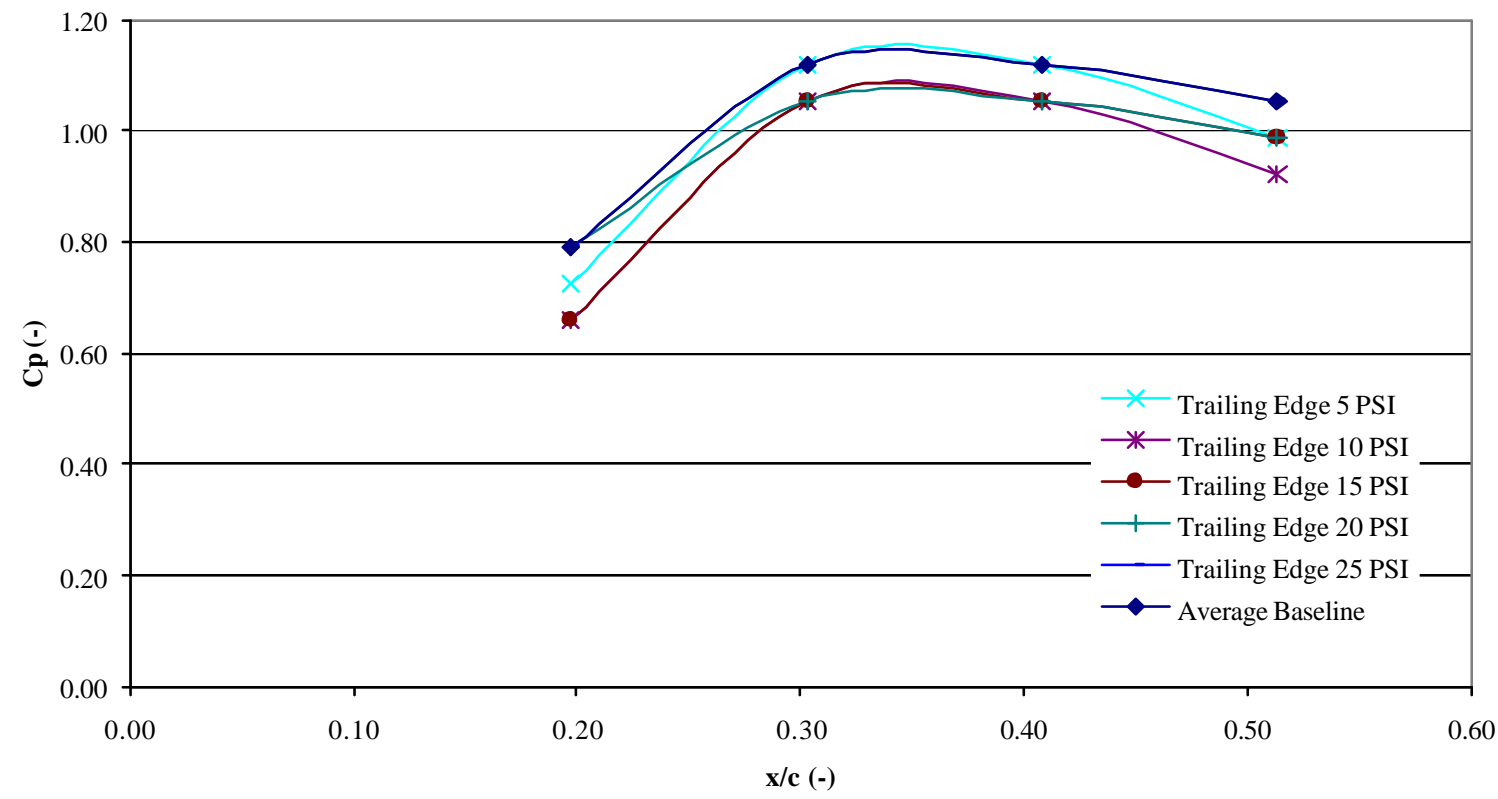

Figure 6.12: Upper surface Cp values for trailing edge active circulation control

Table 6.3: Upper surface $\mathrm{Cp}$ values for trailing edge active circulation control

\begin{tabular}{|c|c|c|c|c|}
\cline { 2 - 5 } \multicolumn{1}{c|}{} & \multicolumn{4}{c|}{ Upper Surface Cp Values } \\
\hline Test & Tap 11 & Tap 12 & Tap 13 & Tap 14 \\
\hline Ave Baseline & 0.7895 & 1.0526 & 1.0526 & 1.0088 \\
\hline Trail 5 PSI & 0.7237 & 1.1184 & 1.1184 & 0.9868 \\
\hline Trail 10 PSI & 0.6579 & 1.0526 & 1.0526 & 0.9211 \\
\hline Trail 15 PSI & 0.6579 & 1.0526 & 1.0526 & 0.9868 \\
\hline Trail 20 PSI & 0.7895 & 1.0526 & 1.0526 & 0.9868 \\
\hline Trail 25 PSI & 0.7895 & 1.1184 & 1.1184 & 1.0526 \\
\hline
\end{tabular}

Observing a similar pattern of change, the lower surface pressure values show a slight change in separation around the leading edge region (Figure 6.13 and Table 6.4). As the pressure in the trailing edge slot was adjusted from 0 to $5 \mathrm{psi}$, the $\mathrm{C}_{\mathrm{p}}$ values along the surface showed very little or no change. Once the slot pressure reached 10 psi and 15 
psi, the surface pressures of the entire lower surface pressure decreased, showing a slight increase in the velocity of flow around the lower surface area. Similar to the trend observed in the upper surface, the surface pressure values of the lower surface begin to increase at a slot pressure of $20 \mathrm{psi}$ and then conform to the original baseline values once the slot pressure reaches its maximum testing range of 25 psi.

At 20 psi, Tap 19 (point 1) shows a trend dissimilar to those shown from the previous tests performed. While the first two points of each test are shown to be of the same value, the 20 psi testing shows this point as being relatively higher than the second point (Tap 20). In order to check to see if this trend consistently appears at this slot pressure value, a repeat test was conducted at 20 psi. As shown in Figure 6.13, the repeated test performed observed a similar trend to those shown at other slot pressures. Again, the flaw in the original point may have been an error in the reading of the value from the manometer bank. 


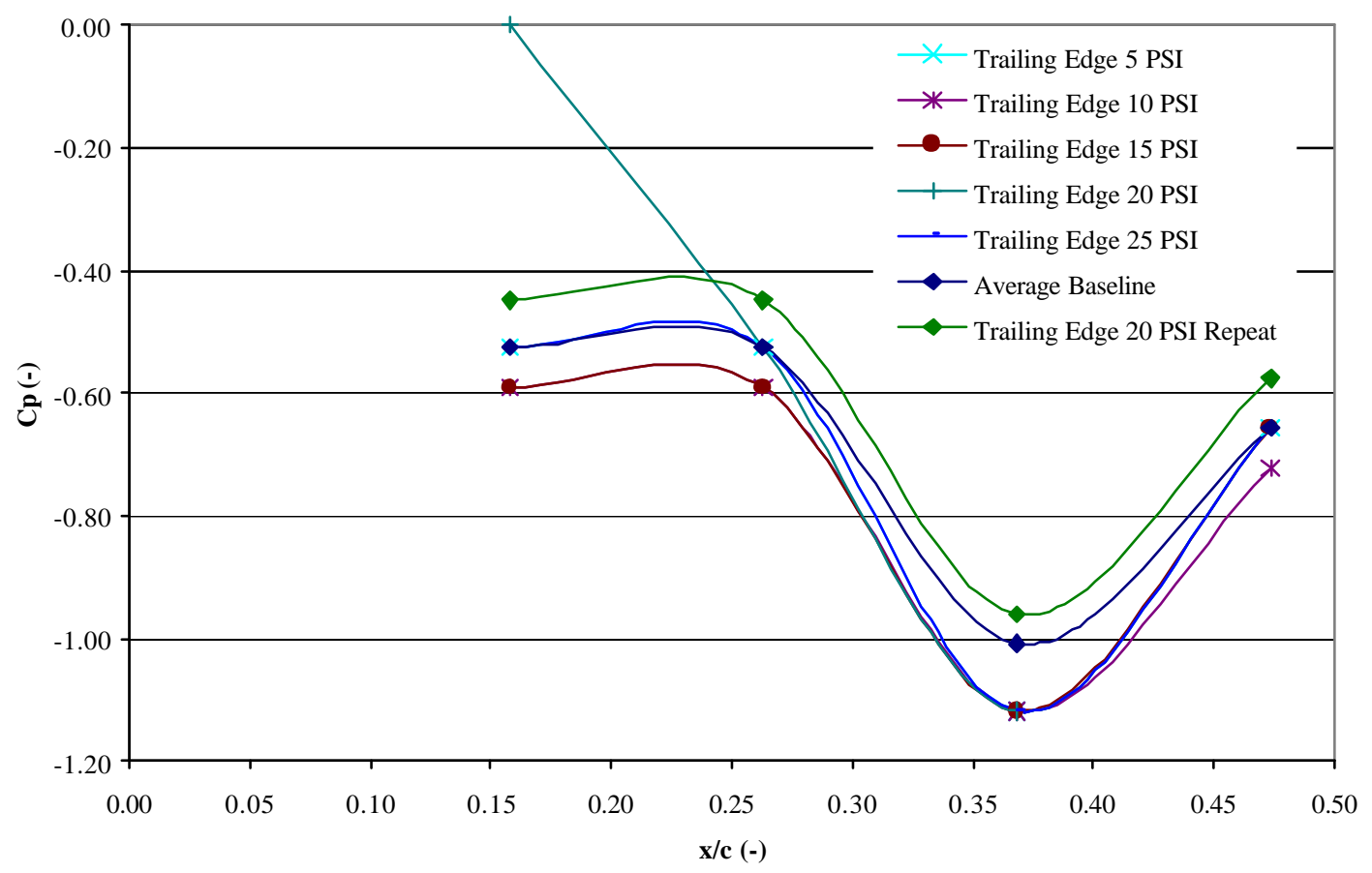

Figure 6.13: Lower surface $\mathrm{Cp}$ values for trailing edge active circulation control

Table 6.4: Lower surface $\mathrm{Cp}$ values for trailing edge active circulation control

\begin{tabular}{|c|c|c|c|c|}
\cline { 2 - 5 } \multicolumn{1}{c|}{} & \multicolumn{4}{c|}{ Lower Surface Cp Values } \\
\hline Test & Tap 19 & Tap 20 & Tap 21 & Tap 22 \\
\hline Ave Baseline & -0.5263 & -0.5263 & -1.0088 & -0.6579 \\
\hline Trail 5 PSI & -0.5263 & -0.5263 & -1.1184 & -0.6579 \\
\hline Trail 10 PSI & -0.5921 & -0.5921 & -1.1184 & -0.7237 \\
\hline Trail 15 PSI & -0.5921 & -0.5921 & -1.1184 & -0.6579 \\
\hline Trail 20 PSI & 0.0000 & -0.5263 & -1.1184 & -0.6579 \\
\hline Trail 25 PSI & -0.5263 & -0.5263 & -1.1184 & -0.6579 \\
\hline Trail 20 PSI B & -0.4487 & -0.4487 & -0.9614 & -0.5768 \\
\hline
\end{tabular}

Unlike the flap data in the leading edge testing, the trailing edge testing shows a significant change in separation of airflow due to active circulation control taking place along this area. The upper surface of the flap lies along the lip of the trailing edge blowing slot and the flow in this region is directly altered by the change in slot pressure. From Figure 6.14, a noticeable change takes place during each increment of slot pressure. 


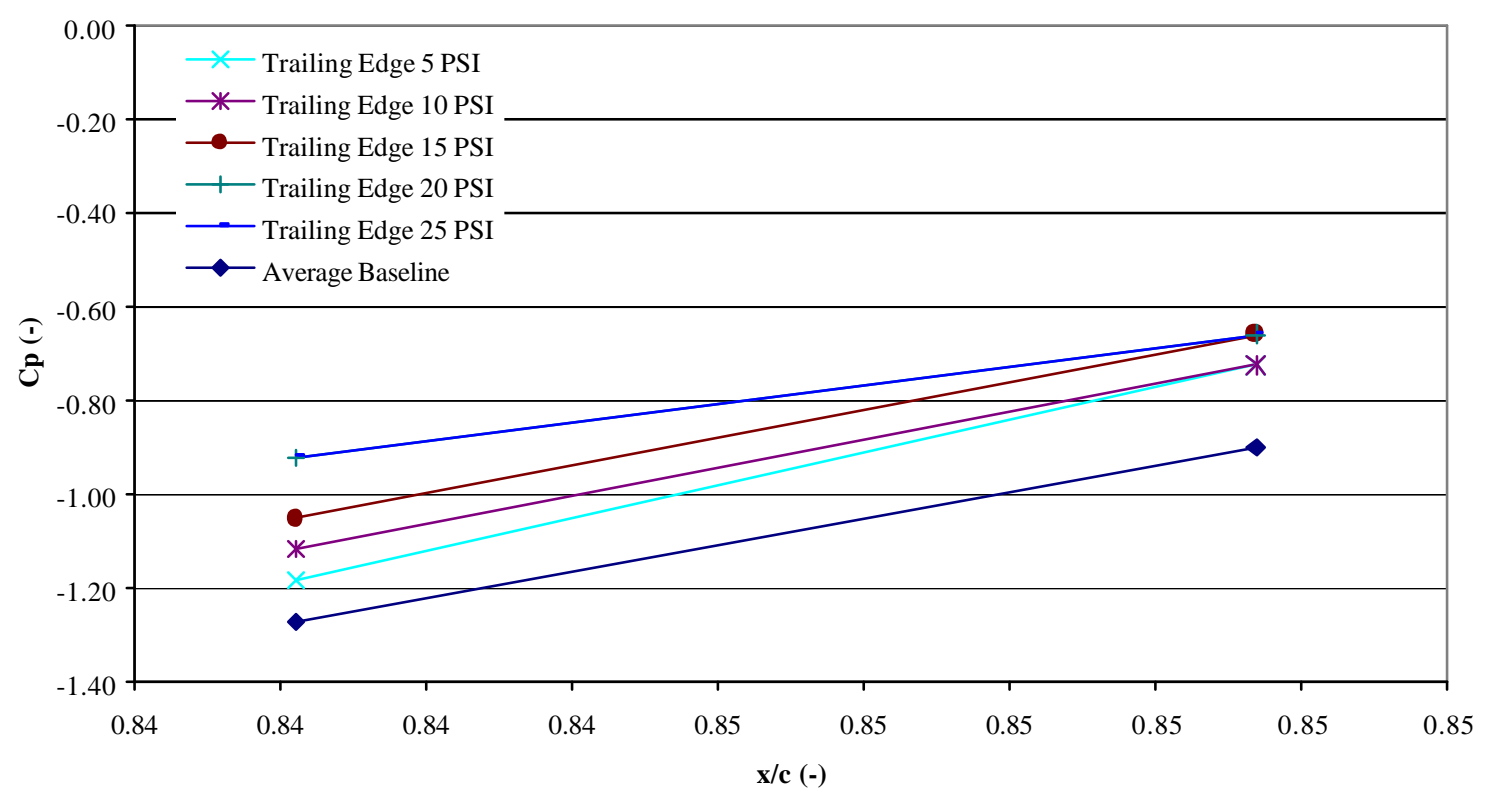

Figure 6.14: Flap upper surface $\mathrm{Cp}$ values for trailing edge active circulation control

As the slot pressure increases from 0 psi to 25 psi, both pressure taps monitored along this area are directly affected by the change in airflow. The pressure along this surface begins to increase as the slot pressure is increased, revealing that the air is possibly separating earlier along the flap than expected. Another possibility is that the trailing edge slot is not positioned at the optimal position for active circulation control, thus causing the airflow to blow directly into the pressure taps along the upper flap.

The data from the lower flap surface is inconclusive and not of importance to the change caused by the trailing edge active circulation control. This statement is due to the lack of airflow along the underside of the flap area to cause any direct change along that surface. 


\subsubsection{Wake Region Observation}

During trailing edge testing, a significant change in the wake region is observed during the activation of the leading edge circulation control. In Figure 6.15, a change in the size of the trailing edge wake region can be seen with the increase in slot pressure. Unlike the leading edge testing, there isn't an initial increase in the size of this region when the slot pressure is initially increased from 0 to 5 psi. At 10 psi, there is a offset in the trend observed during the testing around tap 32. The cause of this trend is unknown, but may be lead to incorrect reading of the manometer bank during the collection of the data. A repeat of this showed the offset in trend to be incorrect, as the new data followed a similar pattern as those observed by the other tests performed previously.

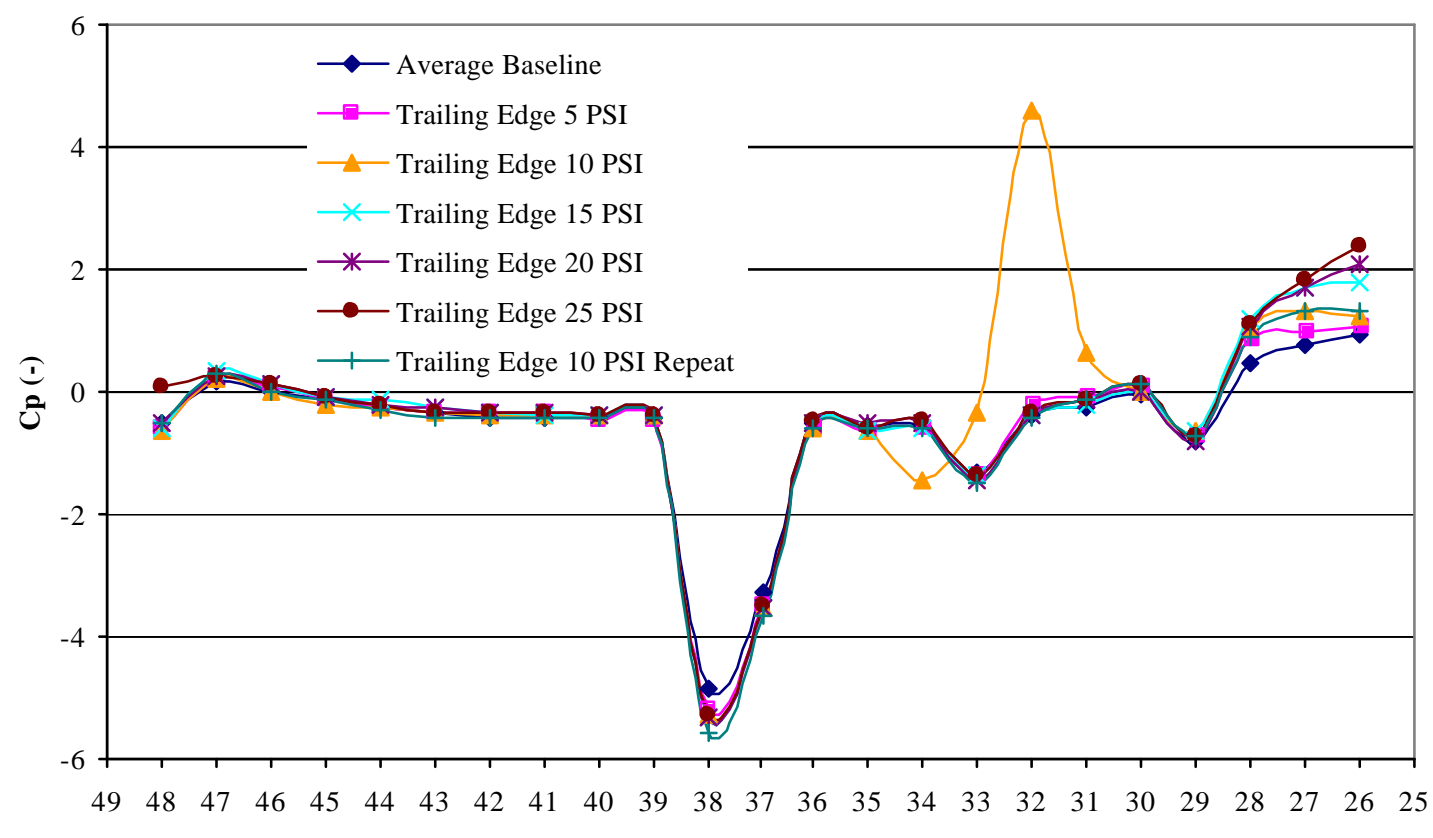

Tap Values (Tap 48 at Leading Edge, Tap 26 at Trailing Edge)

Figure 6.15: Wake region of scaled model during trailing edge active circulation control

While the pressure in the trailing edge blowing slot is increased from 0 psi to 25

psi, a steady decrease in the trailing edge wake region is evident from Figure 6.15 (see 
Taps 26 - 28). With this increase in slot pressure, the higher velocity air moving across the flap area heightens the magnitude of the Coanda Effect.

The impact of circulation control on this region is only shown having a direct impact on the first three static ports of the wake rake. These three wake rake ports are the only ports affected during this phase of testing. The lowered flap acts like a barrier to the underside of the airfoil, restraining the movement of the circulated air to the lower surface. This leads to the lack of pressure change along the lower surface of the airfoil when compared to the initial baseline testing.

\subsubsection{Load Cell Data}

Similar to the trend of wake region reduction examined in the previous section (Section 6.3.2), the load cell data for the trailing edge active circulation control reveals a steady reduction of the overall drag acting on the airfoil. Shown in Figure 6.16, the drag along the trailing edge of the airfoil and overall drag of the airfoil steadily decrease as the slot pressure is increased from 0 to 25 psi. Before circulation control is activated on the trailing edge, the overall airfoil drag is approximately $5.447 \mathrm{lbs}$. After a consistent decline in overall drag, the maximum slot pressure of 25 psi yielded an overall airfoil drag of $3.203 \mathrm{lbs}$, or a $41.2 \%$ reduction in overall airfoil drag.

As noticed in the leading edge testing, the trailing edge testing data shows a similar reaction occurring in the opposite edge load cell, or leading edge cell for this particular test. Due to the torque produced around the central mounting pipe, the leading edge cell provided an opposite reaction to the trailing edge cell by actually showing an increase in load occurring in that region. 


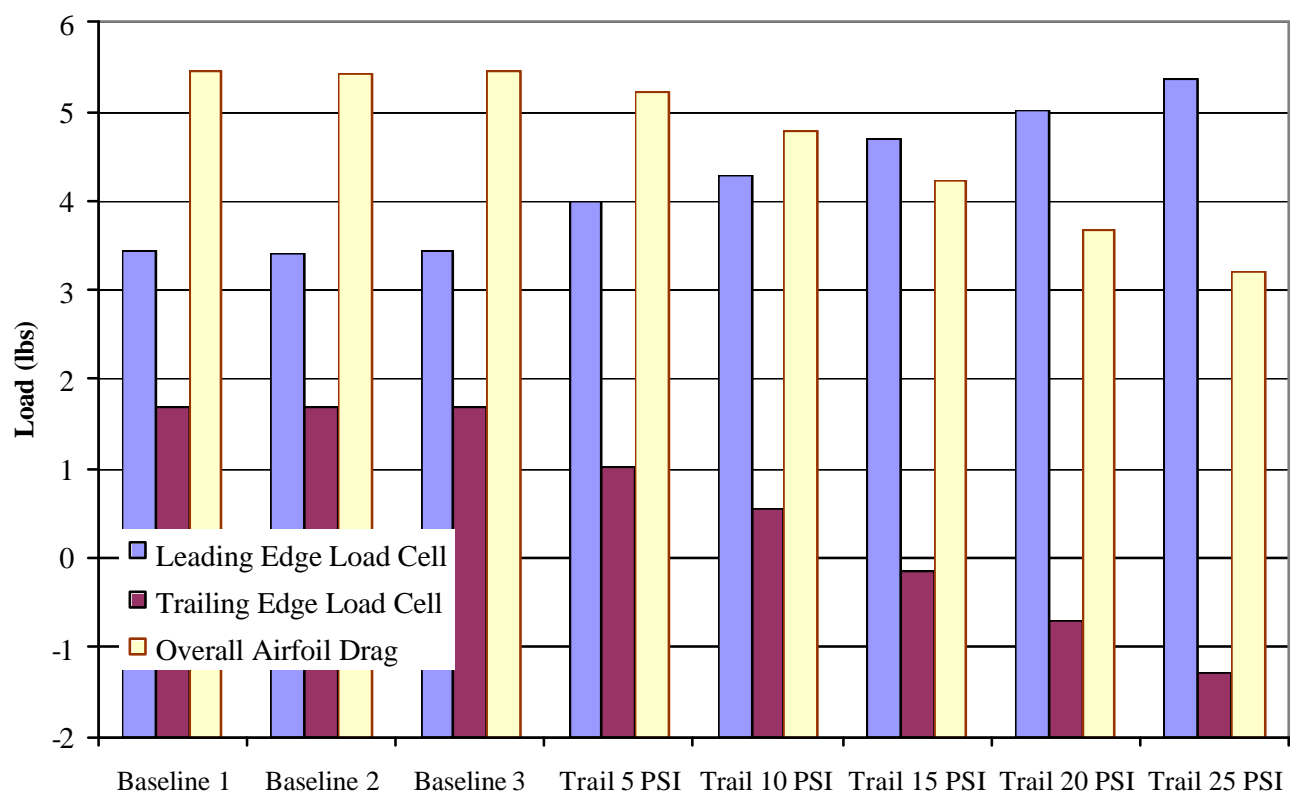

Figure 6.16: Drag values for trailing edge active circulation control

\subsection{Leading and Trailing Edge Simultaneous Testing}

The leading and trailing edge simultaneous testing was conducted by increasing the pressure supplied to leading and trailing edge blowing slots simultaneously. In this phase of testing, only one particular case was examined due to time constraints with the testing facility. A test was conducted with the leading edge and trailing edge slots set at the maximum testing pressure of 25 psi each. During each set of tests, the surface and wake pressures were monitored, as well as the load cell data and tunnel temperature.

\subsubsection{Surface Pressure Data}

Due to the lack of tests performed in this area, the leading edge and trailing edge 25 psi simultaneous test were examined and compared to that of the average values of the original baseline testing. Examining the results shown in Figure 6.17, the surface pressures closest to the leading and trailing edges have decreased. 


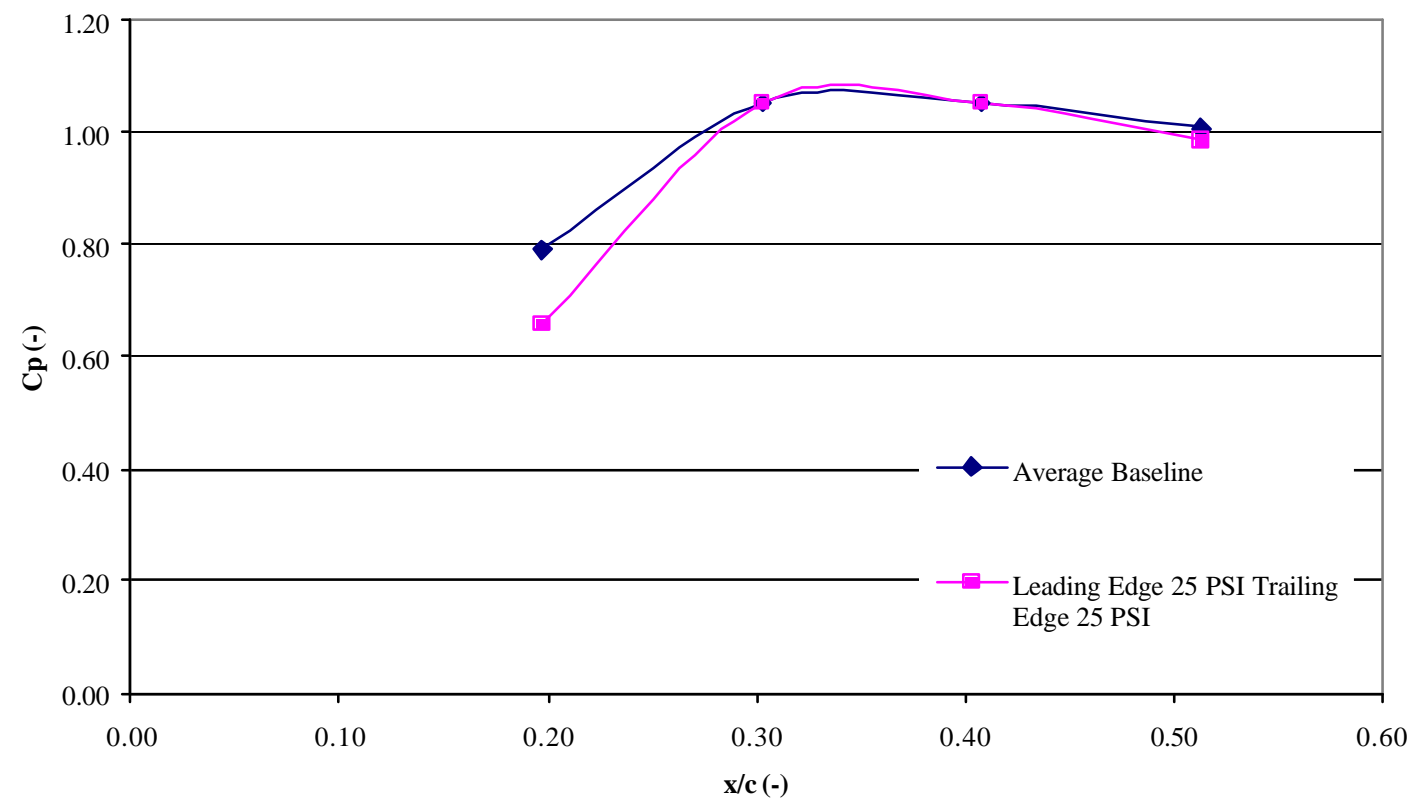

Figure 6.17: Upper surface Cp values for leading and trailing edge simultaneous active circulation control

As the airflow is increased from each of the blowing slots, the effects of the blowing can also be noticed along the lower surface of the airfoil. As the leading edge blowing is increased, similar results are obtained to those from the isolated leading edge circulation control at $25 \mathrm{psi}$. As the airflow is moving throughout the underside of the airfoil, the pressure readings from all monitored pressure taps decreased in value with the simultaneous blowing (Figure 6.18). Due to an insufficient number of taps along this surface, an exact point of separation cannot be determined at this time. 


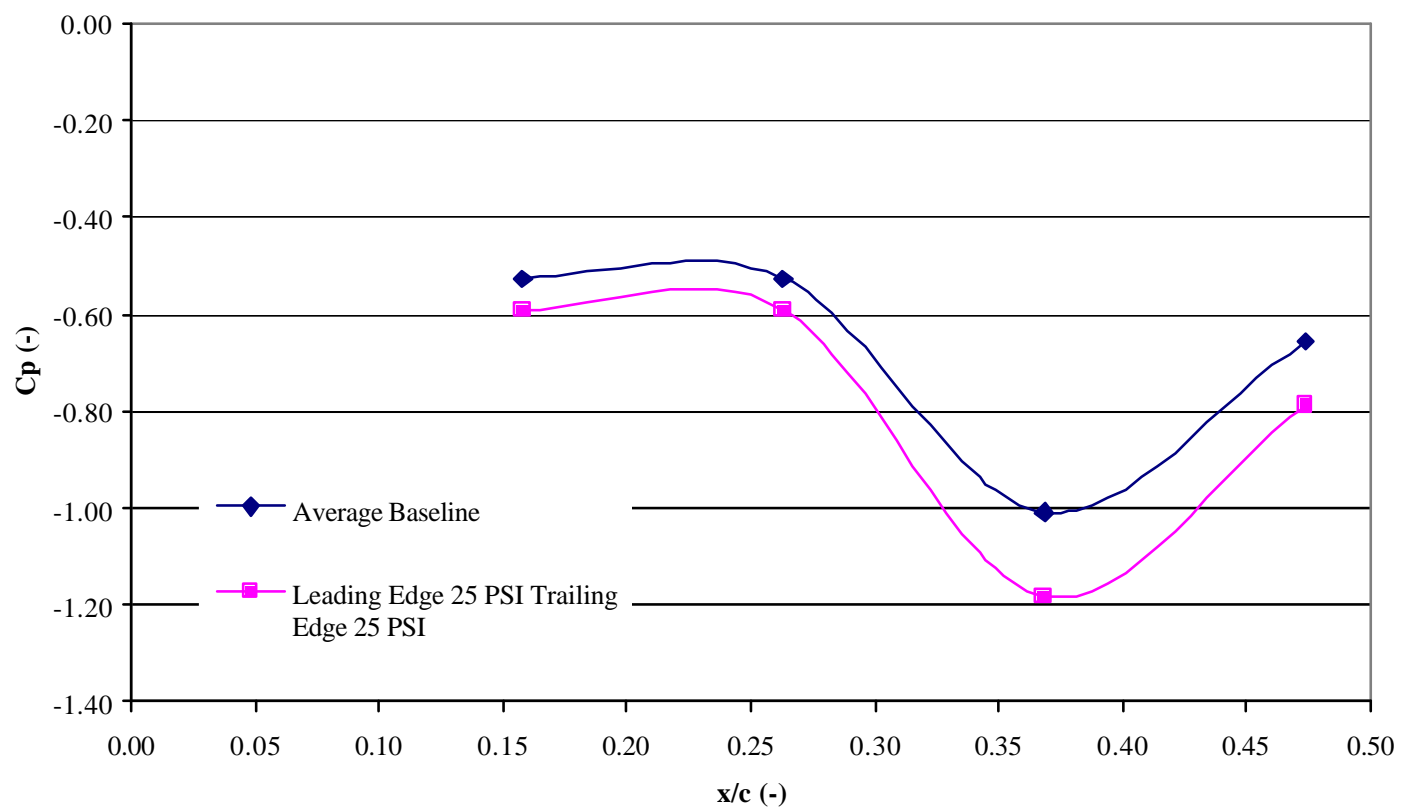

Figure 6.18: Lower surface $\mathrm{Cp}$ values for leading and trailing edge simultaneous active circulation control

The flap pressure values resemble the values and trend demonstrated by the trailing edge active circulation control in isolation. As the pressure from the trailing edge slot is increased from 0 psi to $25 \mathrm{psi}$, the surface pressure across the upper flap surface increases as well (Figure 6.19). The lower flap surface pressures show some air movement, but again are not of any significance to the results due to their position on the underside of the flap. The decrease in value along the lower flap surface may be due to the movement of airflow around the opposite surface of the flap, taking away from any airflow that may have seeped underneath the slot area during baseline testing. 


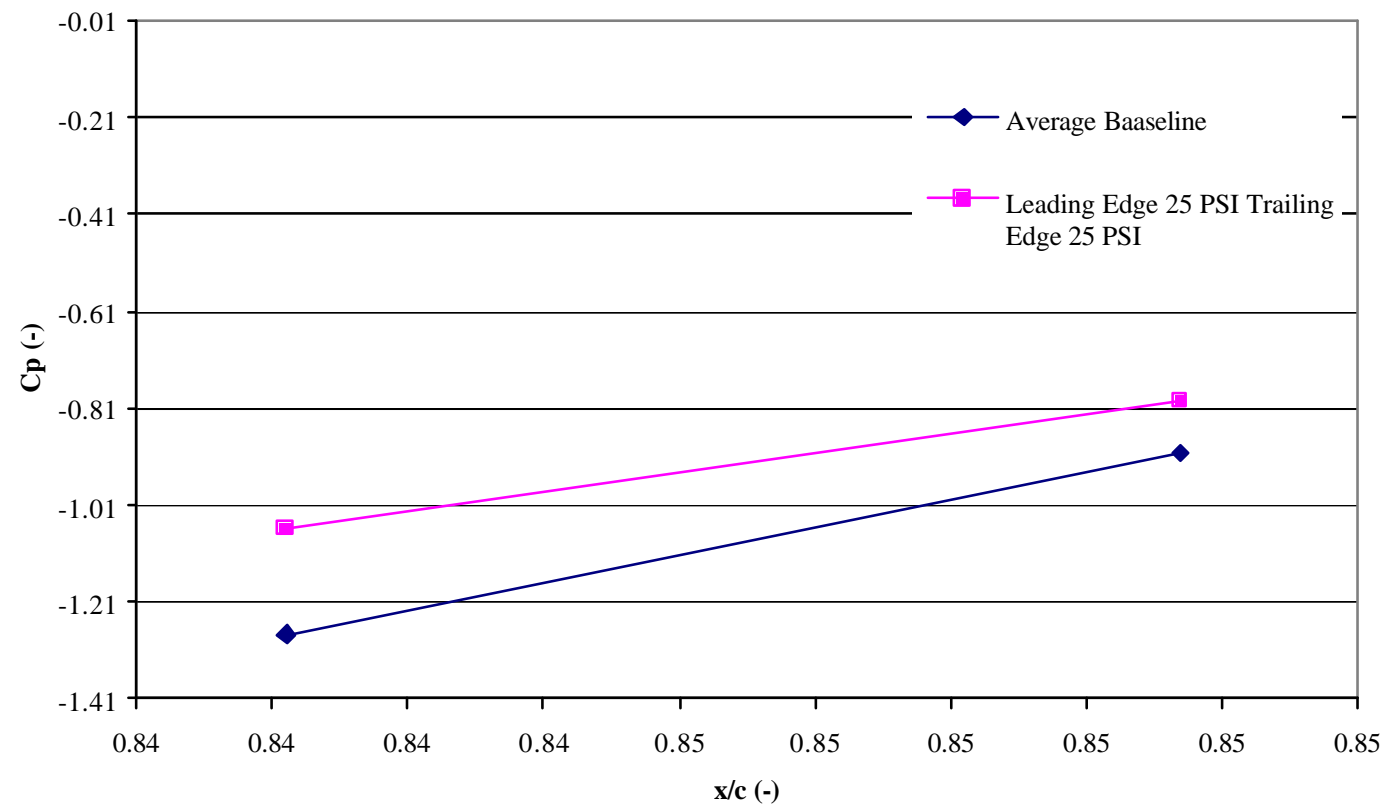

Figure 6.19: Flap upper surface $\mathrm{Cp}$ values for leading and trailing edge simultaneous active circulation control

\subsubsection{Wake Region Observation}

During the wake region observation of this particular test, the higher velocity air moving into the wake region can be noticed as the slot pressure is increased in each slot simultaneously from 0 to $25 \mathrm{psi}$. As shown in Figure 6.20, the magnitude of the Coanda Effect is amplified around both leading and trailing edges. Similar to the individual blowing slot tests described previously, the simultaneous blowing combines the trends each individual blowing slot test demonstrated at a slot pressure of 25 psi. With the circulation control activated along the leading and trailing edges, the wake area shows a decrease in size compared to the wake region of the baseline. 


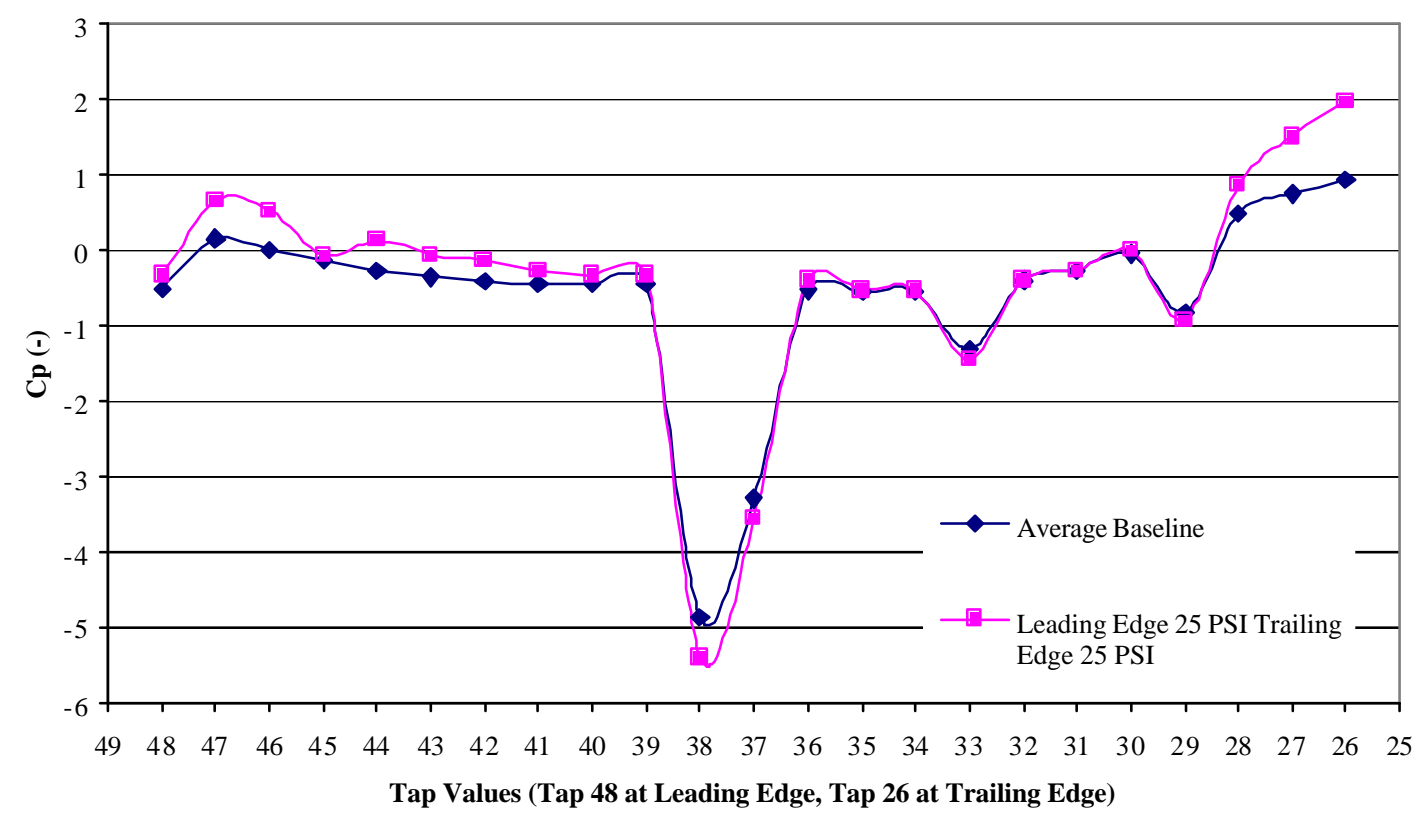

Figure 6.20: Wake region of scaled model during leading and trailing edge simultaneous active circulation control

\subsubsection{Load Cell Data}

With both blowing slots active simultaneously and each operating at the same pressure, a unique result is shown in Figure 6.21. The trend in the previous series of testing has shown that the load cell corresponding to the edge with active circulation control has a decrease in the load value. The overall airfoil drag in that particular test also has followed the load reduction patterns of that cell.

With the leading and trailing edge blowing slots simultaneously active, the trailing edge load cell shows a decrease in load. Unlike previous testing with the leading edge slot activated, the leading edge load cell shows an increase in the load. The trend for the overall airfoil drag follows the trend of the load cell that reduced in load value (Figure 6.21). In this particular case, the overall drag mirrors the pattern of the trailing 
edge load cell, decreasing from a baseline value of $5.447 \mathrm{lbs}$ to $2.581 \mathrm{lbs}$ with circulation control active, yielding a $52.6 \%$ overall drag reduction.

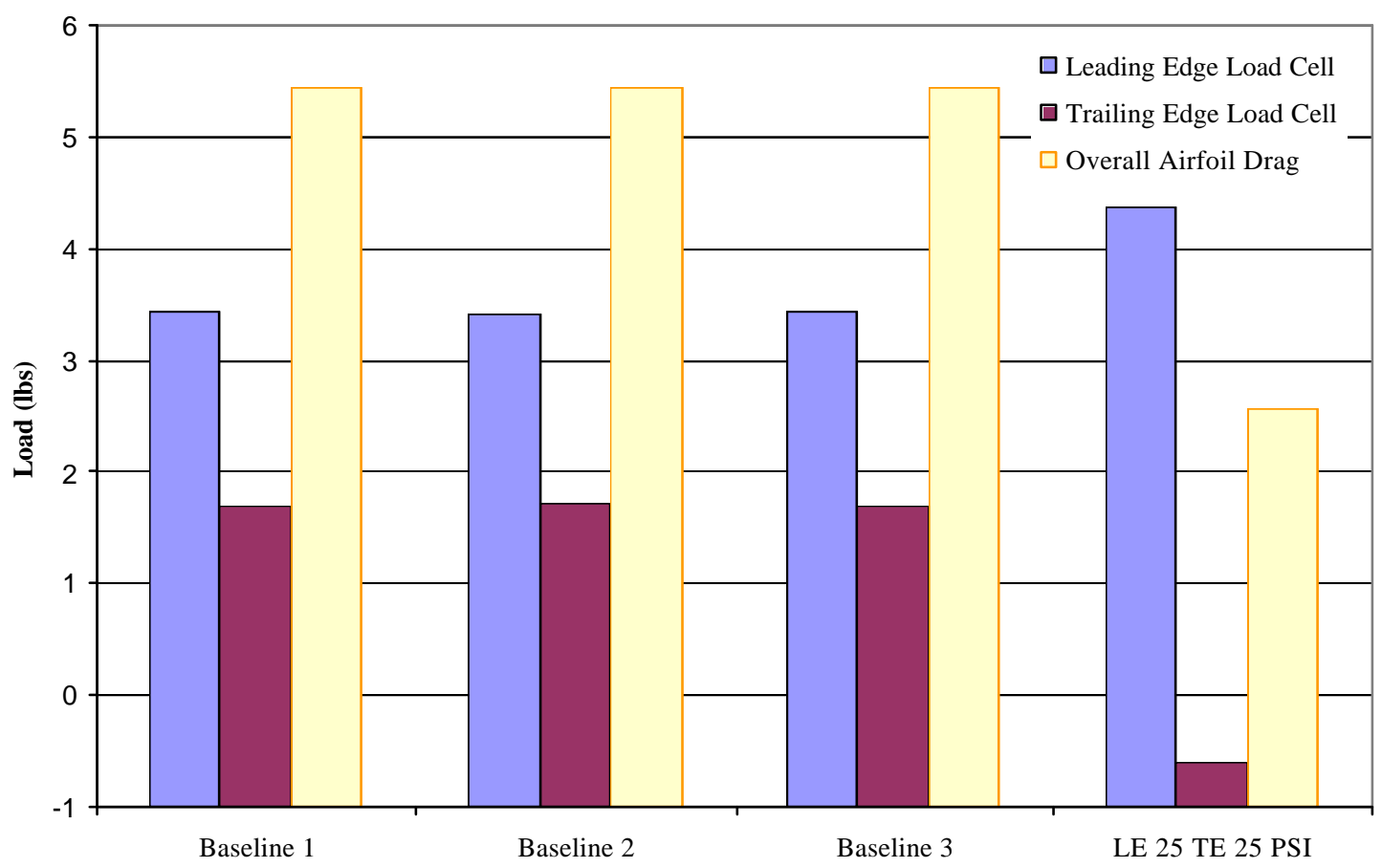

Figure 6.21: Drag values for leading and trailing edge simultaneous active circulation control

\subsection{Power Consumption}

Given the maximum download reduction occurred during simultaneous active blowing, the power used to supply the airflow was calculated for this blowing configuration. The amount of power supplied was calculated for the WVU scaled airfoil and the full-scaled V-22 airfoil and wingspan. Using the methods discussed in Section 4.5, approximately 32 horsepower is required to operate the blowing slots during this configuration. The power required to operate this configuration on a full-scaled V-22 Osprey wing over the entire wingspan is approximately 1956 horsepower. 


\subsection{Measurement Error}

Using the method described in Section 4.6, the error for the drag and pressure measurements were calculated. The drag readings obtained in this testing are estimated to have an accuracy of $\pm 0.0014 \mathrm{lb}$. The $\mathrm{C}_{P}$ values obtained observe a calculated accuracy of \pm 0.1853. Tables A.3 and A.4 in Appendix A show the trends of error throughout each particular test performed. 


\section{Conclusions and Recommendations}

The application of active circulation control provides a new possibility in the reduction of the wake region of the V-22 Osprey. The purpose of this section is to discuss the results obtained from the three sets of tests performed on the WVU scaled V22 model with active circulation control. Recommendations for model upgrades and future testing are also discussed at the end of this section.

\subsection{Conclusions}

The purpose of this research was to observe the effectiveness of active circulation control in the reduction of the wake region when applied to the V-22 aircraft. From the results of all three sets of tests performed on this model, active circulation control demonstrates the ability to reduce the overall drag force produced on the airfoil.

From the results gathered from Leading Edge Active Circulation Control testing, slot blowing in this area shows benefits of reducing the overall drag and the wake region at slot pressures higher than 15 psi. The surface data is unclear in showing the amount of change, but the wake region observation and load cell data show congruently this conclusion. At $15 \mathrm{psi}$, the wake region begins to show a decrease in the size of the wake region around the leading edge area due to the increase in higher velocity airflow being pulled into the wake region (Figure 6.3). A slot pressure of 25 psi (the maximum testing pressure) showed the greatest decrease in this size of the wake.

As the wake region is decreasing at these pressures, the load cell data shows a parallel trend. Once the slot pressure is increased above $15 \mathrm{psi}$, the overall airfoil drag 
begins to decrease from the initial baseline average of $5.447 \mathrm{lbs}$ to a minimum drag value of $4.874 \mathrm{lbs}$ at a slot pressure of $25 \mathrm{psi}$ (Figure 6.4).

Unlike the trends displayed in the leading edge testing, Trailing Edge Active Circulation Control testing showed benefits of wake and drag reduction as soon as the slot pressure was increased above 0 psi. Referring back to Figure 6.8 in the Results Section, the size of the wake around the trailing edge from the wake region observation shows a steady decrease as the slot pressure is increased from 0 psi to 25 psi. As with the leading edge testing, the maximum slot pressure of 25 psi shows the greatest amount of decrease in the wake region.

Congruent to the wake region observation, the overall airfoil drag from the trailing edge testing decreased as the slot pressure was raised above 0 psi. With the slot pressure increasing, the airfoil drag shows a steady decline (Figure 6.9). Starting again at a baseline drag value of $5.447 \mathrm{lbs}$, the overall airfoil drag steadily declines to a minimum drag value of $3.203 \mathrm{lbs}$ at a slot pressure of $25 \mathrm{psi}$.

Due to problems with the wind tunnel testing facility, one set of congruent slot pressures was tested during the Leading and Trailing Edge Simultaneous Active Circulation Control. Like the trends shown in the individual blowing slot testing, the leading and trailing edge wake region observation shows a decrease in both areas where active circulation control is present. As the slot pressures are increased from 0 psi directly to $25 \mathrm{psi}$, the wake region around the leading and trailing edges shows a substantial decrease in the size of these areas (Figure 6.13). The decreases are not as 
heightened as those shown by the individual blowing slot activation at $25 \mathrm{psi}$, but a noticeable change is created by the circulation control.

The load cell data shows a congruent trend as the overall airfoil drag is decreased as the blowing slots are activated simultaneously. As the leading and trailing edge slot pressures are simultaneously increased directly to $25 \mathrm{psi}$, the overall airfoil drag shows a decrease from $5.447 \mathrm{lb}$ to $2.581 \mathrm{lbs}$.

Collectively observing the results of all testing configurations, leading and trailing edge simultaneous active circulation control produced the best overall results. Simultaneous slot blowing heightens the benefits of individual slot blowing by producing a greater overall reduction in the overall drag dissipated on the airfoil. With two blowing slots active, the wake around both the leading and trailing edges benefit from a decrease in this region as both slots work together to train the airflow to produce the greatest overall drag and wake reduction. At this point, the best configuration of simultaneous active circulation control slot pressure values is unknown due to time and facility constraints.

\subsection{Recommendations}

As future testing proceeds from this research, improvements to the model and test setup need to be reevaluated in order to improve the quality of testing. The design of the model should be restructured first. The inability to monitor the surface pressures around prominent areas, such as the leading and trailing edges, appropriately hinders the ability to discover the actual point of separation of airflow during active circulation control. 
The blockage the model creates within the low speed test section of the WVU Low Speed Closed Return Subsonic Wind Tunnel is another factor to be looked upon. Without the mounting piping and hosing from the air supply, the overall blockage of the model is around $10 \%$. Once the piping and hosing is taken into account in the blockage calculations, the overall blockage is then increased to $12.5 \%$. The excess blockage in the tunnel causes additional drag to the overall system, leading to question the accuracy of the values obtained for the airfoil drag.

Due to constraints caused by time and the working conditions of the wind tunnel facility, additional flap angles and slot pressure values should be tested to find the settings that would allow for maximum wake reduction. Greater flap angles have shown in previous download testing the ability to delay the separation of airflow along the flap. As the flap angle is increased, the higher velocity airflow would be pushed farther into the underside of the aircraft, relaying to a greater decrease in unbeneficial flow in the wake region.

Before any application of this technology is applied to an aircraft, extensive testing should be performed under more realistic conditions. A new model should be created and examined in a better emulation of the real life situations observed by the actual V-22 aircraft, such as the turbulence and swirl effects placed upon the airfoil setup. 


\section{References}

1) The Boeing Company, "The V-22 Osprey," (Online)

http://www.boeing.com/rotorcraft/military/v22/flash.html

2) Department of Defense, "Report to the Panel to Review the V-22 Program," April 2001.

3) Felker, Fort F., "Wing Download Results from a Test of a 0.658-Scale V-22 Rotor and Wing," Journal of the American Helicopter Society, pp. 58-63, Oct. $10,1992$.

4) Felker, Fort F., Shinoda, Patrick R., Heffernam, Ruth M., Sheehy, Hugh F., "Wing Force and Surface Pressure Data from a Hover Test of a 0.658-Scale V-22 Rotor and Wing," NASA, February 1990.

5) Felker, Fort F., and Light, Jeffery S., "Reduction of Tilt Rotor Download Using Circulation Control," Proceedings of the Circulation-Control Workshop, pp. 429-447, 1986.

6) Fanucci, Jerome B., Loth, John L., Ness, Nathan, Walters, Richard E., "Navy V/STOL Aerodynamics: Final Report," West Virginia University, February 1974.

7) Anderson, David, and Eberhardt, Scott, A Physical Description of Flight, McGraw-Hill, New York, 2001.

8) Churchill, Randolph Allen, "Coanda Effect Jet Around a Cylinder with an Interacting Adjacent Surface,” Dissertation, West Virginia University, 1992.

9) Huebsch, Wade W., "Experimental Aerodynamics: WVU Low Speed Wind Tunnel Facility," Class Notes: MAE 434, West Virginia University, 2002.

10) Angle, Gerald Martin II, “Aerodynamic Drag Reduction of a Racing Motorcycle through Vortex Generation," Thesis, West Virginia University, 2002.

11) Taylor, John R., An Introduction to Error Analysis: The Study of Uncertainties in Physical Measurements, Second Edition, University Science Books, Sausalito, CA, 1997.

12) Young, D. F., Munson, B. R., Okiishi, T. H., A Brief Introduction to Fluid Mechanics, Second Edition, John Wiley \& Sons, Inc., New York, NY, 1997. 
13) Englar, Robert J., "Experimental Investigation of the High Velocity Coanda Wall Jet Applied to Bluff Trailing Edge Circulation Control Airfoils," Thesis, University of Maryland, 1973.

14) Loth, John L., Chandra, Subrato, Gibbs, Edward H., "Inlet and Internal Aerodynamics of a VTOL Thrust Augmenter: Final Report," West Virginia University, January 31, 1976.

15) Young, Larry A., Booth, Earl R. Jr., Yamauchi, Gloria K., Botha, Gavin, Dawson, Seth, "Overview of the Testing of a Small-Scale Proprotor," American Helicopter Society, Inc., 1999.

16) Chandra, Subrato, and Loth, John L., "Asymmetric Entrainment of 2-D Curved Jets: Contract Report,” West Virginia University, August 1975.

17) Ambrosiani, J. P., and Ness, N., "Analysis of a Circulation Controlled Elliptical Airfoil," Thesis, West Virginia University, April 1971.

18) Loth, John L., Fanucci, J. B., and Chandra, Subrato, "Design Aspects of the WVU Technology Demonstrator STOL Aircraft," West Virginia University, February 1974. 


\section{Appendix A:}

\section{Cp Values, Drag Values, and Error Estimation Values}


Table A1: Cp values for 67 degree testing

\begin{tabular}{|c|c|c|c|c|c|c|c|c|}
\hline $\begin{array}{c}\text { Upper } \\
\text { Surface }\end{array}$ & $x / c$ & Cp Base 1 & Cp Base 2 & Cp Base 3 & Cp LE 5 & Cp LE 10 & Cp LE 15 & Cp LE 20 \\
\hline Tap 11 & 0.197 & 0.789 & 0.789 & 0.789 & 0.855 & 0.789 & 0.724 & 0.658 \\
\hline Tap 12 & 0.303 & 1.053 & 1.053 & 1.053 & 1.118 & 1.118 & 1.053 & 1.053 \\
\hline Tap 13 & 0.408 & 1.053 & 1.053 & 1.053 & 1.053 & 1.118 & 1.053 & 1.053 \\
\hline Tap 14 & 0.513 & 0.987 & 0.987 & 1.053 & 0.987 & 0.987 & 0.987 & 0.987 \\
\hline Tap 2 & 0.842 & -1.316 & -1.250 & -1.250 & -1.250 & -1.250 & -1.250 & -1.316 \\
\hline Tap 3 & 0.849 & -0.921 & -0.855 & -0.921 & -0.855 & -0.855 & -0.921 & -0.987 \\
\hline & & & & & & & & \\
\hline $\begin{array}{l}\text { Lower } \\
\text { Surface }\end{array}$ & $x / c$ & Cp Base 1 & Cp Base 2 & Cp Base 3 & Cp LE 5 & Cp LE 10 & Cp LE 15 & Cp LE 20 \\
\hline Tap 19 & 0.158 & -0.526 & -0.526 & -0.526 & -0.526 & -0.526 & -0.526 & -0.592 \\
\hline Tap 20 & 0.263 & -0.526 & -0.526 & -0.526 & -0.526 & -0.526 & -0.526 & -0.526 \\
\hline Tap 21 & 0.368 & -1.053 & -0.987 & -0.987 & -0.987 & -0.987 & -1.118 & -1.118 \\
\hline Tap 22 & 0.474 & -0.658 & -0.658 & -0.658 & -0.658 & -0.658 & -1.250 & -0.658 \\
\hline Tap 7 & 0.697 & -0.724 & -0.658 & -0.658 & -0.724 & -0.724 & -0.724 & -0.724 \\
\hline Tap 6 & 0.750 & -0.658 & -0.658 & -0.658 & -0.658 & -0.658 & -0.658 & -0.724 \\
\hline $\begin{array}{c}\text { Upper } \\
\text { Surface }\end{array}$ & $x / c$ & Cp LE 25 & Cp TE 5 & Сp TE 10 & Cp TE 15 & Cp TE 20 & Cp TE 25 & $\begin{array}{c}\text { Cp LE } 25 \\
\text { TE 25 }\end{array}$ \\
\hline Tap 11 & 0.197 & 0.658 & 0.724 & 0.658 & 0.658 & 0.789 & 0.789 & 0.658 \\
\hline Tap 12 & 0.303 & 1.053 & 1.118 & 1.053 & 1.053 & 1.053 & 1.118 & 1.053 \\
\hline Tap 13 & 0.408 & 1.053 & 1.118 & 1.053 & 1.053 & 1.053 & 1.118 & 1.053 \\
\hline Tap 14 & 0.513 & 1.053 & 0.987 & 0.921 & 0.987 & 0.987 & 1.053 & 0.987 \\
\hline Tap 2 & 0.842 & -1.250 & -1.184 & -1.118 & -1.053 & -0.921 & -0.921 & -1.053 \\
\hline Tap 3 & 0.849 & -0.921 & -0.724 & -0.724 & -0.658 & -0.658 & -0.658 & -0.789 \\
\hline $\begin{array}{c}\text { Lower } \\
\text { Surface }\end{array}$ & $\mathrm{x} / \mathrm{c}$ & Cp LE 25 & Cp TE 5 & Cp TE 10 & Cp TE 15 & Cp TE 20 & Cp TE 25 & $\begin{array}{c}\text { Cp LE 25 } \\
\text { TE 25 }\end{array}$ \\
\hline Tap 19 & 0.158 & -0.526 & -0.526 & -0.592 & -0.592 & 0.000 & -0.526 & -0.592 \\
\hline Tap 20 & 0.263 & -0.526 & -0.526 & -0.592 & -0.592 & -0.526 & -0.526 & -0.592 \\
\hline Tap 21 & 0.368 & -1.118 & -1.118 & -1.118 & -1.118 & -1.118 & -1.118 & -1.184 \\
\hline Tap 22 & 0.474 & -0.658 & -0.658 & -0.724 & -0.658 & -0.658 & -0.658 & -0.789 \\
\hline Tap 7 & 0.697 & -0.658 & -0.724 & -0.789 & -0.789 & -0.724 & -0.789 & -0.789 \\
\hline Tap 6 & 0.750 & -0.658 & -0.724 & -0.724 & -0.724 & -0.658 & -0.658 & -0.789 \\
\hline
\end{tabular}


Table A.2: Load cell values for 67 degree testing

\begin{tabular}{|c|c|c|c|}
\hline Test & $\begin{array}{c}\text { Cell One } \\
\text { (Lbs) }\end{array}$ & $\begin{array}{c}\text { Cell Two } \\
\text { (Lbs) }\end{array}$ & $\begin{array}{c}\text { Drag on airfoil } \\
\text { (lbs) }\end{array}$ \\
\hline Baseline 1 & 1.699 & 3.437 & 5.451 \\
\hline Baseline 2 & 1.703 & 3.429 & 5.442 \\
\hline Baseline 3 & 1.693 & 3.443 & 5.449 \\
\hline Lead 5 PSI & 1.674 & 3.587 & 5.718 \\
\hline Lead 10 PSI & 1.800 & 3.298 & 5.370 \\
\hline Lead 15 PSI & 1.905 & 3.226 & 5.439 \\
\hline Lead 20 PSI & 2.083 & 2.943 & 5.218 \\
\hline Lead 25 PSI & 2.232 & 2.633 & 4.874 \\
\hline Trail 5 PSI & 1.023 & 4.005 & 5.220 \\
\hline Trail 10 PSI & 0.541 & 4.289 & 4.798 \\
\hline Trail 15 PSI & -0.132 & 4.699 & 4.238 \\
\hline Trail 20 PSI & -0.703 & 5.013 & 3.691 \\
\hline Trail 25 PSI & -1.277 & 5.358 & 3.203 \\
\hline LE 25 TE 25 PSI & -0.591 & 4.380 & 2.581 \\
\hline \multicolumn{2}{|r|}{}
\end{tabular}

Table A.3: Drag error estimation for 67 degree testing

\begin{tabular}{|l|c|c|}
\hline \multicolumn{1}{|c|}{ Test } & $\mathbf{C}_{\mathbf{D}}$ & $\partial \mathbf{C}_{\mathbf{D}}$ \\
\hline 67 Baseline 1 & 0.623 & 0.000187 \\
\hline 67 Baseline 2 & 0.628 & 0.000188 \\
\hline 67 Baseline 3 & 0.632 & 0.000190 \\
\hline 67 Lead 5 PSI & 0.665 & 0.000200 \\
\hline 67 Lead 10 PSI & 0.627 & 0.000188 \\
\hline 67 Lead 15 PSI & 0.618 & 0.000185 \\
\hline 67 Lead 20 PSI & 0.599 & 0.000180 \\
\hline 67 Lead 25 PSI & 0.562 & 0.000169 \\
\hline 67 Trail 5 PSI & 0.604 & 0.000181 \\
\hline 67 Trail 10 PSI & 0.556 & 0.000167 \\
\hline 67 Trail 15 PSI & 0.493 & 0.000148 \\
\hline 67 Trail 20 PSI & 0.430 & 0.000129 \\
\hline 67 Trail 25 PSI & 0.373 & 0.000112 \\
\hline 67 LE 25 TE 25 & 0.301 & 0.000090 \\
\hline
\end{tabular}


Table A.4: Pressure error estimation for 67 degree testing

\begin{tabular}{|l|c|c|}
\hline \multicolumn{1}{|c|}{ Test } & $\mathbf{C}_{\mathbf{P}}$ & $\partial \mathbf{C}_{\mathbf{P}}$ \\
\hline 67 Baseline 1 & 1.066 & 0.1832 \\
\hline 67 Baseline 2 & 1.077 & 0.1840 \\
\hline 67 Baseline 3 & 1.081 & 0.1845 \\
\hline 67 Lead 5 PSI & 1.153 & 0.1904 \\
\hline 67 Lead 10 PSI & 1.156 & 0.1907 \\
\hline 67 Lead 15 PSI & 1.058 & 0.1812 \\
\hline 67 Lead 20 PSI & 1.069 & 0.1824 \\
\hline 67 Lead 25 PSI & 1.074 & 0.1830 \\
\hline 67 Trail 5 PSI & 1.145 & 0.1888 \\
\hline 67 Trail 10 PSI & 1.081 & 0.1838 \\
\hline 67 Trail 15 PSI & 1.084 & 0.1842 \\
\hline 67 Trail 20 PSI & 1.086 & 0.1844 \\
\hline 67 Trail 25 PSI & 1.156 & 0.1900 \\
\hline 67 LE 25 TE 25 & 1.089 & 0.1848 \\
\hline
\end{tabular}


Appendix B:

Structure of LabVIEW Code 


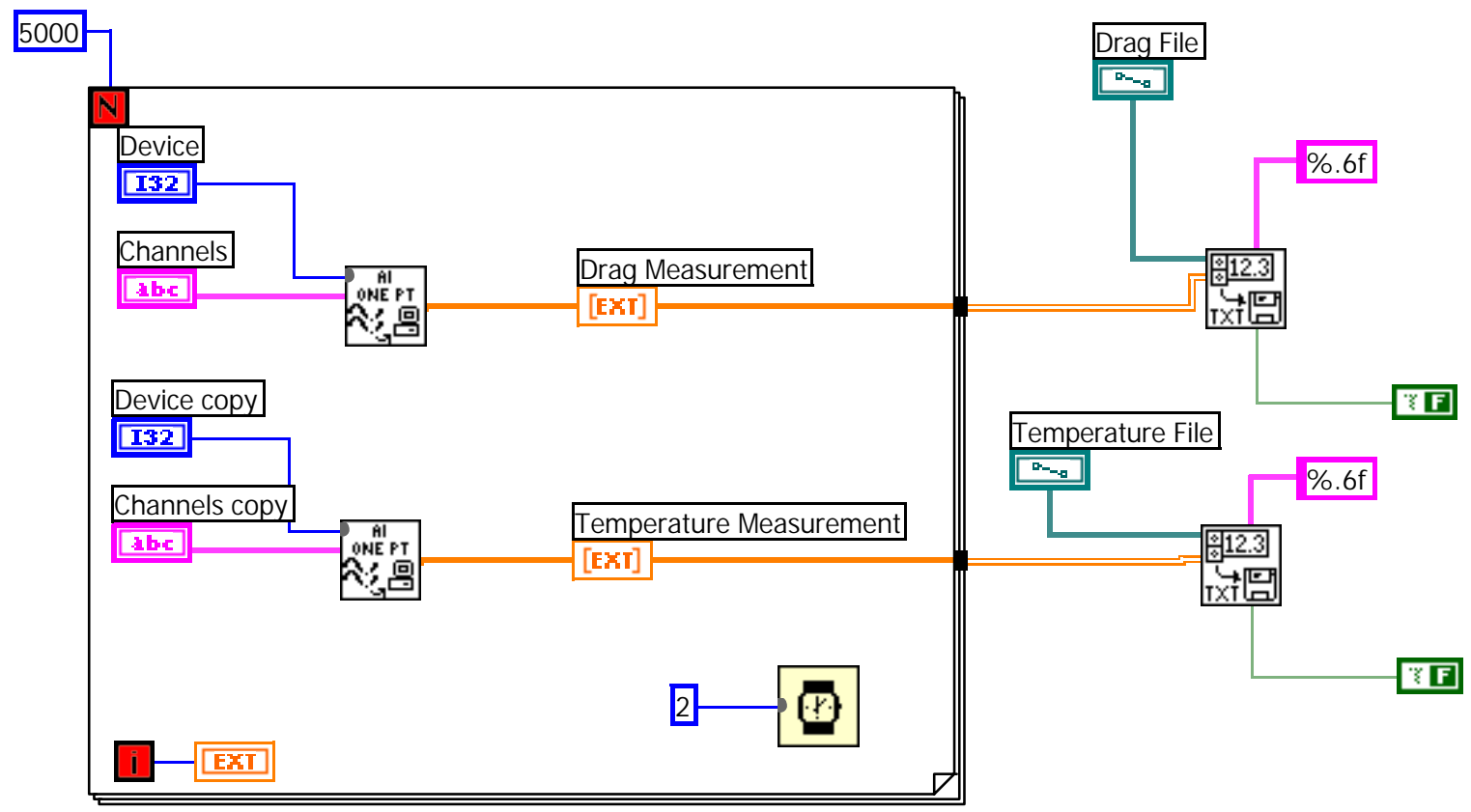

Figure B.1: Structure of LabVIEW code for scaled model testing. 


\section{Appendix C:}

Test Matrices and Load Cell Offset Values 
Table C.1: 67 degree test matrix with data log

\begin{tabular}{|l|c|c|c|c|c|}
\hline \multirow{2}{*}{ Test } & \multicolumn{2}{|c|}{ ATM } & \multicolumn{3}{c|}{ Speed (mph) } \\
\cline { 2 - 6 } & P (inHg) & T (degF) & Start & Stop & Average \\
\hline 67 Baseline 1 & 29.3 & 69 & 58.79 & 58.79 & 58.79 \\
\hline 67 Baseline 2 & 29.3 & 69 & 58.79 & 58.79 & 58.79 \\
\hline 67 Baseline 3 & 29.3 & 69 & 58.79 & 58.79 & 58.79 \\
\hline 67 Lead 5 PSI & 29.3 & 69 & 58.79 & 58.79 & 58.79 \\
\hline 67 Lead 10 PSI & 29.3 & 69 & 58.79 & 58.79 & 58.79 \\
\cline { 2 - 6 } 67 Lead 15 PSI & 29 & 72 & 59.26 & 59.26 & 59.26 \\
\hline 67 Lead 20 PSI & 29 & 72 & 59.26 & 59.26 & 59.26 \\
\hline 67 Lead 25 PSI & 29 & 72 & 59.26 & 59.26 & 59.26 \\
\hline 67 Trail 5 PSI & 29 & 72 & 59.26 & 59.26 & 59.26 \\
\hline 67 Trail 10 PSI & 29 & 72 & 59.26 & 59.26 & 59.26 \\
\hline 67 Trail 15 PSI & 29 & 72 & 59.26 & 59.26 & 59.26 \\
\hline 67 Trail 20 PSI & 29 & 72 & 59.26 & 59.26 & 59.26 \\
\hline 67 Trail 25 PSI & 29 & 72 & 59.26 & 59.26 & 59.26 \\
\hline 67 LE 25 PSI TE 25 PSI & 29 & 72 & 59.26 & 59.26 & 59.26 \\
\hline
\end{tabular}

Table C.2: 67 degree test matrix with load cell offset values

\begin{tabular}{|l|c|c|}
\hline \multirow{2}{*}{ Test } & \multicolumn{2}{|c|}{ Load Cell Offset (Volts) } \\
\cline { 2 - 3 } & Cell One & Cell Two \\
\hline 67 Baseline 1 & 0.00146 & 0.00977 \\
\hline 67 Baseline 2 & 0.00146 & 0.00977 \\
\hline 67 Baseline 3 & 0.00146 & 0.00977 \\
\hline 67 Lead 5 PSI & 0.00146 & 0.00977 \\
\hline 67 Lead 10 PSI & 0.00146 & 0.00977 \\
\hline 67 Lead 15 PSI & 0.00171 & 0.00952 \\
\hline 67 Lead 20 PSI & 0.00171 & 0.00952 \\
\hline 67 Lead 25 PSI & 0.00171 & 0.00952 \\
\hline 67 Trail 5 PSI & 0.00171 & 0.00952 \\
\hline 67 Trail 10 PSI & 0.00171 & 0.00952 \\
\hline 67 Trail 15 PSI & 0.00171 & 0.00952 \\
\hline 67 Trail 20 PSI & 0.00171 & 0.00952 \\
\hline 67 Trail 25 PSI & 0.00171 & 0.00952 \\
\hline 67 LE 25 PSI TE 25 PSI & 0.00171 & 0.00952 \\
\hline
\end{tabular}


Table C.3: 67 degree repeatability test matrix with data log

\begin{tabular}{|l|c|c|c|c|c|}
\hline \multirow{2}{*}{ Test } & \multicolumn{2}{|c|}{ ATM } & \multicolumn{3}{c|}{ Speed (mph) } \\
\cline { 2 - 6 } & P (inHg) & T (degF) & Start & Stop & Average \\
\hline 67 Baseline & 28.7 & 81 & 60.86 & 60.86 & 60.86 \\
\hline 67 Lead 15 PSI A & 28.7 & 81 & 60.86 & 60.86 & 60.86 \\
\hline 67 Lead 15 PSI B & 28.7 & 81 & 60.86 & 60.86 & 60.86 \\
\hline 67 Trail 20 PSI B & 28.7 & 81 & 60.86 & 60.86 & 60.86
\end{tabular}

Table C.4: 67 degree repeatability test matrix with load cell offset values

\begin{tabular}{|l|c|c|}
\hline \multirow{2}{*}{ Test } & \multicolumn{2}{|c|}{ Load Cell Offset (Volts) } \\
\cline { 2 - 3 } & Cell One & Cell Two \\
\hline 67 Baseline & 0.00146 & 0.00977 \\
\hline 67 Lead 15 PSI A & 0.00146 & 0.00977 \\
\hline 67 Lead 15 PSI B & 0.00146 & 0.00977 \\
\hline 67 Trail 20 PSI B & 0.00146 & 0.00977 \\
\hline
\end{tabular}




\section{Appendix D:}

ANSYS Representation, Overall Airfoil Drag Calculation Setup, Load Cell Calibration Curves, and Pressure Tap Placement Diagrams 


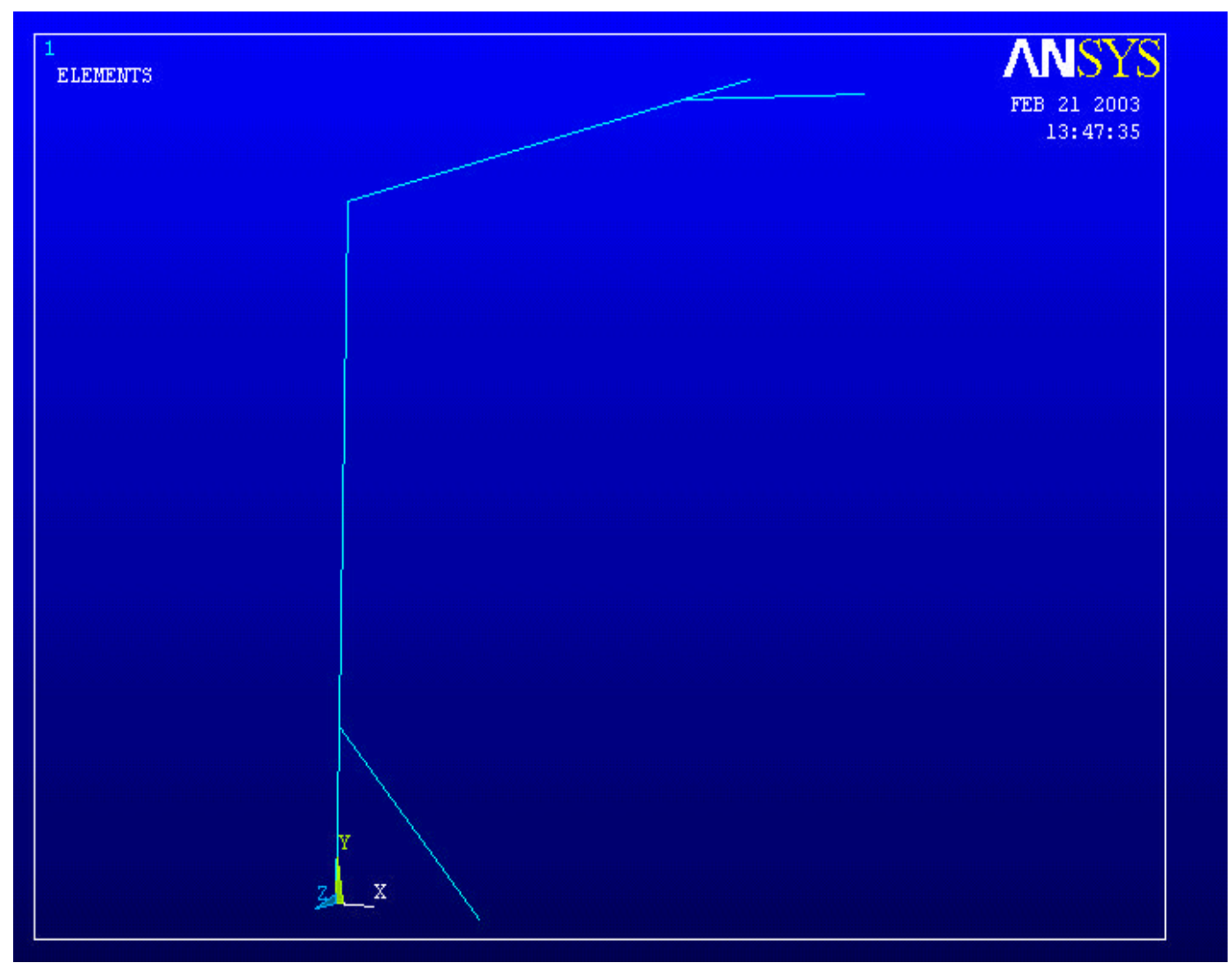

Figure D.1: Ansys representation of the WVU scaled model mounting system.

For structural and dynamic analysis, a simple ANSYS simulation was created. This was used to validate calculations determining maximum beam deflection and frequency response. Upon completion, the main cross member was estimated to deflect less than 0.1 " vertically and horizontally under a static loading of $100 \mathrm{lbs}$ vertically and 50lbs horizontally. The dynamic analysis revealed that sympathetic vibration or resonance would occur near $180 \mathrm{~Hz}$. During testing, no vibration or deflection problems were encountered, mainly due to the weight and construction of the design. 
Table D.1: Overall airfoil drag calculation setup example

\begin{tabular}{|c|c|}
\hline Theoretical Values (at 40mph) & Value \\
\hline${ }^{* \star * *} \mathrm{D} 1$ (drag on hosing) (lbs) $=$ & 0.0000 \\
\hline D2 (drag on upper center pipe) (lbs) = & 3.3628 \\
\hline D3 (drag on wing) (lbs) = & unknown \\
\hline D4 (drag on lower center pipe) (lbs) $=$ & 2.6462 \\
\hline \multicolumn{2}{|l|}{${ }^{* * * *}$ negligible due to redesign of placement } \\
\hline L1 (distance from hinge to center of top pipe) $(\mathrm{ft})=$ & 2.1458 \\
\hline L2 (distance from hinge to center of wing) $(\mathrm{ft})=$ & 4.1667 \\
\hline L3 (distance from hinge to center of bottom pipe) $(\mathrm{ft})=$ & 5.9167 \\
\hline L4 (distance from hinge to load cells) $(\mathrm{ft})=$ & 8.8750 \\
\hline \multicolumn{2}{|l|}{ Measured Values (at approx $40 \mathrm{mph}$ ) } \\
\hline F1(trailing edge cell) (lbs) $=$ & 2.0834 \\
\hline F2(leading edge cell) (lbs) $=$ & 2.9435 \\
\hline Drag Exerted on Wing (D3) (Ibs) = & 5.2177 \\
\hline
\end{tabular}

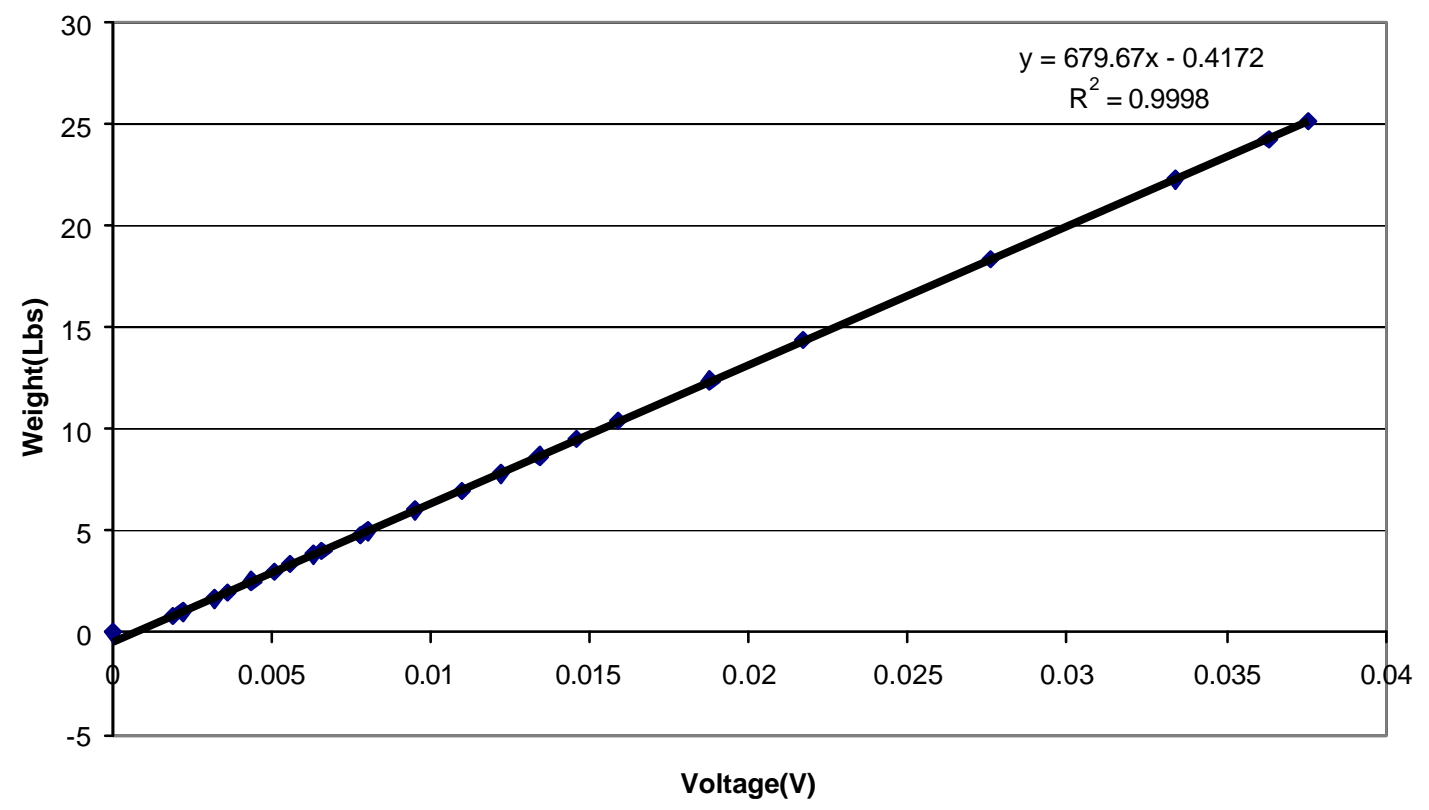

Figure D.2: Calibration curve for trailing edge load cell 


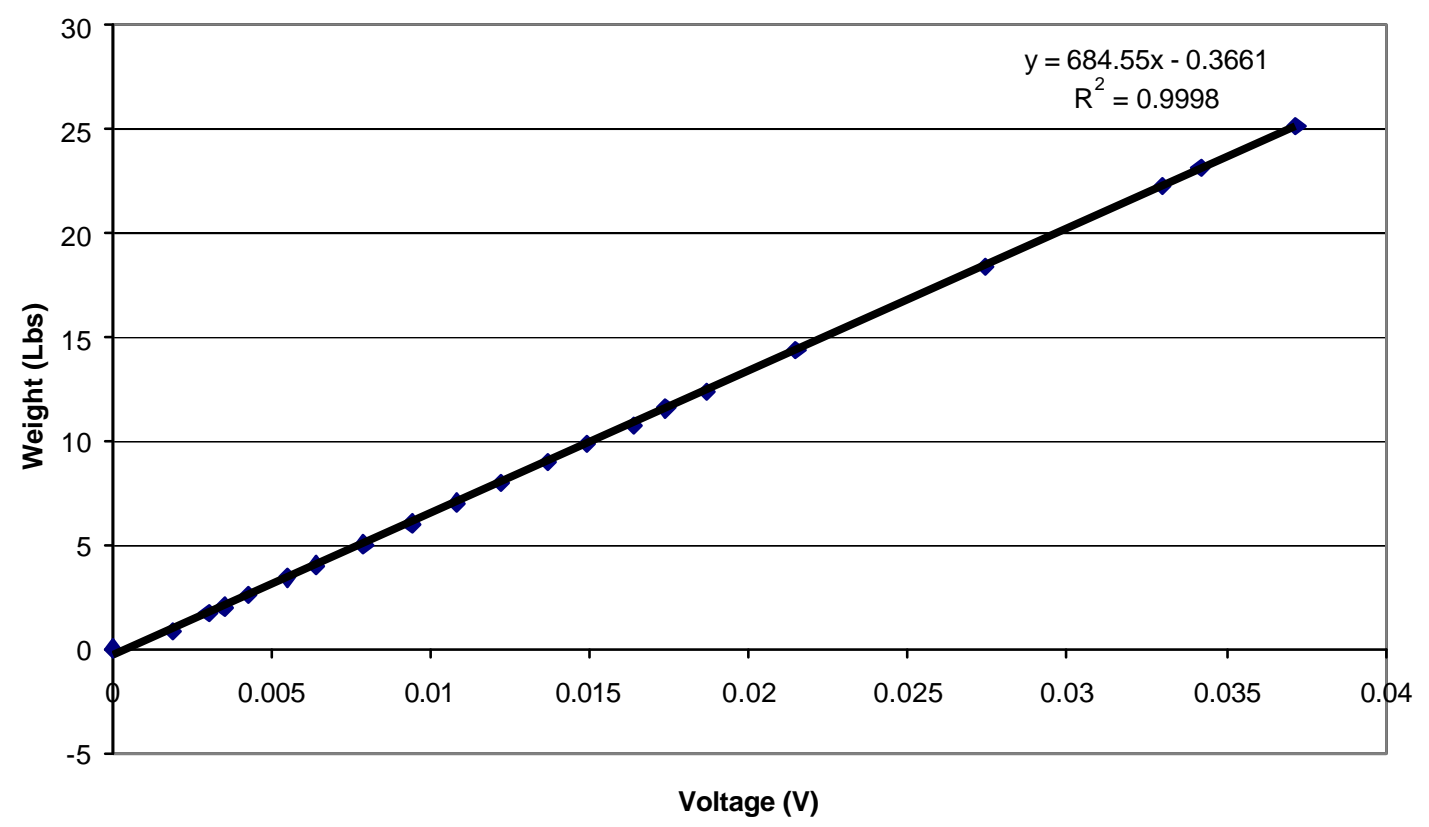

Figure D.3: Calibration curve for leading edge load cell

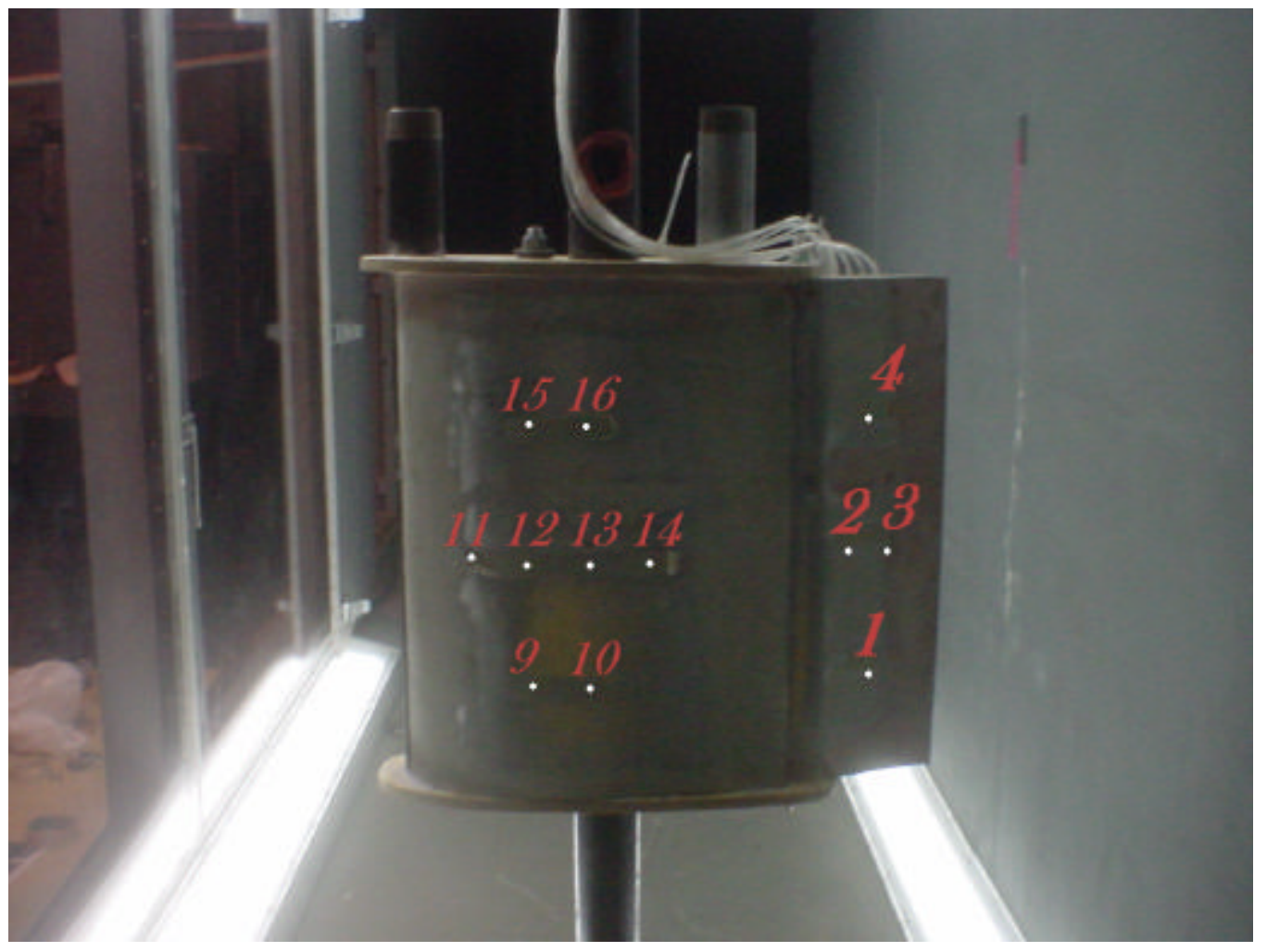

Figure D.4: Upper surface tap placement. 


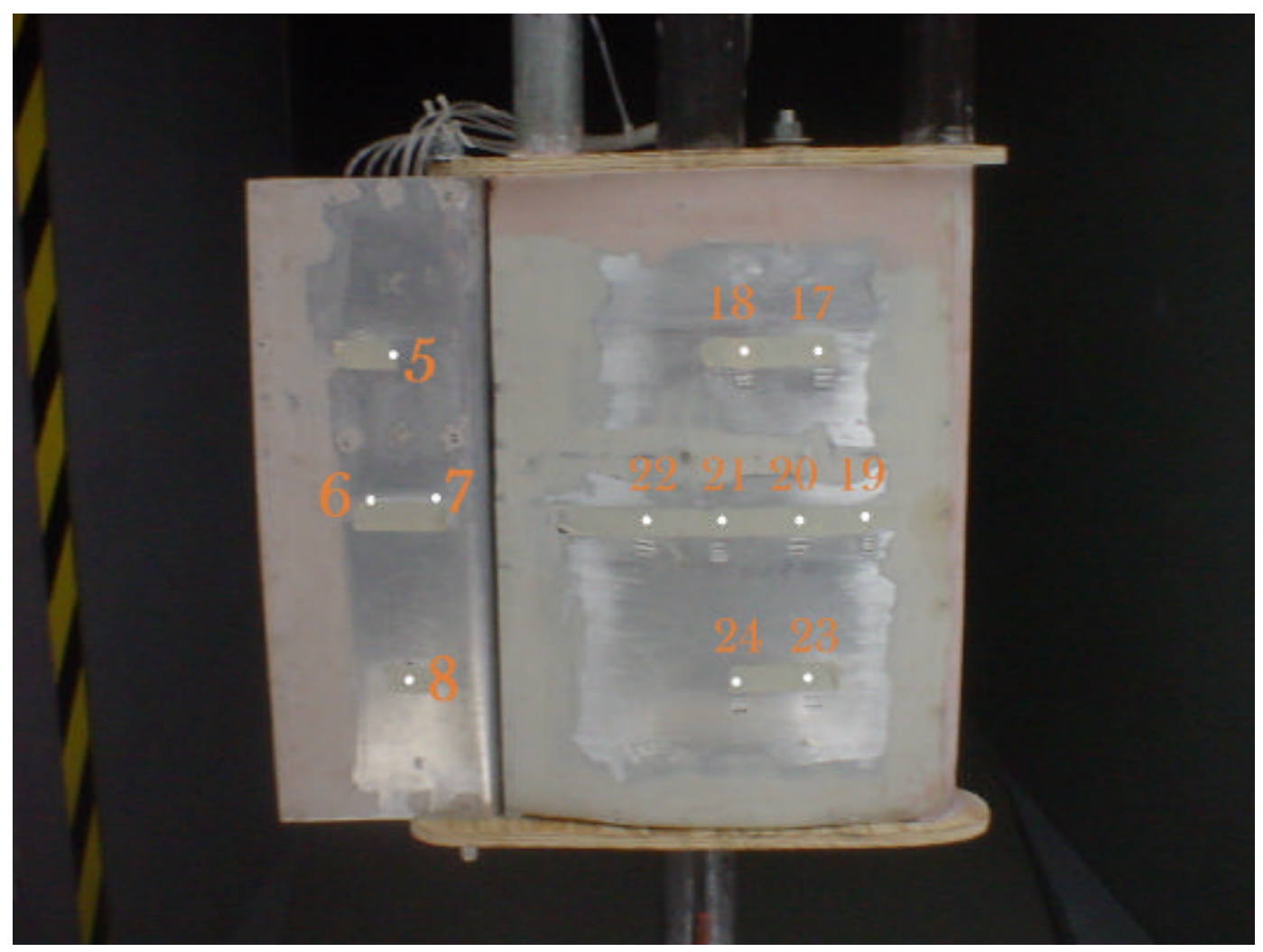

Figure D.5: Lower surface tap placement. 